FINAL REPORT

U.S. Department of Energy

\title{
TECHNETIUM ATTENUATION IN THE VADOSE ZONE: ROLE OF MINERAL INTERACTIONS
}

\author{
Principal Investigator: Nancy J. Hess \\ Institution: Pacific Northwest National Laboratory \\ Co- Principal Investigator: Kenneth M. Krupka \\ Institution: Pacific Northwest National Laboratory \\ Collaborators: James P. McKinley, James E. Szecsody, Raymond E. Wildung, and \\ Dhanpat Rai \\ Institution: Pacific Northwest National Laboratory \\ Collaborator: Steven D. Conradson \\ Institution: Los Alamos National Laboratory
}

Project Number: EMSP-70177

Grant Number:

Grant Project Officers: Dr. Roland Hirsch

Project Duration: 9/15/99-9/30/2003 


\section{Table of Contents}

Executive Summary 3

Relevance Summary 6

Research Objectives: $\quad 7$

Methods and Results. $\quad 7$

I. $\quad$ Tc Attenuation in Hanford Site Sediments.

II. Surface-Mediated Reduction of Pertechnetate on Fe II $^{I I}$ Containing Minerals. 13

III. Thermodynamic model of reduced Tc solid solubility 17

Relevance, Impact, and Technology Transfer 25

$\begin{array}{ll}\text { Product Productivity } & 28\end{array}$

Personnel Supported 28

$\begin{array}{lr}\text { Publications } & 29\end{array}$

$\begin{array}{ll}\text { Interactions } & 30\end{array}$

$\begin{array}{ll}\text { Transitions } & 30\end{array}$

None at this time. $\quad 30$

$\begin{array}{ll}\text { Patents } & 30\end{array}$

$\begin{array}{ll}\text { Future Work } & 30\end{array}$

$\begin{array}{ll}\text { Literature Cited } & 30\end{array}$

$\begin{array}{ll}\text { Feedback } & 32\end{array}$

$\begin{array}{ll}\text { Appendix } & 32\end{array}$

A Thermodynamic Model for the Solubility of $\mathrm{TcO}_{2} \cdot \mathrm{xH}_{2} \mathrm{O}(\mathrm{am})$ in the Aqueous $\mathrm{Tc}(\mathrm{IV})-\mathrm{Na}^{+}-\mathrm{Cl}^{-}-\mathrm{H}^{+}-\mathrm{OH}^{-}-\mathrm{H}_{2} \mathrm{O}$ System 


\section{Executive Summary}

Technetium-99 is a manmade radionuclide produced by the fission of U-235 and Pu-239 and has been introduced to the environment as a byproduct of the nuclear fuel cycle, predominately from the processing of spent fuel, discharges of low-level radioactive waste, and nuclear weapons testing (Schulte and Scoppa 1987). Because of its long half-life, $2.1 \times 10^{5} \mathrm{y}$, and environmental mobility, Tc is one of the most important radionuclides in calculating long-term, high-value risks at DOE sites. The fate of Tc in the environment depends on its oxidation state. The most stable oxidation states under environmental conditions are VII and IV. The chemical behavior of Tc in these two oxidation states differs drastically. In the VII oxidation state, Tc forms highly soluble solids. In aqueous solution, $\mathrm{Tc}$ exists as pertechnetate, $\mathrm{TcO}_{4}{ }^{-}$, which is not strongly sorbed, and thus, is highly mobile. Indeed, studies have shown that under oxidizing conditions Tc(VII) will migrate at nearly $90 \%$ of groundwater velocity (Rudin et al., 1992). In contrast, in the IV oxidation state, Tc forms the sparingly soluble hydrous dioxide, $\mathrm{TcO}_{2} \cdot x \mathrm{H}_{2} \mathrm{O}(\mathrm{am})$, and is relatively immobile in the absence of strongly complexing ligands.

At the Hanford Site, approximately $4.5 \times 10^{8} \mathrm{~L}$ of liquid waste containing $930 \mathrm{Ci}$ of ${ }^{99} \mathrm{Tc}$ from uranium recovery processing were discharged directly to the ground at the Hanford Site from 1953 to 1958 (Waite et al. 1991; Jones et al. 1998). As a result, the entire soil column beneath many of the disposal sites became saturated, potentially providing a conduit for the migration of Tc to groundwater. Alternatively, it is hypothesized that Tc reduction through surface-mediated reactions with $\mathrm{Fe}(\mathrm{II})$-containing minerals can result in precipitation of low solubility Tc solids, effectively immobilizing Tc in the vadose zone. The goal of this research is the investigation of heterogeneous reduction of $\mathrm{Tc}(\mathrm{VII})$ on $\mathrm{Fe}(\mathrm{II})$-containing mineral surfaces and the stability of the resulting precipitated Tc solids. The major findings are summarized below:

\section{Technetium attenuation in Hanford sediments associated with HLW leakages. Possible}

mechanisms for the retention of pertechnetate in Hanford sediments were investigated using batch reactors and 1-D column systems under a variety of solution and sediment pretreatments conditions. Significant Tc retention and resistance to remobilization only occurred under extremely caustic conditions or when the sediments were pretreated with chemical reductants. Our experimental results from column studies suggest that dissolution of sediments by caustic solutions results in the reduction of $\mathrm{TcO}_{4}{ }^{-}$due to the exposure of $\mathrm{Fe}(\mathrm{II})$ sites on Fe-bearing minerals. In addition, subsequent precipitation of $\mathrm{Al}$ and Si phases may aid in the retention of $\mathrm{Tc}$ in the sediment. Furthermore, Tc was found to be associated with alteration minerals and glass 
fragments contained in basalt clasts of the Hanford sediments using scanning electron microscopy and the oxidation state was determined to be Tc(IV) using spatially resolved micro-X-ray absorption spectroscopy.

- An increase in the amount of extractable Fe in Hanford Formation sediments occurs under extreme caustic conditions. Analogous Fe extraction studies on mineral separates suggests that the increased Fe results from the breakdown of Fe-silicates and oxides under caustic conditions.

- Pertechnetate is retained in $1 \mathrm{D}$ column studies only under caustic conditions. The rate of Tc attenuation was found to independent on the Tc or Fe content of the sediments yet very dependent on the flow rate. This result suggests that a simple Tc reduction mechanism does not completely describe the mechanism of Tc attenuation.

- Micro-XANES analysis of column sediments confirmed the presence of reduced Tc (IV) precipitates.

- Scanning electron microprobe mapping identified an association of precipitated Tc and basalt clasts in sediments. Detailed mapping of the basalt clasts revealed that Tc was associated with secondary clay minerals within the clasts and with Fe-rich glass fragments.

Caustic conditions, which are likely to occur adjacent to HLW tank leakages, can create the chemical conditions by which Tc is reduced and precipitated in the vadose zone sediment; however, these chemical conditions are but are unlikely to occur where Tc was intentionally discharged to the ground.

Technetium sorption on Fe-bearing minerals under oxic conditions.

Batch equilibration experiments were completed to measure the sorption of pertechnetate as a function of time by several iron-containing minerals in contact with otherwise uncontaminated Hanford Site groundwater solution under oxic conditions. These experiments approximate the chemical conditions of intentional discharges of Tc to the ground. The objectives of these experiments were to 1) determine if $\mathrm{Fe}(\mathrm{II})$-containing minerals exhibit detectable sorption of 
technetium under oxic conditions, and if so, 2) identify the mechanism(s) responsible for this uptake. The iron-containing minerals used in the experiments included hematite, magnetite, biotite, and hornblende.

- No detectable sorption of Tc was observed on the Fe-oxides or hornblende, and only limited uptake was observed in biotite.

- Micro x-ray fluorescence elemental maps did not detect Tc on surface of any of the mineral grains.

Batch experimental results strongly suggest that surface sorption of Tc on Fe-bearing minerals is not a viable mechanism for the attenuation of Tc in the vadose zone under oxic conditions and near neutral $\mathrm{pH}$ conditions that approximate direct disharges to the ground. Such contamination events are likely to result in widespread, highly mobile Tc plumes.

Thermodynamic model of reduced Tc solid solubility. Solubility studies of $\mathrm{TcO}_{2} \cdot x \mathrm{H}_{2} \mathrm{O}(\mathrm{am})$ were conducted under solutions conditions where concentrations of reduced Tc aqueous species exceeded detection limits. These experiments were conducted under carefully controlled reducing conditions such that the preponderance of Tc is present in solution is in the reduced oxidation state. The measured solubility was in general agreement with earlier studies in the absence of $\mathrm{NaCl}$. The aqueous species and solid phases were characterized using a combination of techniques including thermodynamic analyses of solubility data, XRD, and XANES, EXAFS, and UV-Vis spectroscopies.

- The solubility experiments confirms earlier results that precipitated amorphous Tc(IV) solids have low solubility over much of the $\mathrm{pH}$ range.

- Under acidic conditions, chloride was found to significantly affect Tc(IV) concentrations through 1) the formation of Tc(IV) chloro complexes [i.e., $\mathrm{TcCl}_{4}(\mathrm{aq})$ and $\mathrm{TcCl}_{6}{ }^{2-}$ ] and a stable precipitate, most likely $\mathrm{TcCl}_{4}(\mathrm{am})$, and 2) through chloride ion interactions with the positively charged hydrolyzed Tc(IV) species in solutions. 
- A thermodynamic model was developed that includes chemical potentials of Tc(IV)chloro species and Pitzer ion-interaction parameters for Tc(IV) hydrolyzed species with bulk electrolyte ions used in this study. The thermodynamic model is consistent with the data reported and with the reliable literature data, and is applicable to a wide range in $\mathrm{H}^{+}$ and $\mathrm{Cl}^{-}$concentrations and ionic strengths.

\section{Relevance Summary}

The results of this study are highly relevant to one of DOE's most critical environmental management issues, that is, the fate of Tc in vadose zone, and the design of cost-effective remediation strategies. Our experimental results indicate that $\mathrm{Tc}$ is not attenuated by mineral interactions under most environmental conditions and will migrate freely. These contamination events are likely to result in widespread, highly mobile contamination plumes. Contamination created by such events will likely require remediation strategies such as "pump and treat". However, Tc may be attenuated under unique environmental conditions such as those created by the leakage of caustic HLW. Under these conditions it appears that reduced Tc solid phase is formed that resistant to remobilization, tightly bound to the sediment, and may be confined in proximity to the source of the leak. These contained contamination events may be cost effectively treated by excavation and treatment of the sediment. 


\section{Research Objectives:}

The research objective was to provide fundamental information on surface-mediated reduction/precipitation reactions of $\mathrm{Tc}$ on $\mathrm{Fe}^{\mathrm{II}}$-containing mineral surfaces and the stability of those precipitates under conditions relevant to the vadose zone at the Hanford Site. Our strategy was to investigate (1) Tc attenuation in Hanford Site sediments, (2) surface-mediated reduction of $\mathrm{Tc}^{\mathrm{VII}}$ on $\mathrm{Fe}^{\mathrm{II}}$-containing minerals, and (3) the stability of the precipitated $\mathrm{Tc}^{\mathrm{IV}}$ solids. This information provides crucial support for the development of models of Tc mobility in the vadose zone. The methods used and results generated in these three research efforts are presented below.

\section{Methods and Results.}

\section{Tc Attenuation in Hanford Site Sediments.}

We have investigated these reactions in Hanford sediments using batch reactors and in 1D column systems. Our experimental results indicate that dissolution of sediments by caustic solutions results in the reduction of $\mathrm{TcO}_{4}{ }^{-}$and the precipitation $\mathrm{Tc}(\mathrm{IV})$ solids. Furthermore, the precipitation of $\mathrm{Al}$ and $\mathrm{Si}$ phases may aid in the retention of $\mathrm{Tc}$ in the sediment. The sediment used in this study consists of a mixture of two subsurface sediments from the Hanford Formation in the 200 East HLW tank farms. Iron extractions were conducted on Hanford sediments and specific minerals (biotite, magnetite) that were untreated, treated with $4 \mathrm{M} \mathrm{NaOH}$ for 192 and $490 \mathrm{~h}$, or treated with dithionite. These extractions were used to quantify changes in the available ferrous, ferric and total iron with various treatments. Column experiments were conducted to quantify Tc reduction and oxidation rates under varying conditions. Column experiments consisted of injecting HLW solution, pertechnetate (reduction experiments) or oxygen-saturated water (oxidation experiments) into a $2.5 \mathrm{~cm}$ diameter by $30 \mathrm{~cm}$ length stainless steel column at specified flow rates with a liquid chromatography pump to achieve $0.8 \mathrm{~h}$ to $100 \mathrm{~h}$ residence times. Effluent samples were collected under anaerobic conditions using an automated multiplexing syringe pump system (Kloehn, Inc., Las Vegas, NV) and septatop vials. Pertechnetate reduction experiments were conducted in the columns under natural $\mathrm{pH}$ conditions (8.0), and in $4 \mathrm{M} \mathrm{NaOH}$ solution with varying Tc concentration $\left(10^{-4}\right.$ to $\left.10^{-5} \mathrm{~mol} / \mathrm{L}\right)$, and varying flow rate (residence times $\left.10,24,90 \mathrm{~h}\right)$. The pertechnetate reduction rate was also investigated in column experiments in which the sediment was chemically reduced using sodium dithionite. Since we anticipated that the mechanism of Tc reduction and oxidation might be influenced indirectly by the flow rate in column experiments, batch experiments were also conducted to determine the rate of pertechnetate reduction and oxidation in the absence of flow.

Iron extractions on untreated sediments were compared to sediments that had been pretreated with $4 \mathrm{M} \mathrm{NaOH}$ for $192 \mathrm{hr}$ and $450 \mathrm{hr}$, and sediments pretreated with dithionite (Table 1). Although little change was observed between untreated and $192 \mathrm{hr}$ pretreated sediments, the total quantity of $\mathrm{Fe}^{\mathrm{II}}$ and $\mathrm{Fe}^{\mathrm{III}}$ species extracted more than doubled between the $192 \mathrm{hr}$ and $450 \mathrm{hr}$ pretreatments, indicating that a significant amount of chemical reaction is required before the Fe is effectively extracted. This reaction 
likely represents the breakdown of highly crystalline structures that then enables more efficient chemical extraction of $\mathrm{Fe}$. The increase was largely represented by an increase in availability of $\mathrm{Fe}^{\mathrm{III}}$ species. As expected, the surface concentration of ionexchangeable $\mathrm{Fe}^{\mathrm{II}}$ decreases during $\mathrm{NaOH}$ leaching. However, the extractable ferrous iron fraction, which is likely present as precipitated $\mathrm{Fe}(\mathrm{OH})_{2}$ hydroxide, increases. Dithionite treatment of sediment results even in a $700 \%$ increase in the extractable ferrous iron faction, and corresponding decreases in the total ferric content.

Table 1. Iron Surface Species Based on Fe-Extractions.

\begin{tabular}{|c|c|c|c|c|c|c|c|c|}
\hline \multirow[b]{2}{*}{$\begin{array}{c}\text { sample/ } \\
\text { treatment }\end{array}$} & \multicolumn{4}{|c|}{ - $\mathrm{Fe}^{\mathrm{II}}$ phases } & \multicolumn{3}{|c|}{ Fe } & \multirow{2}{*}{$\begin{array}{c}\mathbf{F e}^{\text {II }}+\mathbf{F e}^{\text {III }} \\
\text { total } \\
(\mu \mathrm{g} / \mathrm{g})\end{array}$} \\
\hline & $\begin{array}{c}\text { exchang- } \\
\text { able } \\
\text { Fe }^{\mathrm{II}} \\
(\mu \mathrm{g} / \mathrm{g}) \\
\end{array}$ & $\begin{array}{c}\begin{array}{c}\text { extract- } \\
\text { able }\end{array} \\
\text { Fe }^{\text {II }} \\
(\mu \mathrm{g} / \mathrm{g}) \\
\end{array}$ & $\begin{array}{c}\text { residual } \\
\mathbf{F e}^{\mathrm{II}} \\
(\mu \mathrm{g} / \mathrm{g}) \\
\end{array}$ & $\begin{array}{c}\text { total } \\
\mathrm{Fe}^{\mathrm{II}} \\
(\mu \mathrm{g} / \mathrm{g}) \\
\end{array}$ & $\begin{array}{c}\text { amorphous } \\
\text { Fe }^{\text {III }} \text { oxides } \\
(\mu \mathrm{g} / \mathrm{g}) \\
\end{array}$ & $\begin{array}{c}\text { crystalline } \\
\text { Fe }^{\text {III }} \\
\text { oxides } \\
(\mu \mathrm{g} / \mathrm{g}) \\
\end{array}$ & $\begin{array}{c}\text { total } \\
\mathrm{Fe}^{\mathrm{III}} \\
(\mu \mathrm{g} / \mathrm{g}) \\
\end{array}$ & \\
\hline \multicolumn{9}{|l|}{ Hanford } \\
\hline untreated & 16 & 0 & 78 & 89 & 4 & 27 & 1250 & 1340 \\
\hline 192 h $4 \mathrm{M} \mathrm{NaOH}$ & 5 & 8 & 80 & 93 & 5 & 42 & 1170 & 1260 \\
\hline $450 \mathrm{~h} 4 \mathrm{M} \mathrm{NaOH}$ & 4 & 17 & 76 & 96 & 4 & 93 & 2620 & 2720 \\
\hline reduced $^{1}$ & 6 & 690 & 8 & 700 & --- & --- & 738 & 1440 \\
\hline \multicolumn{9}{|l|}{ magnetite } \\
\hline untreated & 2 & 2 & 22,000 & 22,000 & 146 & $0 *$ & 9100 & 31,100 \\
\hline 192 h $4 \mathrm{M} \mathrm{NaOH}$ & 6 & 12 & 33,200 & 33,200 & 810 & $0 *$ & 47800 & 80,700 \\
\hline \multicolumn{9}{|l|}{ biotite } \\
\hline untreated & 7 & 17 & 16,700 & 16700 & 0.5 & 1 & 2770 & 19,500 \\
\hline 192 h $4 \mathrm{M} \mathrm{NaOH}$ & 3 & 30 & 5360 & 5360 & 333 & $0.0^{*}$ & 3420 & 8,780 \\
\hline
\end{tabular}

1. Treated $120 \mathrm{~h}$ with $0.1 \mathrm{M}$ dithionite.

The measured rates of Tc removal in batch and column experiments are summarized in Table 2. The general behavior observed in columns experiments is an initial breakthrough of Tc that is followed additional flow without significant Tc retention and a subsequent approach to a steady state removal Tc removal rate. In the absence of $4 \mathrm{M}$ $\mathrm{NaOH}$, an injection of $2.45 \times 10^{-6} \mathrm{M} \mathrm{TcO}_{4}{ }^{-}$in oxygen-free aqueous solution resulted in minimal retention of Tc that only occurred for the first few pore volumes (Table 2 - Exp A). There was no measurable retention of Tc in subsequent pore volumes suggesting a saturation of the active surface sites for Tc reduction. The injection of oxygen-free $4 \mathrm{M}$ $\mathrm{NaOH}$ with $4 \times 10^{-4} \mathrm{M} \mathrm{TcO}_{4}{ }^{-}$solution (Fig. 2, Table 2 - Exp B) results in initial Tc breakthrough at 1 pore volume $(90 \mathrm{~h})$ that is followed by an additional pore volume without significant Tc retention. Over the next 5 pore volumes (or 450 hours), an increasing fraction, up to $8 \%$ of the Tc, was retained in the column. The initial lag in Tc retention observed between 1 and 2 pore volumes may reflect the gradual increase in $\mathrm{Fe}^{\mathrm{II}}$ concentration from the dissolution of $\mathrm{Fe}$ bearing minerals or exposure of ferrous iron sites in the presence of $4 \mathrm{M} \mathrm{NaOH}$. At 600 hours, the concentration of Tc in the influent 
was decreased by an order of magnitude (Exp C) and resulted in retention of $87 \%$ of the Tc. The increase in percentage of Tc retention by an order of magnitude with the order of magnitude decrease in influent Tc concentration indicates that the absolute amount of Tc retained is independent of the concentration of Tc injected. Furthermore, the rate of Tc retention, dTc/dt, determined for Exp. $\mathrm{B}$ and $\mathrm{C}$ are nearly equivalent, ca. $1.6 \times 10^{-8} \mathrm{~mol}$ $\mathrm{Tc} / \mathrm{h}$ (Table 2), which indicates that $\mathrm{dTc} / \mathrm{dt}$ is also independent of concentration of $\mathrm{Tc}$ injected.

Table 2. Pertechnetate Reduction Rates Observed in Batch and 1-D Column Experiments.

\begin{tabular}{|c|c|c|c|c|c|c|c|c|}
\hline \multirow[b]{2}{*}{ Exp } & \multirow[b]{2}{*}{ type } & \multirow{2}{*}{$\begin{array}{c}\text { soil/ } \\
\text { water } \\
\left(\mathrm{g} / \mathrm{cm}^{3}\right)\end{array}$} & \multirow[b]{2}{*}{$\begin{array}{l}\text { reaction } \\
\text { time (h) }\end{array}$} & \multirow[b]{2}{*}{$\begin{array}{c}\text { initial Tc } \\
(\mathrm{mol} / \mathrm{L})\end{array}$} & \multirow[b]{2}{*}{ treatment: } & \multicolumn{3}{|c|}{ observed Tc removal } \\
\hline & & & & & & $\begin{array}{c}\text { first order } \\
(1 / \mathbf{h})\end{array}$ & $\begin{array}{c}\text { half life } \\
\text { (h) }\end{array}$ & $\begin{array}{c}\text { rate } \\
(\mathrm{mol} \mathrm{Tc} / \mathrm{h})\end{array}$ \\
\hline A & column & 5.06 & 90 & $2.45 \times 10^{-6}$ & untreated & 0.00234 & 296 & $2.73 \times 10^{-10}$ \\
\hline $\mathrm{B}$ & column & 4.89 & 90 & $3.72 \times 10^{-4}$ & $4 \mathrm{M} \mathrm{NaOH}$ & 0.00093 & 748 & $1.66 \times 10^{-8}$ \\
\hline $\mathrm{C}$ & column & 4.89 & 90 & $3.51 \times 10^{-5}$ & $4 \mathrm{M} \mathrm{NaOH}$ & 0.0227 & 30.6 & $3.83 \times 10^{-8}$ \\
\hline $\mathrm{D}$ & column & 4.89 & 24 & $3.51 \times 10^{-5}$ & $4 \mathrm{M} \mathrm{NaOH}$ & 0.022 & 31.5 & $3.71 \times 10^{-8}$ \\
\hline $\mathrm{E}$ & column & 4.89 & 9.9 & $3.51 \times 10^{-5}$ & $4 \mathrm{M} \mathrm{NaOH}$ & 0.0304 & 22.8 & $5.13 \times 10^{-8}$ \\
\hline $\mathrm{F}$ & batch & 0.50 & $0-700$ & $2.45 \times 10^{-6}$ & $4 \mathrm{M} \mathrm{NaOH}$ & 0.0188 & 28.9 & $4.61 \times 10^{-9}$ \\
\hline $\mathrm{J}$ & column & 4.43 & 5.0 & $4.10 \times 10^{-5}$ & dithionite $+4 \mathrm{M} \mathrm{NaOH}$ & 1.52 & 0.46 & $1.65 \times 10^{-7}$ \\
\hline $\mathrm{K}$ & column & 4.43 & 5.32 & $1.38 \times 10^{-4}$ & dithionite & 1.71 & 0.40 & $6.25 \times 10^{-7}$ \\
\hline $\mathrm{L}$ & column & 4.43 & 0.412 & $1.38 \times 10^{-4}$ & dithionite & 21.9 & 0.032 & $8.01 \times 10^{-6}$ \\
\hline
\end{tabular}

The average rate of Tc removal in five batch experiments using sediments treated with 4 $\mathrm{M} \mathrm{NaOH}$ (Fig. 3a; Table 2 - Exp F) was $4.6 \times 10^{-9} \mathrm{~mol} \mathrm{Tc} / \mathrm{h}$ or a $29 \mathrm{~h}$ half-life. This removal rate was nearly an order of magnitude slower than the average for four column experiments with $\mathrm{NaOH}$-treated sediments (Table 2 - Exp C through E). However, direct comparison of the removal rates may not be valid because the soil to water ratio for the batch experiments is an order of magnitude lower than the column experiments.

After $1400 \mathrm{hrs}$ of 4M NaOH and Tc injection (exp. B, C, D), twelve sediment samples were removed from along the length of the column and subjected to various treatments to determine how tightly Tc was retained on the sediments (see Figure 1). These treatments included atmosphere-equilibrated water, $5 \mathrm{M} \mathrm{HCl}, 0.1 \mathrm{M} \mathrm{HNO}_{3}$ and $1 \mathrm{M} \mathrm{HNO}_{3}$. Atmosphere-equilibrated water, $0.1 \mathrm{M} \mathrm{HNO}_{3}$ and $5 \mathrm{M} \mathrm{HCl}$ were relatively ineffective at oxidizing and remobilizing the Tc. Only $1 \mathrm{M} \mathrm{HNO}_{3}$ removed all the retained Tc as shown in Figure 1. The failure of mild oxidative treatments to remove more than $25 \%$ of the Tc from the column sediments strongly suggests that $\mathrm{Tc}$ is present as reduced species that are relatively insoluble and resistant to re-oxidation. 


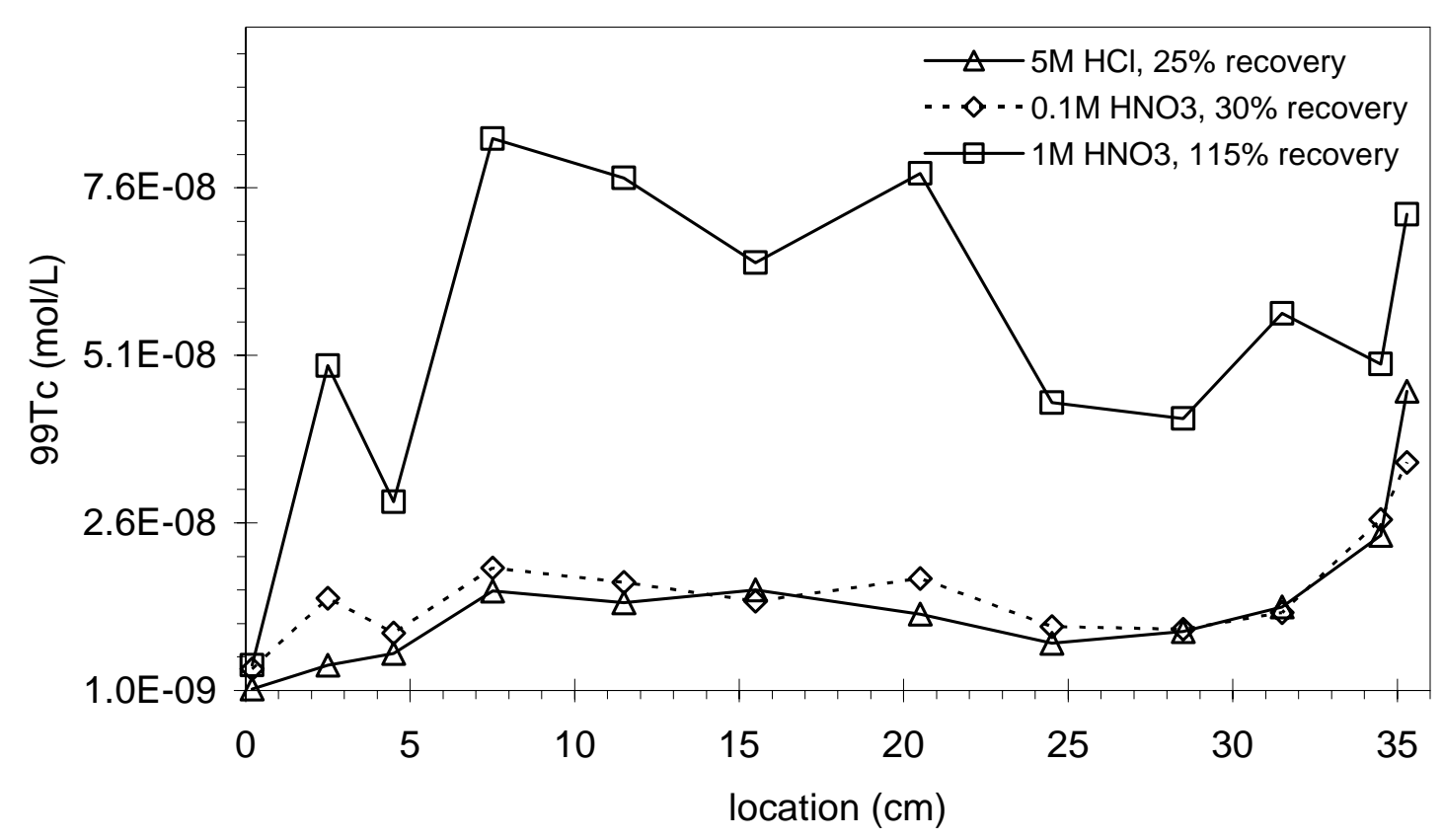

Figure 1. Efficacy of Tc remobilization treatments on sediments extracted from 1-D column experiments as a function of location along the length of the column.

Sediments were removed from along the length of the column after $1440 \mathrm{~h}$ reaction for analysis using scanning electron microscopy (SEM), micro x-ray fluorescence elemental mapping, and micro x-ray absorption near edge structure spectroscopy at the Tc K-edge. The SEM images were collected using a JEOL 840 SEM with Oxford ISIS 300 Energy Dispersive Spectrometer. The $\mu$-xrf and $\mu$-xanes were collected at the undulator beamline 20-ID-B at the Advanced Photon Source (Argonne National Laboratory) operated by PNC-CAT. Si(111) monochrometer crystals were used to create a monochromatic beam that was focused to 5 micron spot on the sample using Kirpatrick-Baez (K-B) mirrors.

Figure 2 shows SEM images and X-ray microprobe (XMP) elemental distribution maps from sediment located at the bottom of the 1-D column. The false-color elemental abundance overlays were constructed from the micro x-ray fluorescence data. Each overlay was self-normalized (i.e., the maximum intensity was assigned red on the blue to red spectrum). The backscattered electron (BSE) images from SEM depict compositional variability on the sample surface, with brighter areas representing higher average atomic number. The BSE image in the upper left shows the locations of two basalt clasts, A and B. A third smaller basalt clast is located between A and B. Note that since X-rays penetrate the surface of the sample further than electrons, the XMP elemental distribution originate from deeper within the sample than the BSE images, therefore there is not always direct correspondence between the BSE and XMP. The lack of correspondence is particularly noticeable when comparing the BSE image and the Fe elemental distribution in the vicinity of the clast A. Within the basalt clasts, the gray rectangles are plagioclase minerals, the bright crystals are titanomagnetite, and the gray equant shapes, slightly brighter than plagioclase, are augite. The rest of the basalt clasts consist of mesostasis glass. The glass 

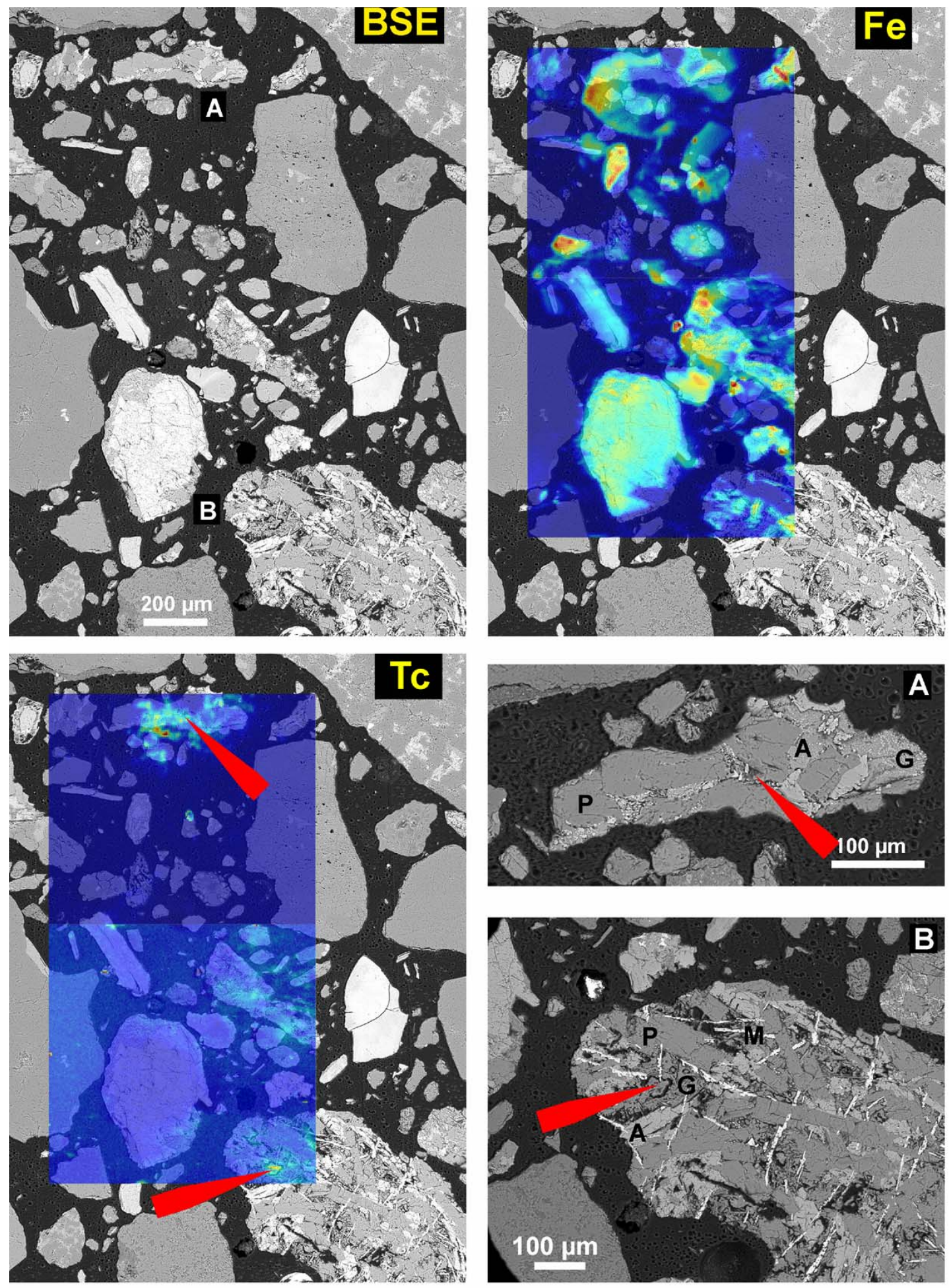

Figure 2. Overlays of SEM images and X-ray microprobe (XMP) elemental distribution maps from sediment located at the bottom of the 1-D column. SEM image, upper left, of sediment with two basalt clasts (A and B) indicated. Fe and Tc XMP elemental distribution maps, upper right and lower left, respectively with red arrows indicating localized Tc concentrations. See text for discussion. Constituents of the basalt clasts include $\mathrm{P}=$ plagioclase, $\mathrm{M}=$ titanomagnetite, $\mathrm{G}=$ mesostasis glass, and $\mathrm{A}=$ augite. 
in clast A shows the effects of liquid immiscibility, the bright speckles, indicated by the red arrow, are regions of exsolved Fe-rich glass. The glass in clast B contains inclusions of smectite alteration, indicated by red arrow. These two regions are enlarged in the BSE images in the lower right.

The Tc and Fe elemental distributions do not show a simple correspondence as would be expected from a heterogeneous reduction mechanism alone. However, the Tc is associated with basalt clasts, which do include reactive components containing ferrous iron, as described above. In particular, localized Tc appears to be associated with the exsolved Fe-rich glass and Fe-containing smectite inclusions within the basalt clasts. The Tc oxidation state in regions of localized Tc concentration was determined by collection of the micro-XANES spectrum at several locations. At several location along the column, the oxidation state was determined to be Tc(IV), which is consistent with our model of the reduction of pertechnetate leading to the precipitation of low solubility Tc precipitates such as $\mathrm{TcO}_{2} \cdot n \mathrm{H}_{2} \mathrm{O}$. Representative Tc K-edge XANES spectra are compared to a pertechnetate stock solution in Figure 7.

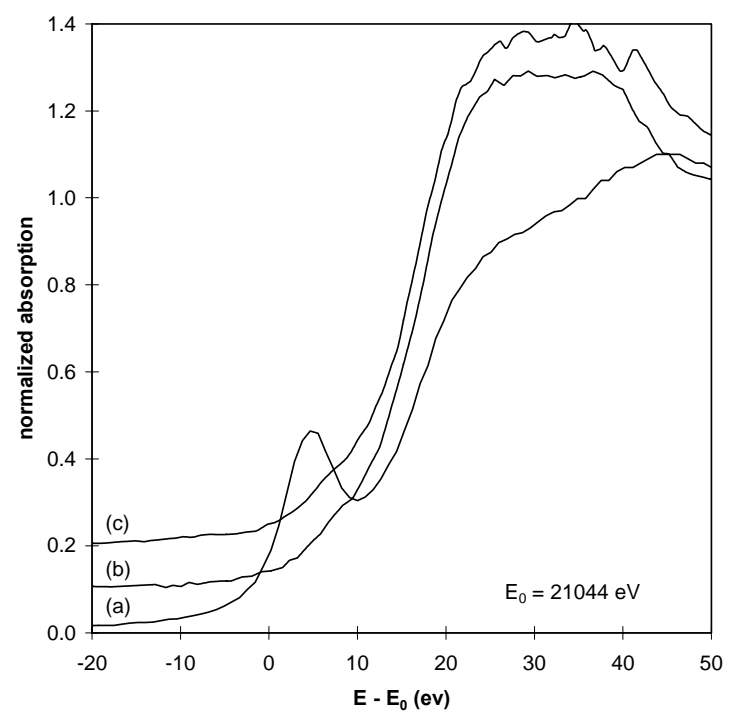

Figure 3. Representative Tc K-edge micro-XANES spectra collected at regions of localized Tc concentration shown in Figure 1. (a) pertechnetate standard, (b) basalt clast A, from bottom of column, and (c) sediment from $20 \mathrm{~cm}$ along length of column. 


\section{Surface-Mediated Reduction of Pertechnetate on $\mathrm{Fe}^{I I}$-Containing Minerals.}

A suite of batch equilibration experiments was completed to measure the sorption of ${ }^{99} \mathrm{Tc}(\mathrm{VII})$ as a function of time by several iron-containing minerals in contact with an uncontaminated Hanford Site groundwater solution under oxic conditions. The objectives of these experiments were to 1) determine if $\mathrm{Fe}(\mathrm{II})$-containing minerals exhibit detectable sorption of technetium under oxic conditions, and if so, 2) identify the mechanism(s) responsible for this uptake. It was proposed that the sorption of $\mathrm{Tc}(\mathrm{VII})$ under oxic conditions resulted from surface-mediated reduction of Tc(VII) to low solubility $\mathrm{Tc}(\mathrm{IV})$ species that precipitate on $\mathrm{Fe}(\mathrm{II})$-containing mineral surfaces. Vandergraaf et al. (1984) and Walton et al. (1986) have observed small, but detectable, uptake of ${ }^{99} \mathrm{Tc}$ by iron-oxide/hydroxide minerals equilibrated with synthetic groundwater solutions under oxic conditions, but the mechanisms responsible for this uptake under these conditions is not understood.

The iron-containing minerals used in the experiments included hematite, magnetite, biotite, and hornblende. Hematite, magnetite, biotite, and amphibole have been identified as trace constituents in the Hanford Site sediments. Hornblende was selected as a representative amphibole for purpose of these experiments. "Research-grade" specimens of the four minerals were obtained from Ward's Geology, and include hematite from Casa de Pedra, Congonhas do Campo, Minas Gerais, Brazil; magnetite from Mineville, New York; biotite from Bancroft, Ontario; and hornblende from Gore Mountain, New York. The identification of each mineral specimen was confirmed using standard powder $\mathrm{X}$-ray powder diffraction techniques. The particle size range of the hematite, magnetite, and hornblende samples used in the sorption experiments was $106 \mu \mathrm{m}$ (140 mesh) to $212 \mu \mathrm{m}(70 \mathrm{mesh})$. The size range of biotite particles was less than $106 \mu \mathrm{m}$. The compositions and surface characteristics of the mineral samples were characterized using scanning electron microscopy (SEM) in conjunction with energy dispersive spectroscopy (EDS). SEM micrographs showing the typical morphology of these minerals in the $<106 \mu \mathrm{m}$ size fraction are shown in Figure 4.

The sorption experiments consisted of equilibrating separate samples of each type of iron-containing mineral with an uncontaminated groundwater solution $(\mathrm{pH} \mathrm{8.4)} \mathrm{spiked}$ with ${ }^{99} \mathrm{Tc}$ (VII) using a solution volume-to-mineral mass ratio of 10:1. The composition of the uncontaminated Hanford groundwater is listed in Table 3, and is based on that reported by Kaplan et al. (1998). The starting concentration of dissolved ${ }^{99} \mathrm{Tc}$ in the spiked groundwater solution was $10^{-8} \mathrm{~mol} / \mathrm{L}(0.99 \mu \mathrm{g} / \mathrm{L})$. Separate containers of the ${ }^{99} \mathrm{Tc}(\mathrm{VII})$-spiked groundwater/suspensions were sampled at 20, 63, 112, 139, and 181 days to determine if any changes in the initial concentration of dissolved ${ }^{99} \mathrm{Tc}$ had occurred. The solution samples were filtered through $0.001-\mu \mathrm{m}$ pore-size membranes, and then analyzed for the concentrations of dissolved ${ }^{99} \mathrm{Tc}$ using inductively coupled plasma/mass spectroscopy (ICP-MS).

Table 4 lists the concentrations of dissolved ${ }^{99} \mathrm{Tc}(\mathrm{VII})$ measured in the supernatant collected from the various batch equilibration experiments with hematite, magnetite, hornblende, and biotite. The results indicate that potential sorption of ${ }^{99} \mathrm{Tc}(\mathrm{VII})$ may 
have occurred on biotite and possibly magnetite and hornblende. As much as 10 and 5\% of the initial concentration of ${ }^{99} \mathrm{Tc}$ may have adsorbed to biotite and magnetite, respectively, over the duration of these experiments. Although the concentrations of ${ }^{99} \mathrm{Tc}$ measured in the filtered solution samples were greater than the minimum limit of

Table 3. Composition of Uncontaminated Hanford Site Groundwater Sample.

\begin{tabular}{l|c|l|c}
\hline \multicolumn{1}{c|}{ Constituent } & $\begin{array}{c}\text { Concentration } \\
(\mathbf{m g} / \mathbf{L})\end{array}$ & \multicolumn{1}{c|}{ Constituent } & $\begin{array}{c}\text { Concentration } \\
(\mathbf{m g} / \mathbf{L})\end{array}$ \\
\hline $\mathrm{pH}$ & 8.4 (unitless) & $\mathrm{Ba}$ & 0.069 \\
$\mathrm{Cl}^{-}$ & 24 & $\mathrm{Ca}$ & 58 \\
$\mathrm{NO}_{3}{ }^{-}$ & 1.7 & $\mathrm{Fe}$ & 0.14 \\
$\mathrm{SO}_{4}{ }^{2-}$ & 109 & $\mathrm{~K}$ & 14 \\
$\mathrm{Total}^{-}$Organic Carbon & 0.73 & $\mathrm{Mg}$ & 16 \\
Total Alkalinity (as $\left.\mathrm{CO}_{3}{ }^{2-}\right)$ & 160 & $\mathrm{Mn}$ & 0.046 \\
$\mathrm{Al}$ & 0.14 & $\mathrm{Na}$ & 30 \\
$\mathrm{~B}$ & 0.05 & $\mathrm{Si}$ & 16.2 \\
\hline
\end{tabular}

Table 4. Initial and Final Mass of ${ }^{99} \mathrm{Tc}(\mathrm{Mg})$ in Solution.

\begin{tabular}{|c|c|c|c|c|}
\hline \multirow{3}{*}{ Sample ID } & \multirow{3}{*}{$\begin{array}{c}\text { Equilibration } \\
\text { Time } \\
\text { (days) }\end{array}$} & \multicolumn{2}{|c|}{ Mass of ${ }^{99} \mathrm{Tc}$ in Solution } & \multirow{3}{*}{$\begin{array}{c}{ }^{99} \text { Te Sorbed } \\
(\%)\end{array}$} \\
\hline & & Initial & Final & \\
\hline & & \multicolumn{2}{|c|}{ - } & \\
\hline Hematite-1 & 20 & 0.010 & 0.010 & 1.0 \\
\hline Hematite-2 & 63 & 0.010 & 0.0101 & -0.5 \\
\hline Hematite-3 & 112 & 0.010 & 0.0100 & -0.1 \\
\hline Hematite-4 & 139 & 0.010 & 0.0099 & 0.7 \\
\hline Hematite-5 & 181 & 0.010 & 0.0100 & 0.6 \\
\hline Magnetite-1 & 20 & 0.010 & 0.010 & 3.2 \\
\hline Magnetite-2 & 63 & 0.010 & 0.0095 & 5.0 \\
\hline Magnetite-3 & 112 & 0.010 & 0.0104 & -3.9 \\
\hline Magnetite-4 & 139 & 0.010 & 0.0101 & -0.5 \\
\hline Magnetite-5 & 181 & 0.010 & 0.0095 & 5.5 \\
\hline Hornblende-1 & 20 & 0.010 & 0.010 & 4.6 \\
\hline Hornblende-2 & 63 & 0.010 & 0.101 & -1.1 \\
\hline Hornblende-3 & 112 & 0.010 & 0.108 & -8.3 \\
\hline Hornblende-4 & 139 & 0.010 & 0.0099 & 1.0 \\
\hline Hornblende-5 & 181 & 0.010 & 0.0097 & 2.8 \\
\hline Biotite-1 & 20 & 0.005 & 0.0046 & 8.5 \\
\hline Biotite-2 & 63 & 0.005 & 0.0047 & 6.3 \\
\hline Biotite- 3 & 112 & 0.005 & 0.0052 & -3.6 \\
\hline Biotite-4 & 139 & 0.005 & 0.0051 & -1.5 \\
\hline Biotite-5 & 181 & 0.005 & 0.0048 & 4.2 \\
\hline Biotite-6 (sample) & 181 & 0.003 & 0.0027 & 10.1 \\
\hline
\end{tabular}




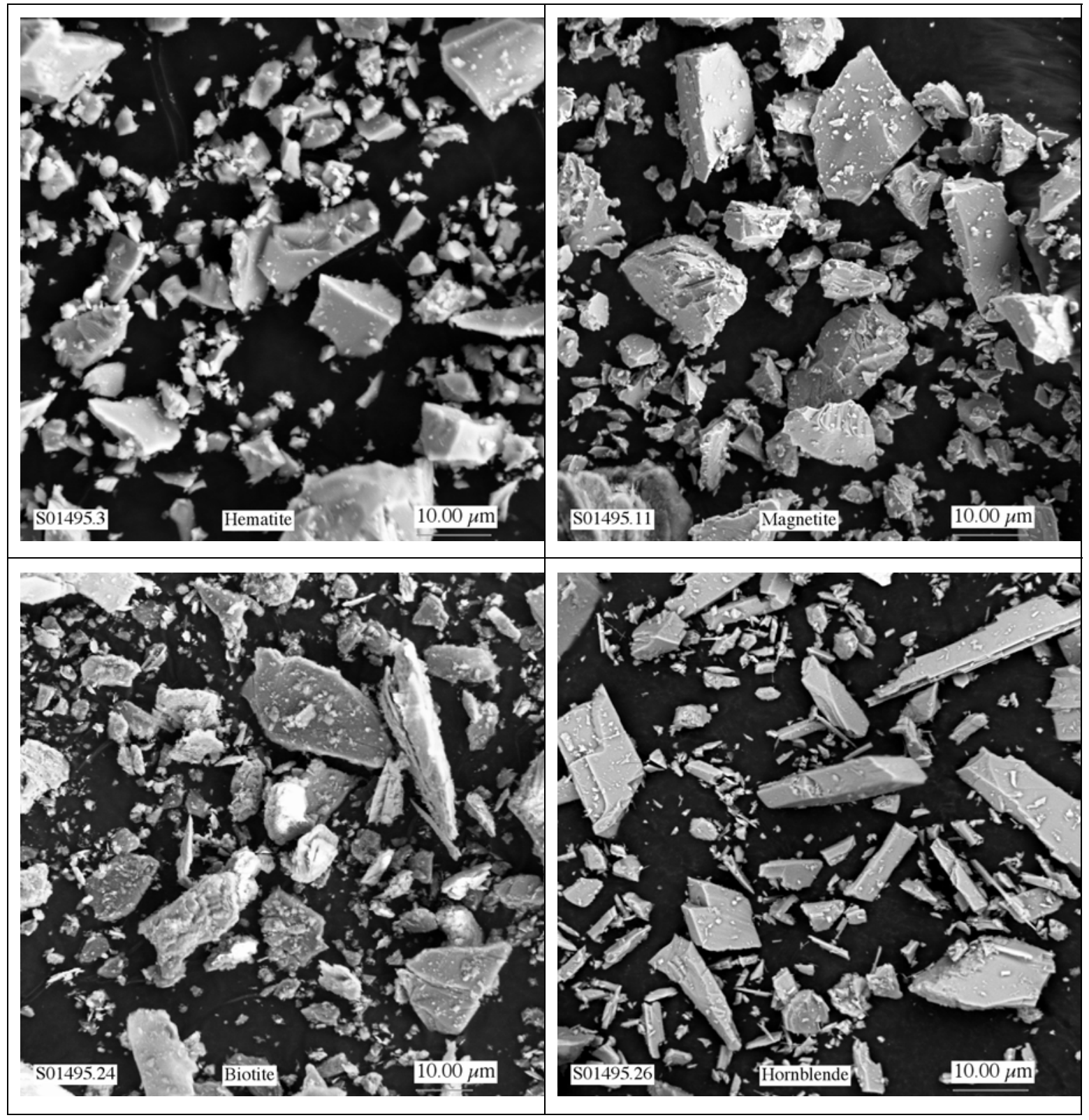

Figure 4. SEM micrographs showing general morphology of hematite, magnetite, biotite, and hornblende particles in $<106 \mu \mathrm{m}$ size fraction. 
quantification (LOQ) for these ICP-MS analyses, it was difficult to conclude absolutely that the decrease in dissolved ${ }^{99} \mathrm{Tc}(\mathrm{VII})$ concentrations was due to sorption, and not analytical error given the small percentage differences between the starting and final concentrations of ${ }^{99} \mathrm{Tc}$.

Samples of hematite, magnetite, hornblende, and biotite from the 20-day experiments were analyzed by X-ray absorption spectroscopy (XAS) in an attempt to characterize the extent, oxidation state, and speciation of technetium that may have sorbed to the mineral surfaces. The XAS analyses were completed at the Advanced Photon Source at the Argonne National Laboratory. Because biotite showed the greatest extent of technetium sorption, it was hoped that the XAS analyses would show detectable concentrations of localized sorption of technetium on the biotite grains. Figure 5 shows a set of XAS probe scans for a dispersed particle mount of biotite from the 20-day experiment. Some areas of potential concentrations of technetium (bright green areas in image B in Figure 5) were observed in the technetium scan. These areas corresponded to areas of high iron concentrations, but detailed energy analyses indicated that the hot spots were due to localized concentrations of niobium and zirconium and not technetium. Similar potential technetium "hot spots" were observed in the magnetite sample, but these too were determined to be due to zirconium and/or niobium. The XAS analyses of the particle mounts of hematite and hornblende did not identify any potential concentrated areas of technetium. If localized sorption of technetium had occurred on these minerals samples, then the concentrations of sorbed technetium were less than the minimum detection level for this XAS instrumentation. Because the results of the 63-, 112-, 139-, and 181-day experiments did not indicate any significant increase in technetium sorption relative to that measured at 20 days, no additional XAS analyses were conducted.

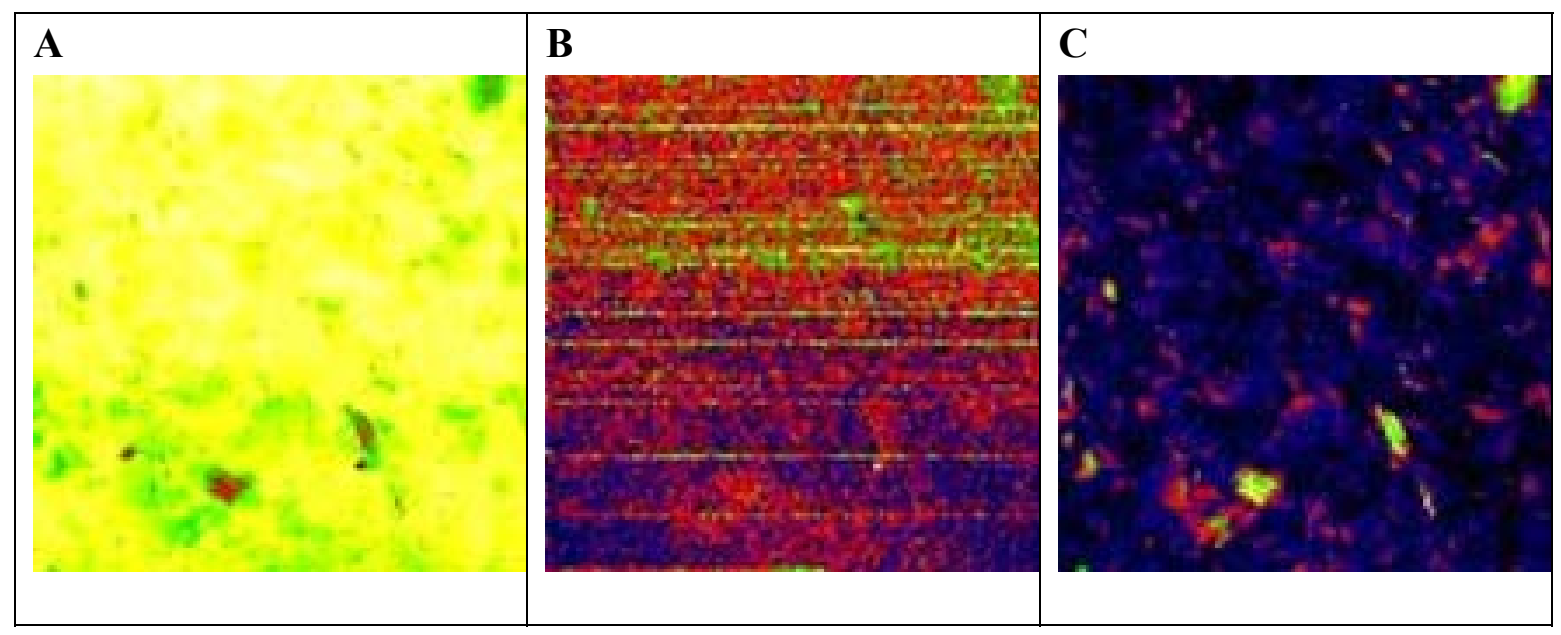

Figure 5. X-ray absorption spectroscopy (XAS) probe scans for biotite particles from the 20-day ${ }^{99} \mathrm{Tc}$ (VII) equilibration experiments. Images A, B, and C correspond to the absorption, technetium, and iron scans, respectively. The darkness of the color in image A and the brightness of the colors in images $\mathrm{B}$ and $\mathrm{C}$ are a relative measure of increasing concentrations. 
The results of these batch equilibration experiments indicate that some sorption of

${ }^{99} \mathrm{Tc}(\mathrm{VII})$ may have occurred on biotite and possibly magnetite and hornblende under oxic conditions over the course of the 181-day experiments. However, the amount of sorption on biotite and magnetite did not likely exceed 10 and $5 \%$, respectively. Given the limited extent of total sorbed ${ }^{99} \mathrm{Tc}(\mathrm{VII})$, the masses of sorbed ${ }^{99} \mathrm{Tc}(\mathrm{VII})$ were too low to be detected by XAS to determine the extent, oxidation state, and speciation of technetium sorbed to the surfaces of these hematite, magnetite, hornblende, and biotite materials.

\section{Thermodynamic model of reduced Tc solid solubility}

We conducted extensive solubility studies of $\mathrm{TcO}_{2} \cdot x \mathrm{H}_{2} \mathrm{O}(\mathrm{am})$ over a large range of $\mathrm{H}^{+}(6$ $\mathrm{M}$ to $\left.10^{-5} \mathrm{M} \mathrm{HCl}\right)$ and chloride concentrations $\left(10^{-3} \mathrm{M}\right.$ to $\left.5 \mathrm{M} \mathrm{NaCl}\right)$ from both over- and under-saturation directions. All solubility experiments were conducted under carefully controlled redox conditions such that greater than $80 \%$ of the Tc in solution is in the reduced Tc(IV) oxidation state for the majority of measurements. A combination of techniques involving solubility, XAS, spectroscopic measurements and XRD were used to identify the aqueous and solid phases. The thermodynamic model we have developed provides close agreement with extensive data obtained in this study and is consistent with the most reliable literature data.

\section{Methods}

All experiments and sample preparations were conducted in an atmosphere-controlled chamber under an Ar atmosphere. Deionized distilled water, degassed by boiling and cooling in the Ar atmosphere, was used in all cases. $\mathrm{TcO}_{2} \cdot x \mathrm{H}_{2} \mathrm{O}(\mathrm{am})$ precipitate was prepared individually for each sample starting from pertechnetate stock solution and under basic conditions. The precipitate was then washed three times using $20 \mathrm{~mL}$ of freshly prepared $0.01 \mathrm{M} \mathrm{Na}_{2} \mathrm{~S}_{2} \mathrm{O}_{4}$ in near neutral aqueous solution. The precipitate was equilibrated with $20 \mathrm{~mL}$ of $\mathrm{pH}$ adjusted solution for at least 3-days prior to initial sampling. The total Tc concentration in solution was determined by beta-scintillation counting. The detection limit for this technique is approximately $10^{-8} \mathrm{M} \mathrm{Tc}$. The concentration of $\mathrm{Tc}(\mathrm{VII})$ and reduced $\mathrm{Tc}$ in the sample were determined using the solvent extraction technique where tetraphenylphosphoniumchloride (TPPC) in chloroform extracts pertechnetate, Tc(VII), into the organic phase leaving reduced Tc in the aqueous phase. After centrifugation, the Tc concentration in the organic and aqueous fractions was subsequently determined by beta-scintillation counting.

A limited number of solid samples were selected for powder X-ray diffraction (XRD) measurements on a Scintag PAD V X-ray diffractometer using $\mathrm{Cu} \mathrm{K} \alpha$ radiation at $45 \mathrm{KV}$ and $40 \mathrm{ma}$. Spectrophotometric measurements (Cary 500) were made in the UV to visible region from 200 to $450 \mathrm{~nm}$. The molar extinction coefficients for the $\mathrm{TcCl}_{6}{ }^{2-}$, $\mathrm{TcCl}_{5}{ }^{-}$, and $\mathrm{TcCl}_{4}(\mathrm{aq})$ species are reported in the literature (Ianovic et al. 1981; Kanchiku 1969). However, the molar extinction coefficient for the $\mathrm{TcO}^{2+}$ and $\mathrm{TcO}(\mathrm{OH})^{+}$species are unknown. Therefore, absorption spectra of $\mathrm{TcO}^{2+}$ and $\mathrm{TcO}(\mathrm{OH})^{+}$were measured as a function of concentration at constant $\mathrm{pH}$ to determine the molar extinction coefficients. 
Nine equilibrated solid samples and solution samples were analyzed using X-ray absorption spectroscopy (XAS) at the Stanford Synchrotron Radiation Laboratory (SSRL) (beamline 4-2) to verify the Tc oxidation state and to characterize the equilibrated solution and solid phases. In general the concentration of Tc in solution must exceed $1 \times 10^{-4} \mathrm{M}$ for acquisition of data with acceptable signal-to-noise ratio for EXAFS analysis. Spectra were collected at the Tc K-edge and were measured in transmission of fluorescence modes. All spectra were measured to photoelectron wavevector value of $13.0 \AA^{-1}$. Energy calibration was based on the assignment of the first inflection point in the absorption edge of the SSRL Tc standard to $21035 \mathrm{eV}$.

The ion-interaction model of Pitzer and co-workers (Pitzer and Mayorga 1973; Pitzer 1991) was used to interpret the solubility data. This aqueous thermodynamic model emphasizes a detailed description of the specific ion interactions in the solution. The effects of specific ion interactions on the excess solution free energy are contained in the expressions for the activity coefficients. The activity coefficients can be expressed in a virial-type expansion as

$\ln \gamma_{\mathrm{i}}=\ln \gamma_{\mathrm{i}}^{\mathrm{DH}}+\sum_{\mathrm{j}} \beta_{\mathrm{ij}}(\mathrm{I}) \mathrm{m}_{\mathrm{j}}+\sum_{\mathrm{j}} \sum_{\mathrm{k}} \mathrm{C}_{\mathrm{ijk}} \mathrm{m}_{\mathrm{j}} \mathrm{m}_{\mathrm{k}}+\ldots$

where $\mathrm{m}$ is the molality, $\gamma_{\mathrm{i}}^{\mathrm{DH}}$ is a modified Debye-Hückel activity coefficient that is a universal function of ionic strength, and $\beta_{\mathrm{ij}}(\mathrm{I})$ and $\mathrm{C}_{\mathrm{ijk}}$ are specific for each ion interaction and are functions of ionic strength. The third virial coefficient, $\mathrm{C}$, is understood to be independent of ionic strength. A detailed description of the exact form of Eq. (2) is published in Felmy and Weare (1986) and Felmy et al. (1989), and is contained in the nonlinear least-squares program INSIGHT (Sterner et al. 1997) for estimating activity coefficients and calculating chemical equilibria involving multiple solid and aqueous species. To interpret the experimental data with INSIGHT, all concentrations were converted to molality units.

Results

In general, the $\mathrm{TcO}_{2} \cdot x \mathrm{H}_{2} \mathrm{O}(\mathrm{am})$ solubility in the low $\mathrm{pH}$ region decreases by about an order of magnitude with each unit increase in $\mathrm{pH} / \mathrm{p} C_{\mathrm{H}+}$. At relatively high $\mathrm{pH} / \mathrm{p} C_{\mathrm{H}^{+}}$ values (e.g., at $\mathrm{pH} 4$ ), the solubility appears to be independent of $\mathrm{pH} / \mathrm{p} C_{\mathrm{H}+}$. In the absence of $\mathrm{NaCl}$, the solubility of $\mathrm{TcO}_{2} \cdot x \mathrm{H}_{2} \mathrm{O}(\mathrm{am})$ as a function of $\mathrm{pH} / \mathrm{p} C_{\mathrm{H}^{+}}$is in good agreement with the results of Meyer et al. $(1991,1986)$ as shown in Figure 6, particularly under very acidic conditions. Above $\mathrm{pH}=2$, the measured solubilities are approximately an order of magnitude greater than those measured by Meyer et al. $(1991,1986)$. In the presence of fixed $\mathrm{NaCl}$ concentrations the solubility of $\mathrm{TcO}_{2} \cdot x \mathrm{H}_{2} \mathrm{O}(\mathrm{am})$ shows a similar dependence on $\mathrm{pH} / \mathrm{p} C_{\mathrm{H}+}$. A comparison of the Tc concentrations from the $\mathrm{TcO}_{2} \cdot x \mathrm{H}_{2} \mathrm{O}(\mathrm{am})$ solubility after 11 days in $0.8 \mathrm{M}, 2.5 \mathrm{M}$, and $5.0 \mathrm{M} \mathrm{NaCl}$ solutions as a function of $\mathrm{p} C_{\mathrm{H}^{+}}$and their comparison to the Tc concentrations in the absence of $\mathrm{NaCl}$ shows a finite increase in concentrations with the increase in $\mathrm{NaCl}$ concentrations (Figure 6). This increase in concentration with the increase in $\mathrm{NaCl}$ concentrations indicates that the interaction of electrolyte media with the Tc species is significant and cannot be ignored in the interpretation of data. 

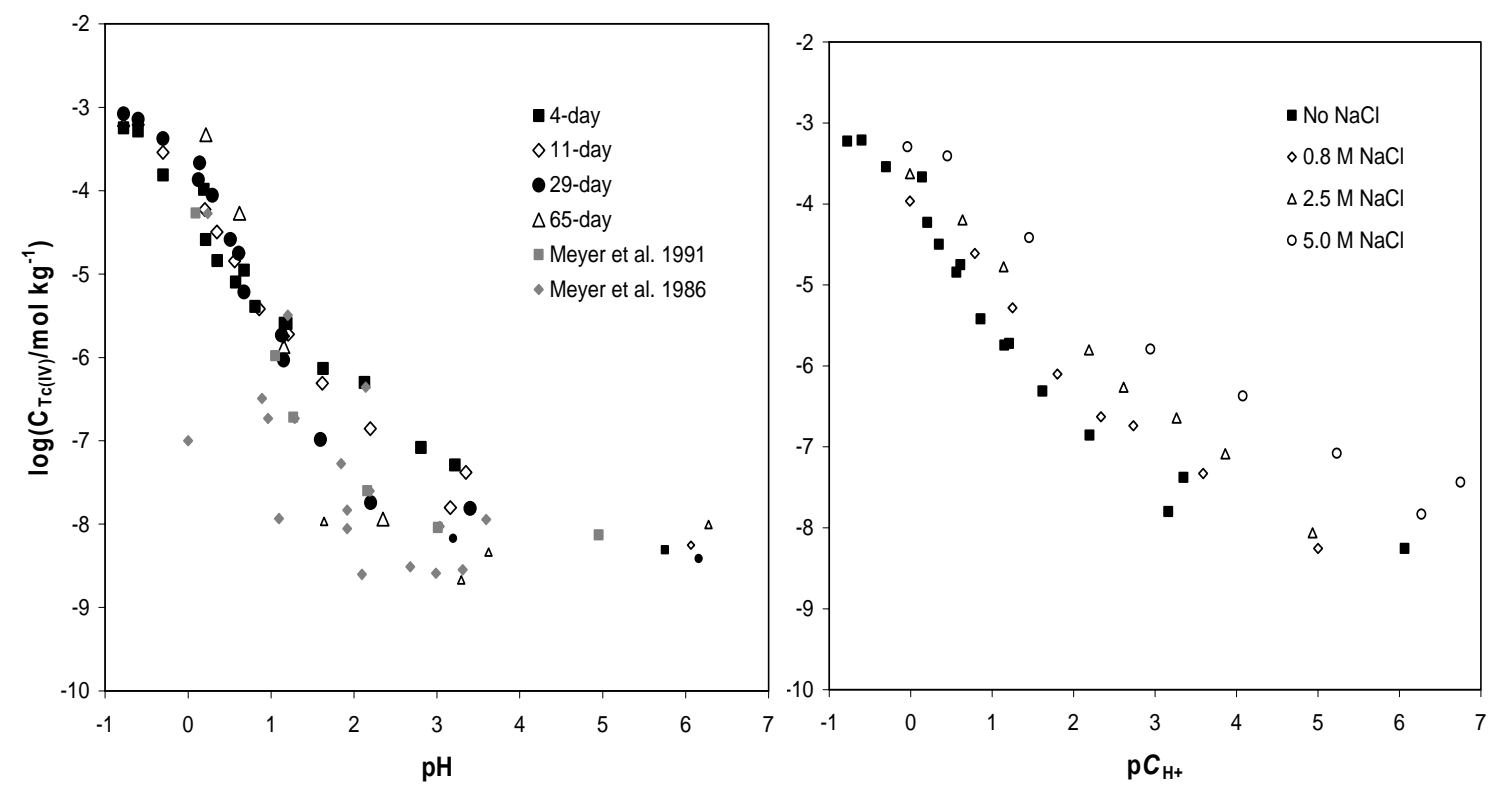

Figure 6. Solubility of Tc(IV)solids $\mathrm{TcO}_{2} \cdot x \mathrm{H}_{2} \mathrm{O}$ and $\mathrm{TcCl}_{4}$ in the absence of $\mathrm{NaCl}$, left, and in the presence of variable $\mathrm{NaCl}$ concentrations, right.

Powder X-ray diffraction and EXAFS analyses were used to characterize the solid phases (Figure 7). These studies indicate the presence of amorphous $\mathrm{TcO}_{2} \cdot x \mathrm{H}_{2} \mathrm{O}$ as the solubility-limiting phase under most of the $\mathrm{pH}$ conditions investigated and the presence of a second amorphous phase at $\mathrm{pH} 0.3$ to $6 \mathrm{M} \mathrm{HCl}$. We have assumed that the composition of the second amorphous phase is $\mathrm{TcCl}_{4}(\mathrm{am})$, which is consistent with the analyses of solubility data presented in the next section.
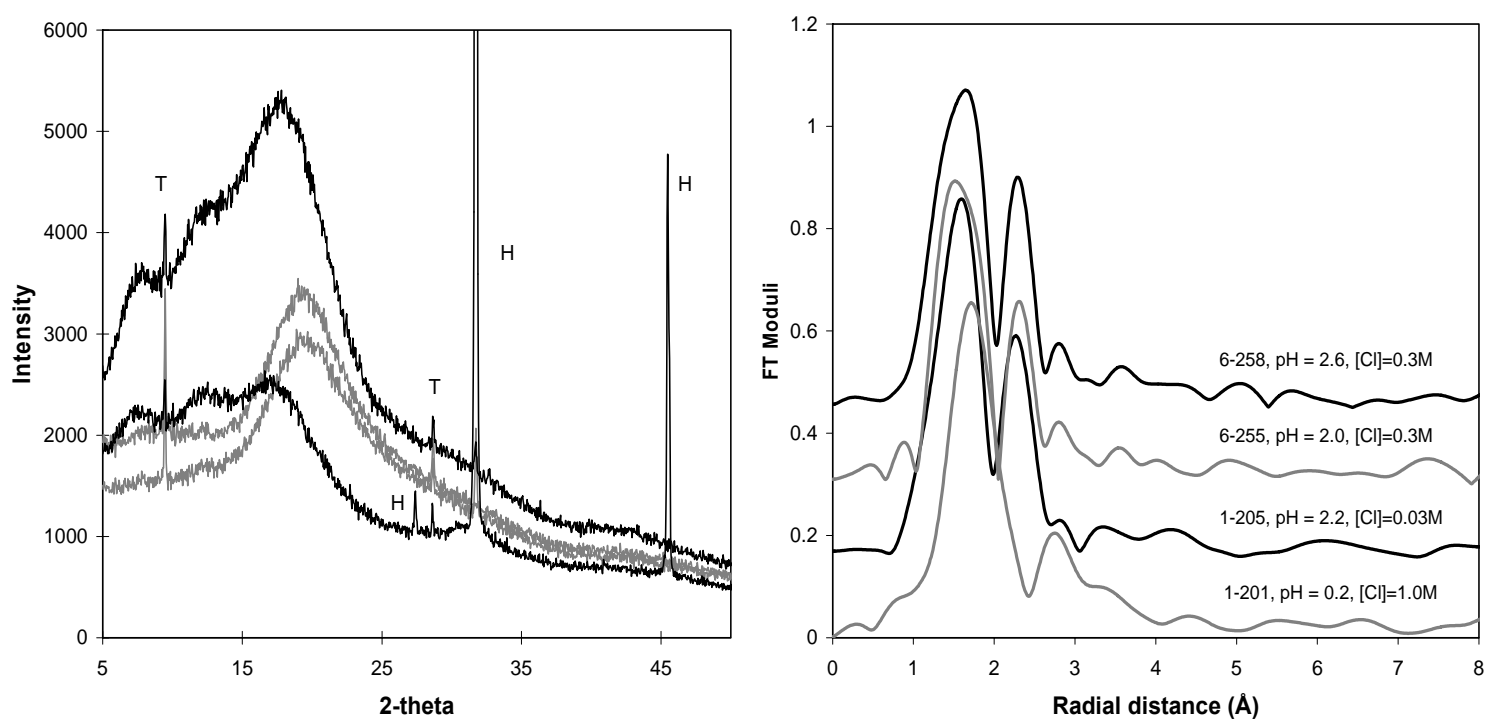

Figure 7. Left, XRD patterns of Tc(IV) solids in equilibrium with low chloride solution (gray), and high chloride solutions (black). Right, Fourier transforms of Tc K-edge EXAFS. The upper three traces are $\mathrm{TcO}_{2} \cdot n \mathrm{H}_{2} \mathrm{O}$, the lower trace is a chloride containing solid of unknown composition. 
Four distinctive UV-Vis spectra that could be assigned to $\mathrm{TcCl}_{6}^{2-}, \mathrm{TcCl}_{4}(\mathrm{aq}), \mathrm{TcO}^{2+}$, and $\mathrm{TcO}(\mathrm{OH})^{+}$species were observed over the range of experimental conditions investigated (Figure 8). Molar extinction coefficients for the $\mathrm{TcCl}_{6}^{2-}$ and $\mathrm{TcCl}_{4}(\mathrm{aq})$ species have been reported previously. Molar extinction coefficient was determined in this work for the $\mathrm{TcO}^{2+}$ species, attempts to quantify the molar extinction coefficient for the $\mathrm{TcO}(\mathrm{OH})^{+}$ species were not successful. At high chloride concentrations, combined UV-Vis and EXAFS analyses of the solution samples confirmed the stability of the $\mathrm{TcCl}_{6}^{2-}$ and $\mathrm{TcCl}_{4}(\mathrm{aq})$ species (Figure 8). At higher chloride concentrations, the stability of the $\mathrm{TcCl}_{6}{ }^{2-}$ and $\mathrm{TcCl}_{4}(\mathrm{aq})$ extends to higher $\mathrm{pH}$. For example, in the presence of $2.5 \mathrm{M} \mathrm{NaCl}$ the $\mathrm{TcCl}_{4}(\mathrm{aq})$ species is observed at $\mathrm{p} C_{\mathrm{H}^{+}}=0.6$ and in the presence of $5.0 \mathrm{M} \mathrm{NaCl}$ the $\mathrm{TcCl}_{6}^{2-}$ species is observed at $\mathrm{p} C_{\mathrm{H}^{+}}=0.5$. Based on our spectrophotometric measurements and the assignments in the literature (Ianovici et al., 1981;Kanchiku 1969), our observations are in agreement with the conclusions of Ben Said et al. (2000) that the $\mathrm{Tc}(\mathrm{IV})$-aquochloro complexes are likely to exist under these condition than hydroxy or oxo-chloro Tc(IV) compounds.
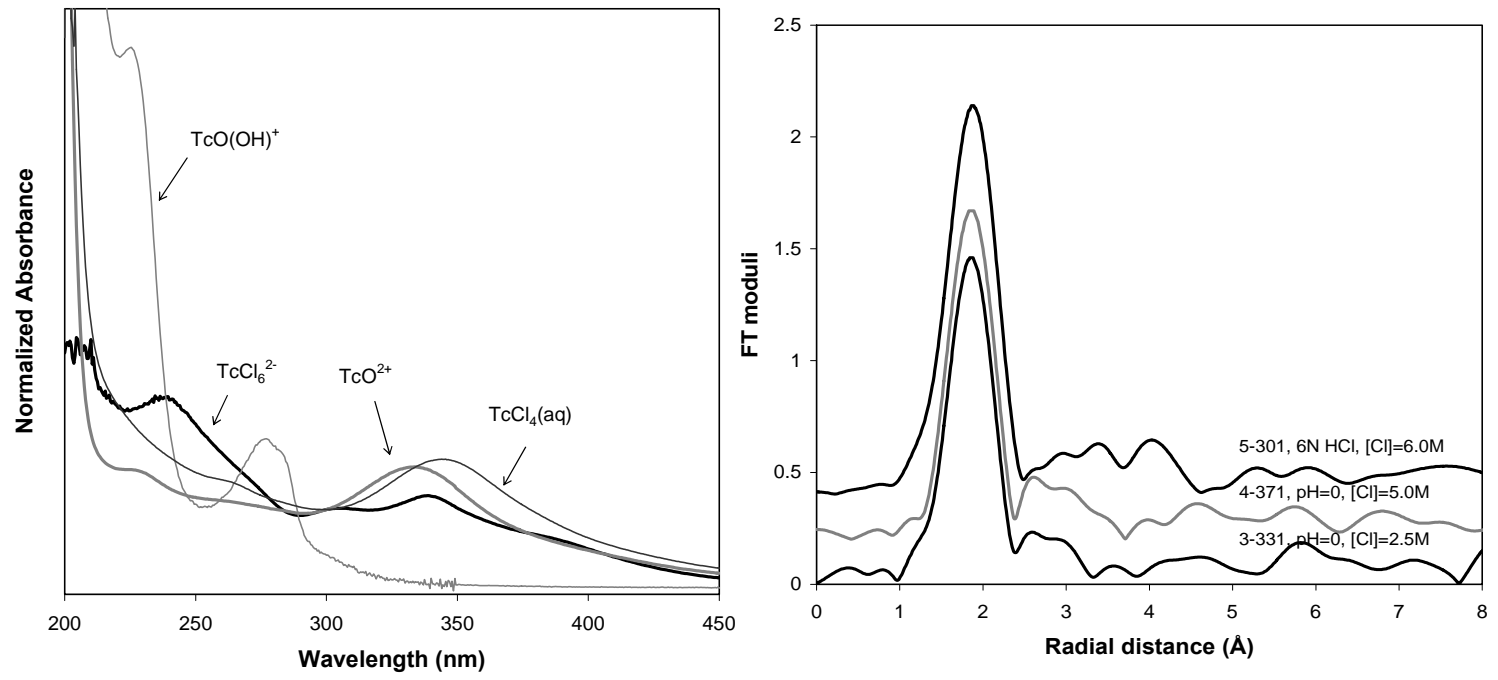

Figure 8. Characteristic UV-Vis spectra of the dominant Tc(IV) solution species, left. Fourier transform of the Tc K-edge EXAFS data of equilibrated solutions with high chloride content, right. Fits to the EXAFS suggest that the upper trace is $\mathrm{TcCl}_{6}{ }^{2-}$, the lower two traces are $\mathrm{TcCl}_{4}(\mathrm{aq})$.

Our solubility studies indicate that the measured Tc concentration and Tc solution speciation have a complex dependence on the solubility limiting phase, $\mathrm{pH}$, and chloride concentration. The XRD and EXAFS analyses of the solid phases show the presence of two discrete amorphous $\mathrm{Tc}$ compounds whose stability is a stronger function of $\mathrm{pH}$ than chloride concentration. Therefore, the increase in solubility with increase in $\mathrm{NaCl}$ concentrations (Figure 6) cannot be due to the solid phase transformations alone but must result from either the formation of chloride complexes of Tc(IV) or from the interactions of aqueous species with the electrolyte ions. As discussed above, the UV-Vis spectrophotometric analyses of aqueous species in the absence of $\mathrm{NaCl}$ show that the aqueous chloride complexes at $\mathrm{pH} \sim>0.1$ are not important and that the dominant species are either $\mathrm{TcO}^{2+}$ or $\mathrm{TcO}(\mathrm{OH})^{+}$. In the presence of greater than $2.5 \mathrm{M} \mathrm{NaCl}$, the aqueous 
chloride complexes are only important at $\mathrm{pH} \sim<1.0$. This information, along with the knowledge that the solubility-controlling phase at $\mathrm{pH}$ values greater than 0.5 is $\mathrm{TcO}_{2} \cdot x \mathrm{H}_{2} \mathrm{O}(\mathrm{am})$ and the assumption that the composition of the solubility-controlling phase at $\mathrm{pH}$ values less than 0.5 is $\mathrm{TcCl}_{4}$, was used to develop a thermodynamic model for the Tc(IV) system extending from $10^{-7} \mathrm{M}$ to $6 \mathrm{M} \mathrm{H}^{+}$concentrations and $\mathrm{NaCl}$ concentrations extending to $5.0 \mathrm{M}$.

Thermodynamic Analyses of Solubility data

To develop a reliable model, we took advantage of the extensive $\mathrm{TcO}_{2} \cdot 1.6 \mathrm{H}_{2} \mathrm{O}(\mathrm{am})$ solubility data in addition to the spectroscopic identifications (EXAFS and UV-Vis) of the aqueous and solid species. Several different combinations of chemical potentials of the species along with the Pitzer ion-interaction parameters were tried to fit the data. Initial calculation of the predicted species concentrations using Rard et al. (1999) model indicated that the $\mathrm{TcO}^{2+}$ species has a large region of dominance and the $\mathrm{TcO}(\mathrm{OH})^{+}$ species contributes only over a limited region. However, our spectrophotometric analyses of the aqueous phase identified the presence of the $\mathrm{TcO}(\mathrm{OH})^{+}$species between $\mathrm{pH}$ values of 0.8 to values up to about 2.5 (the $\mathrm{pH}$ region where measured Tc concentrations exceeded the detection limits) and the presence of the $\mathrm{TcO}^{2+}$ species at $\mathrm{pH}$ values between 0.1 and 0.8 . These considerations were kept in mind while developing a model for $\mathrm{TcO}_{2} \cdot 1.6 \mathrm{H}_{2} \mathrm{O}(\mathrm{am})$ solubility in the region where $\mathrm{H}^{+}$concentration $<1 \mathrm{M}$. The simplest model that described the entire data (data sets without $\mathrm{NaCl}$ at $\mathrm{pH}$ greater than zero, and sets containing $0.8 \mathrm{M}, 2.5 \mathrm{M}$, and $5.0 \mathrm{M} \mathrm{NaCl}$ ) included $\Delta \mathrm{G}_{\mathrm{f}}^{0} / \mathrm{RT}$ value of $142.306 \pm 0.72$ for $\mathrm{TcO}(\mathrm{OH})^{+}$and values for $\mathrm{TcO}^{2+}, \mathrm{TcO}(\mathrm{OH})_{2}(\mathrm{aq})$ and $\mathrm{TcO}_{2} \cdot 1.6 \mathrm{H}_{2} \mathrm{O}(\mathrm{am})$ as reported in Rard et al., (1999) and in Table 5 along with ioninteraction parameters listed in Table 6. A close agreement between the Tc(IV) concentrations and the identity of aqueous species predicted by this model and those observed indicates the reliability of this model in predicting Tc(IV) concentrations in equilibrium with $\mathrm{TcO}_{2} \cdot 1.6 \mathrm{H}_{2} \mathrm{O}(\mathrm{am})$ over a wide range in $\mathrm{H}^{+}$concentrations (from $1.0 \mathrm{M}$ to $1.0 \times 10^{-6} \mathrm{M}$ ) and $\mathrm{NaCl}$ concentrations ranging up to $5.0 \mathrm{M}$.

We also determined the solubility of $\mathrm{TcO}_{2} \cdot 1.6 \mathrm{H}_{2} \mathrm{O}(\mathrm{am})$ in $\mathrm{HCl}$ solutions ranging in concentrations up to $6 \mathrm{M}$. The predicted Tc(IV) concentrations in equilibrium with $\mathrm{TcO}_{2} \cdot 1.6 \mathrm{H}_{2} \mathrm{O}(\mathrm{am})$ using the model described above were found to be several orders of magnitude higher than those observed. These comparisons indicated that the model would have to be enhanced in order to provide reliable predictions in the concentrated $\mathrm{HCl}$ solutions. The interpretation of these data in concentrated $\mathrm{HCl}$ solutions $(>1.0 \mathrm{M})$ is problematic due to very high concentrations of $\mathrm{HCl}$, the possible presence of multiple aqueous species (e.g., $\mathrm{TcCl}_{6}{ }^{2-}, \mathrm{TcCl}_{5}{ }^{-}, \mathrm{TcCl}_{4}(\mathrm{aq}), \ldots$ (Ianovici et al., 1981; Kanchiku 1969)), and unavailability of chemical potentials for Tc(IV)-Cl complexes and/or ioninteraction parameters for the dominant species in these systems with the bulk electrolyte ions $\left(\mathrm{H}^{+}\right.$and $\left.\mathrm{Cl}^{-}\right)$. An additional complication may also result in these systems where Tc(IV)-chloro compounds may form under these conditions. Our spectrophotometric analyses of the aqueous phase from concentrated $\mathrm{HCl}$ solutions $(1.0$ to $6.0 \mathrm{M})$ indicate the presence of $\mathrm{TcCl}_{6}{ }^{2-}$ at high $\mathrm{HCl}$ concentrations and $\mathrm{TcCl}_{4}(\mathrm{aq})$ in moderate $\mathrm{HCl}$ concentrations. The literature data also reports the presence of these species along with the presence of species such as $\mathrm{TcCl}_{5}{ }^{-}$(Ianovici et al., 1981). The dominance of any of 
these species at $1.0 \mathrm{M} \mathrm{HCl}$ would dictate over about six orders of magnitude increase in solubility with the increase in $\mathrm{HCl}$ concentrations from $1.0 \mathrm{M}$ to $6.0 \mathrm{M}$ (Eqs. 1-3).

$\mathrm{TcO}_{2} \cdot 1.6 \mathrm{H}_{2} \mathrm{O}(\mathrm{am})+6 \mathrm{Cl}^{-}+4 \mathrm{H}^{+}=\mathrm{TcCl}_{6}^{2-}+3.6 \mathrm{H}_{2} \mathrm{O}$

[Eq. 1]

$\mathrm{TcO}_{2} \cdot 1.6 \mathrm{H}_{2} \mathrm{O}(\mathrm{am})+5 \mathrm{Cl}^{-}+4 \mathrm{H}^{+}=\mathrm{TcCl}_{5}{ }^{-}+3.6 \mathrm{H}_{2} \mathrm{O}$

[Eq. 2]

$\mathrm{TcO}_{2} \cdot 1.6 \mathrm{H}_{2} \mathrm{O}(\mathrm{am})+4 \mathrm{Cl}^{-}+4 \mathrm{H}^{+}=\mathrm{TcCl}_{4}(\mathrm{aq})+3.6 \mathrm{H}_{2} \mathrm{O}$

However, the experimental data indicate an increase in Tc concentration of only about an order of magnitude with the increase in $\mathrm{HCl}$ concentrations from $1.0 \mathrm{M}$ to $6.0 \mathrm{M}$.

Therefore, if $\mathrm{TcCl}_{6}{ }^{2-}$ or $\mathrm{TcCl}_{4}(\mathrm{aq})$ are dominant at $\geq 1.0 \mathrm{M} \mathrm{HCl}$ concentration as indicated by the spectroscopic data, $\mathrm{TcO}_{2} \cdot 1.6 \mathrm{H}_{2} \mathrm{O}(\mathrm{am})$ cannot possibly be the solubility-controlling solid phase in these concentrated $\mathrm{HCl}$ solutions. Similar arguments can be made to show that alternative compounds such as $\mathrm{H}_{2} \mathrm{TcCl}_{6}(\mathrm{~s})$ and $\mathrm{TcOCl}_{2}(\mathrm{~s})$, assumed based either on data mentioned in Rard et al., (1999) or in analogy to the U(IV)-Cl system, cannot be the solubility-controlling solid phases.

These considerations lead us to conclude that the equilibrium with $\mathrm{TcCl}_{4}$ (s) can satisfy the observed distribution of $\mathrm{TcCl}_{4}(\mathrm{aq})$ and $\mathrm{TcCl}_{6}{ }^{2-}$ and the observed solubility behavior in the concentrated $\mathrm{HCl}$ solutions. This conclusion is supported by the EXAFS data, which indicates the presence of a Tc(IV) compound containing chloride and the XRD data, which indicates the presence of a second amorphous compound. This unidentified compound may very well be $\mathrm{TcCl}_{4}(\mathrm{am})$ compound. However, because of the large number of difficulties discussed above and the lack of definitive identification of $\mathrm{TcCl}_{4}(\mathrm{am})$ and other $\mathrm{Tc}-\mathrm{Cl}$ compounds are possible, only a preliminary model can be presented for this system. To develop this model, we first estimated the $\Delta \mathrm{G}_{\mathrm{f}}{ }^{0} / \mathrm{RT}$ value for $\mathrm{TcCl}_{4}$ (aq) (-166.867) based on equilibrium with $\mathrm{TcO}_{2} \cdot 1.6 \mathrm{H}_{2} \mathrm{O}(\mathrm{am})$ and the observation that this is the dominant aqueous species in $1.0 \mathrm{M} \mathrm{HCl}$. This also required an ion-interaction value of 0.11 for $\mathrm{TcO}^{2+}-\mathrm{H}^{+}$pair, which is reasonable and identical to the value reported for $\mathrm{Ca}^{2+}-\mathrm{H}^{+}$pair (Pitzer 1991). We then determined $\Delta \mathrm{G}_{\mathrm{f}}{ }^{0} / \mathrm{RT}$ values for $\mathrm{TcCl}_{4}(\mathrm{am})$ and $\mathrm{TcCl}_{6}{ }^{2-}, 175.639$ and -269.356 , respectively, and the binary interaction parameters for the $\mathrm{TcCl}_{6}{ }^{2-}-\mathrm{Na}^{+}$pair. These parameters were included in the overall model, and the model was used to predict concentrations for the concentrated $\mathrm{HCl}$ solutions in equilibrium with $\mathrm{TcCl}_{4}(\mathrm{~s})$ and for systems with and without $\mathrm{NaCl}$, at $\mathrm{HCl}$ concentrations $<\sim 1 \mathrm{M}$, and in equilibrium with $\mathrm{TcO}_{2} \cdot 1.6 \mathrm{H}_{2} \mathrm{O}(\mathrm{am})$. As expected, the inclusion of $\mathrm{TcCl}_{4}(\mathrm{aq})$ and $\mathrm{TcCl}_{6}{ }^{2-}$ did not significantly affect the predicted concentrations, with the exception of a few of the lowest $\mathrm{pH}$ data points. The predicted aqueous species and the concentrations are in very good agreement with the spectrophotometric and solubility data (Figure 9). 
Table IV. Dimensionless Standard Molar Gibbs Energy of Formation of Different Species.

\begin{tabular}{|c|c|c|}
\hline Species & $\Delta \mathbf{G}_{\mathrm{f}}^{0} / \mathbf{R T}$ & Reference \\
\hline $\mathrm{TcCl}_{6}^{2-}$ & $-269.356 \pm 0.39$ & This work $^{\mathrm{a}}$ \\
\hline $\mathrm{TcCl}_{4}(\mathrm{aq})$ & $-166.867 \pm 0.39$ & This work ${ }^{\mathrm{b}}$ \\
\hline $\mathrm{TcO}^{2+}$ & $>-47.161$ & Rard et al., 1999 \\
\hline \multirow[t]{2}{*}{$\mathrm{TcO}(\mathrm{OH})^{+}$} & $-142.306 \pm 0.72$ & This work ${ }^{\mathrm{c}}$ \\
\hline & $-139.327 \pm 3.634$ & Rard et al., $1999^{\mathrm{d}}$ \\
\hline $\mathrm{TcO}(\mathrm{OH})_{3}^{-}$ & $-299.798 \pm 3.685$ & Rard et al., 1999 \\
\hline $\mathrm{TcO}(\mathrm{OH})_{2}(\mathrm{aq})$ & $-229.234 \pm 3.568$ & Rard et al., 1999 \\
\hline $\mathrm{TcO}_{2} \cdot 1.6 \mathrm{H}_{2} \mathrm{O}(\mathrm{am})$ & $-305.974 \pm 3.377$ & Rard et al., 1999 \\
\hline $\mathrm{TcCl}_{4}(\mathrm{am})$ & $-175.639 \pm 0.39$ & This work \\
\hline $\mathrm{Cl}^{-}$ & -52.955 & Harvie et al.,1984 \\
\hline $\mathrm{OH}^{-}$ & -63.435 & Harvie et al., 1984 \\
\hline $\mathrm{H}_{2} \mathrm{O}(1)$ & -95.663 & Harvie et al., 1984 \\
\hline
\end{tabular}

Table V. Pitzer Ion-interaction Parameters used in this Study.

\begin{tabular}{|c|c|c|c|c|c|}
\hline \multirow[t]{2}{*}{ Species } & \multicolumn{5}{|c|}{ Binary Parameters } \\
\hline & $\beta^{(0)}$ & $\beta^{(1)}$ & $\beta^{(2)}$ & $\mathbf{C}^{(\Phi)}$ & Reference \\
\hline $\mathrm{TcO}^{2+}-\mathrm{Cl}^{-}$ & 0.3053 & 1.7090 & 0 & 0.0022 & This work $^{\mathrm{e}}$ \\
\hline $\mathrm{TcO}(\mathrm{OH})^{+}-\mathrm{Cl}^{-}$ & -0.2010 & 0 & 0 & 0 & This work \\
\hline $\mathrm{H}^{+}-\mathrm{TcCl}_{6}^{2-}$ & 0.567 & 0 & 0 & 0 & This work \\
\hline $\mathrm{H}^{+}-\mathrm{Cl}^{-}$ & 0.1775 & 0.2945 & 0 & 0.0008 & Harvie et al., 1984 \\
\hline $\mathrm{Na}^{+}-\mathrm{TcCl}_{6}^{2-}$ & 0.6470 & 0 & 0 & -0.1146 & This work \\
\hline $\mathrm{Na}^{+}-\mathrm{OH}^{-}$ & 0.0864 & 0.2530 & 0 & 0.0044 & Harvie et al., 1984 \\
\hline $\mathrm{Na}^{+}-\mathrm{Cl}^{-}$ & 0.0765 & 0.2664 & 0 & 0.00127 & Harvie et al., 1984 \\
\hline \multicolumn{6}{|c|}{ Common-ion ternary parameters } \\
\hline & $\varphi$ & $\Psi$ & & & Reference \\
\hline $\mathrm{OH}^{-}-\mathrm{Cl}^{-}-\mathrm{Na}^{+}$ & -0.006 & 0 & & & Harvie et al., 1984 \\
\hline $\mathrm{H}^{+}-\mathrm{Na}^{+}$ & 0.036 & 0 & & & Harvie et al., 1984 \\
\hline $\mathrm{OH}^{-}-\mathrm{Cl}^{-}$ & -0.050 & 0 & & & Harvie et al., 1984 \\
\hline $\mathrm{TcO}^{2+}-\mathrm{H}^{+}$ & 0.110 & 0 & & & This work \\
\hline
\end{tabular}

${ }^{\text {a }}$ The reported $\Delta \mathrm{G}_{\mathrm{f}}^{0} / \mathrm{RT}$ values of these species are dependent on the value to $\mathrm{TcCl}_{4}(\mathrm{am})$, see footnote 2 for details, and should be considered only as interim values.

${ }^{b}$ Definitive identification of this compound is lacking, although XRD and EXAFS data suggest the presence of another amorphous compound other than $\mathrm{TcO}_{2} \cdot 1.6 \mathrm{H}_{2} \mathrm{O}(\mathrm{am})$ and which contains chloride. The solubility data are consistent with the formation of this compound.

${ }^{\mathrm{c}}$ The standard deviation is based on solubility data in the presence and absence of $\mathrm{NaCl}$, where clear outlier points were excluded from calculations.

${ }^{\mathrm{d}}$ The data obtained in our study is consistent with average $\Delta \mathrm{G}_{\mathrm{f}}^{0} / \mathrm{RT}$ values reported by Rard et al., (1999) for these species however, our data shows much lower standard deviations, \pm 0.72 , in these numbers.

${ }^{\mathrm{e}}$ Assumed to be identical to the parameters for $\mathrm{Ca}^{2+}-\mathrm{Cl}^{-}$reported by Pitzer (1991). 

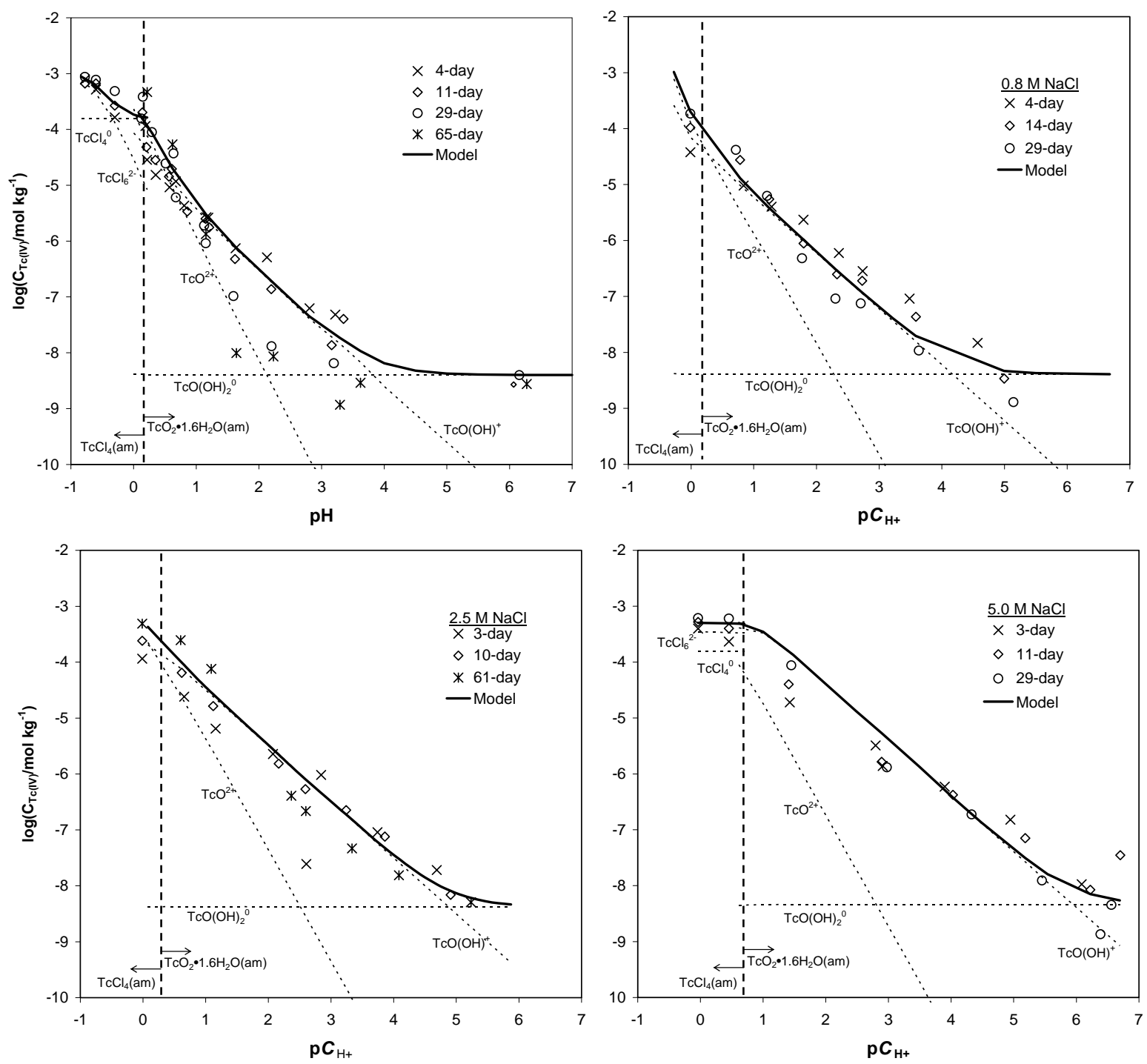

Figure 9. Model predictions of $\mathrm{TcO}_{2} \cdot x \mathrm{H}_{2} \mathrm{O}(\mathrm{am})$ solubility as a function of $\mathrm{pH}$ based on the thermodynamic data developed in this study based on the 10 to 11-day solubility measurements. The contributions of the individual Tc(IV) species to the observed solubility is indicated. Clockwise from upper left, $\mathrm{No} \mathrm{NaCl}$ present, $0.8 \mathrm{M} \mathrm{NaCl}, 2.5 \mathrm{M} \mathrm{NaCl}$, and $5.0 \mathrm{M} \mathrm{NaCl}$. 


\section{Relevance, Impact, and Technology Transfer}

\section{a. How does this new scientific knowledge focus on critical DOE environmental management problems?}

The results of this study are highly relevant to one of DOE's most critical environmental management issues, that is, the fate of $\mathrm{Tc}$ in vadose zone. Our results indicate that $\mathrm{Tc}$ is not attenuated by mineral interactions under most environmental conditions and will migrate freely. However, Tc may be attenuated under unique environmental conditions where it exposed to highly caustic conditions, such as those created by the leakage of HLW tanks. Under these conditions it appears that reduced Tc solid phase is formed that resistant to remobilization. These results may also be applicable the formation of reduced Tc species in HLW tank residuals.

b. How will the new scientific knowledge that is generated by this project improve technologies and cleanup approaches to significantly reduce future costs, schedules, and risks and meet DOE compliance requirements?

These results can help differentiate between contaminated sediments where Tc is likely to be remain relatively immobile and those where Tc is likely to be highly mobile. As a result the remediation strategies that can be employed to stabilize Tc in these sediments will necessarily be different. For example, the results of our study indicate that $\mathrm{Tc}$ introduced to the Hanford Site vadose zone under near neutral conditions, such as the direct discharges of waste to the ground, such as those described by Waite (1991) and Jones (1998), is not be retained to any significant extent by mineral interactions. These contamination events are likely to result in widespread, highly mobile contamination plumes. Contamination created by such events will likely require remediation strategies such as "pump and treat". However, if the Tc contamination occurs with highly basic fluids such as those associated with leakages by HLW, then Tc may be tightly bound to the sediment, as suggested by our stripping experiments, and may be confined in proximity to the source of the leak. These contained contamination events may be cost effectively treated by excavation and treatment of the sediment.

\section{c. To what extent does the new scientific knowledge bridge the gap between broad fundamental research that has wide-ranging applications and the timeliness to meet needs-driven applied technology development?}

Our studies of Tc attenuation in sediment columns and batch experiments were designed to test the hypothesis of heterogeneous reduction of Tc by Fe(II)-containing minerals and our $\mathrm{TcO}_{2} \cdot x \mathrm{H}_{2} \mathrm{O}(\mathrm{am})$ solubility studies were conducted to develop a thermodynamic model of the stability of possible $\mathrm{Tc}$ reduction products under a range of $\mathrm{pH}$ and chloride conditions. These research efforts represent significant contributions to the basic fundamental research in these areas and also contribute to the technology needed to resolve the environmental needs of the DOE complex. For example, our $\mathrm{TcO}_{2} \cdot x \mathrm{H}_{2} \mathrm{O}(\mathrm{am})$ 
solubility studies are the first experimental studies to demonstrate that it possible to maintain rigorous reducing conditions necessary to maintain a high proportion of soluble Tc in the Tc(IV) oxidation state beyond 500 days. We have also determined the molar extinction for reduced Tc species, and determined the ion-interaction parameters necessary for accurate prediction of Tc chemistry under high chloride conditions. These represent substantial contributions to fundamental science.

In addition to the example of application of our results to remediation of Tc contaminated sediment described in (b) above, our $\mathrm{TcO}_{2} \cdot x \mathrm{H}_{2} \mathrm{O}(\mathrm{am})$ solubility studies under very acidic conditions are relevant to unique INEEL tank chemistry. Thermodynamic data for the formation of Tc(IV)-chloride solution complexes and the probable formation of Tc(IV)chloride containing solids will be useful to predicting Tc concentrations of tank liquors for the design of pretreatment and tank closure strategies. These same parameters will be applicable to the evaluation of the proposed European high-level waste repository in geologic salt formations.

Furthermore, we have demonstrated that the hypothesis of heterogeneous reduction of Tc by $\mathrm{Fe}$ (II) containing minerals is viable the mechanism for the immobilization of Tc in the vadose zone. However, our studies have indicated that for heterogeneous reduction to occur under the Hanford Site geochemical conditions, highly alkaline conditions must exist. The alkaline conditions are likely result in the exposure of reactive $\mathrm{Fe}(\mathrm{II})$ sites at the which heterogeneous reduction proceeds. These conclusions are supported by the SEM and micro-XANES analysis of reacted column sediments, which confirm the presence of reduced Tc precipitates on Fe-rich regions of basalt clasts.

d. What is the project's impact on individuals, laboratories, departments and institutions? Will results be used? If so, how will they be used, by whom, and when?

The project will impact researchers departments, and institutions that are involved with either the remediation of Tc contaminated soils or the chemistry of Tc in HLW tanks. Furthermore this research will impact those involved with the prediction of Tc chemistry in tank residuals upon the planned cleanup and closure of portions of the DOE complex. The results will be used to

- $\quad$ Target sediments and design appropriate remediation strategies for Tc contaminated sediments.

- $\quad$ Predict Tc chemistry and pretreatment protocols for Tc in acidic HLW.

- Evaluate the stability of Tc tank residuals upon closure.

e. Are larger scale trials warranted? What difference has the project made? Now that the project is complete, what new capacity, equipment, or expertise has been developed?

At project completion, a greater understanding, expertise, and capabilities have been developed that are needed for the advancement of fundamental Tc chemistry. We have 
developed the experimental capabilities to maintain rigorous reducing conditions necessary to study the aqueous chemistry of reduced Tc species. In addition we have developed the experimental capabilities necessary to apply these fundamental results to relevant technological issues. As example, the SEM and micro-XANES analysis of the 1-D column sediments demonstrates that we have developed the expertise and experimental capability to relate hypothesized mechanisms, e.g. heterogeneous reduction, to observable result, localized Tc(IV) solids in association with Fe-containing minerals.

\section{f. How have the scientific capabilities of collaborating scientists been improved?}

Capabilities have been developed that are needed for the advancement of fundamental Tc chemistry. We have developed the experimental capabilities to maintain rigorous reducing conditions necessary to study the aqueous chemistry of reduced Tc species. We have established sample transfer and containment procedures so that we are able to evaluate the speciation of Tc complexes using X-ray absorption spectroscopy at the DOE sponsored synchrotrons, specifically the Stanford Synchrotron Radiation Laboratory and the Advanced Photon Source. In addition, we have established what chemical conditions necessary for reliable Tc oxidation analysis using solvent extraction techniques at high chloride concentrations. In conjunction with other EMSP research, we have developed the sample preparation techniques necessary so that we can overlay SEM studies and synchrotron based elemental analysis (spatial distribution and oxidation state analysis) the same samples.

\section{g. How has this research advanced our understanding in the area?}

This research has advanced the understanding of Tc chemistry in two areas: development of thermodynamic model of Tc and heterogeneous reduction of Tc under Hanford Site geochemical conditions. Specifically, our solubility studies of $\mathrm{TcO}_{2} \cdot \mathrm{xH}_{2} \mathrm{O}(\mathrm{am})$ conducted as a function of $\mathrm{pH}$ and chloride concentration provided a basis on which a thermodynamic model was developed which included hitherto unavailable chemical potentials of $\mathrm{Tc}(\mathrm{IV})$-chloro species and Pitzer ion-interaction parameters for $\mathrm{Tc}(\mathrm{IV})$ hydrolyzed species with bulk electrolyte ions used in this study. The thermodynamic model developed is consistent with the extensive solubility data that was measured and with the reliable literature data, and is applicable to a wide range in $\mathrm{H}^{+}$and $\mathrm{Cl}^{-}$ concentrations and ionic strengths. Chloride was found to significantly affect Tc(IV) concentrations through the formation of $\mathrm{Tc}(\mathrm{IV})$ chloro complexes [i.e., $\mathrm{TcCl}_{4}(\mathrm{aq})$ and $\left.\mathrm{TcCl}_{6}{ }^{2-}\right]$ and a stable compound, likely to be $\mathrm{TcCl}_{4}(\mathrm{am})$, in highly acidic and relatively concentrated chloride solutions, and through its interactions with the positively charged hydrolyzed Tc(IV) species in solutions of relatively low acidity and high chloride concentrations.

We have demonstrated that the hypothesis of heterogeneous reduction of Tc by Fe(II) containing minerals is viable the mechanism for the immobilization of Tc in the vadose zone. However, our studies have indicated that for heterogeneous reduction to occur 
under the Hanford Site geochemical conditions, highly alkaline conditions must exist. The alkaline conditions are likely result in the exposure of reactive Fe(II) sites at the which heterogeneous reduction proceeds. These conclusions are supported by the SEM and micro-XANES analysis of reacted column sediments, which confirm the presence of reduced Tc precipitates on Fe-rich regions of basalt clasts. These results can aid in the design of remediation strategies by differentiation between contaminated sediments where Tc is likely to be remain relatively immobile and those where Tc is likely to be highly mobile.

h. What additional scientific or other hurdles must be overcome before the results of this project can be successfully applied to DOE Environmental Management problems?

Ideally we would like to demonstrate that Tc is attenuated in sediments in the vicinity of HLW tank leaks as predicted by our 1-D column studies. This could be accomplished by analyzing Tc contaminated sediments from the Hanford Tank Farms using the overlayed SEM images and micro $X$ ray fluorescence elemental distribution maps, in direct analogy to our study of the 1-D column sediments. These studies are to be conducted under existing EMSP programs.

i. Have any other government agencies or private enterprises expressed an interest in the project?

None at this time.

\section{Product Productivity}

The project successfully accomplished the proposed goals of investigating the possible role of mineral interactions in the attenuation of Tc in the vadose zone.

\section{Personnel Supported}

Bruce Arey, Technician IV Sr

Pacific Northwest National Laboratory

Christopher F. Brown, Scientist

Pacific Northwest National Laboratory

Steven D. Conradson, Staff Scientist

Los Alamos National Laboratory

Nancy J. Hess, Staff Scientist

Pacific Northwest National Laboratory 
Kenneth M. Krupka, Senior Research Scientist II

Pacific Northwest National Laboratory

James P. McKinley, Senior Research Scientist II

Pacific Northwest National Laboratory

Dean Moore, Research Scientist

Pacific Northwest National Laboratory

Dhanpat Rai, Laboratory Fellow

Pacific Northwest National Laboratory

James Szecsody, Senior Research Scientist II

Pacific Northwest National Laboratory

Yuanxian Xia, Senior Research Scientist I

Pacific Northwest National Laboratory

\section{Publications}

Journal Articles:

N.J. Hess, Y. Xia, D.A. Moore, and D. Rai. 2002. "Thermodynamic model for the solubility of $\mathrm{TcO}_{2} \cdot n \mathrm{H}_{2} \mathrm{O}$ in acidic solutions and high $\mathrm{NaCl}$ concentrations." Accepted by Journal of Solution Chemistry.

J.E. Szecsody, J.P. McKinley, and N.J. Hess. 2002. "The effect of hyperalkaline high level waste simulants on the retention of Tc in Hanford Formation sediments." To be submitted to Environmental Science and Technology.

Technical Reports:

None at this time.

Presentations:

N.J. Hess, K. Krupka, J. McKinley, D. Rai, R. Wildung, and S. Conradson, "Technetium Attenuation in the Vadose Zone: Role of Mineral Interactions," EMSP Kickoff Workshop, November 1999, Richland WA.

N.J. Hess, Y. Xia, D. Rai, K. Krupka, J. McKinley, R. Wildung, and S. Conradson, "Technetium Attenuation in the Vadose Zone: Role of Mineral Interactions," National DOE/EMSP Workshop, April 2000, Atlanta GA. 
N.J. Hess, D. Rai, J. McKinley, K. Krupka, R. Wildung, and S. Conradson, "Technetium Attenuation in the Vadose Zone: Role of Mineral Interactions," FY2001 Vadose Zone Principal Investigator Workshop, November 2000, Richland WA.

N.J. Hess, J. Szecsody, J. McKinley, D. Rai, K. Krupka, R. Wildung, and S. Conradson, "Technetium Attenuation in the Vadose Zone: Role of Mineral Interactions," FY2002 Vadose Zone Principal Investigator Workshop, November 2001, Richland WA.

\section{Interactions}

a. Participation/presentations at meetings, workshops, conferences, seminars, etc.

The project investigators have participated and have reported project results at several meetings, workshops and conferences. These include the National DOE/EMSP workshops and the annual Vadose Zone Principal Investigator workshops held in Richland WA.

b. Consultative and advisory functions.

c. Collaborations.

\section{Transitions}

None at this time.

\section{Patents}

None

\section{Future Work}

\section{Literature Cited}

K. Ben Said, M. Fattahi, Cl. Musikas, R. Revel, and J. Ch. Abbé. 2000. "The speciation of Tc(IV) in chloride solutions." Radiochimica Acta 88:567-571.

A.R. Felmy and J.H. Weare. 1986."'The prediction of borate mineral equilibria in natural waters: application to Searles Lake, California." Geochimica Cosmochimica Acta 50:2771-2783.

A.R. Felmy, D. Rai, J.A. Schramke, and J. Ryan. 1989. "The solubility of plutonium hydroxide in dilute solution and in high-ionic strength chloride brines." Radiochimica Acta 48:29-35. 
C.E. Harvie, N. Moller, and J.H. Weare. 1984. "The prediction of mineral solubilities in natural waters: The Na-K-Mg-Ca-H-Cl-SO $\mathrm{SO}_{4}-\mathrm{OH}-\mathrm{HCO}_{3}-\mathrm{CO}_{2}-\mathrm{H}_{2} \mathrm{O}$ system." Geochimica Cosmochimica Acta 48:723-751.

E. Ianovici, M. Kosinski, P. Lerch, and A.G. Maddock. 1981. "The aquation of hexachlorotechnetate(IV)." Journal of Radioanalytical Chemistry 64:315-326.

T. E. Jones, R. Khaleel, D. A. Myers, J. W. Shade, M. I. Wood, 1998. "A summary and evaluation of Hanford Site tank farm subsurface contamination," HNF-2603, Lockheed Martin Hanford, Richland, WA.

Y. Kanchiku. 1969. "Separation and identification of chlorocomplexes of Technetium(IV) formed in hyrdrochloric acid solutions." Bulletin of the Chemical Society of Japan 42:2831-2835.

Kaplan, DI, KE Parker, and RD Orr. 1998. "Effects of High-pH and High-Ionic-Strength Groundwater on Iodide, Pertechnetate, and Selenate Sorption to Hanford Sediments: Final Report for Subtask 3a." PNNL-11964, Pacific Northwest National Laboratory, Richland, WA.

R.E. Meyer, W.D. Arnold, and F.I. Case. 1986. "Valence effects on solubility and sorption. The solubility of Tc(IV) oxides." Oak Ridge National Laboratories Technical Report ORNL-6503, Oak Ridge, TN.

R. E. Meyer, W. D. Arnold, F. I. Case, and G. D. O’Kelley. 1991. "Solubilities of Tc(IV) oxides." Radiochimica Acta 55:11-18.

K.S. Pitzer. 1991. "Ion Interaction Approach: Theory and Data Correlation Activity," in Coefficients in Electrolyte Solutions, $2^{\text {nd }}$ edn. K.S. Pitzer, ed. CRC Press, Boca Raton FL.

K.S. Pitzer and G. Mayorga. 1973. "Thermodynamics of electrolytes. II. Activity and osmotic coefficients for strong electrolytes with one or both ions univalent." Journal of Physical Chemistry 77:2300-2307.

J.A. Rard, M.H. Rand, G. Anderegg, and H. Wanner.1999. In Chemical Thermodynamics of Technetium; M.C.A. Sandino and E. Östhols, Eds.; Chemical Thermodynamics 3, Elsevier, New York, NY 544p.

M. J. Rudin, C. Stanton, R. G. Patterson, and R. S. Garcia. 1992. "National Low-Level Waste Management Program Radionuclide Report Series." Vol. 2, Technetium-99, DOE/LLW-118, Idaho National Engineering Laboratory, Idaho Falls, ID.

E.H. Schulte and P. Scoppa. 1987. "Sources and behavior of technetium in the environment." The Science of the Total Environment 64:163-179. 
S.M. Sterner, A.R. Felmy, J.R. Rustad, and K.S. Pitzer. 1997. Battelle Technical Report PNWD-SA-4436., Richland, WA.

T.T. Vandergraaf, K.V. Ticknor, and I.M. George. 1984. "Reactions between Technetium in Solution and Iron-Containing Minerals under Oxic and Anoxic Conditions." In Geochemical Behavior of Disposed Radioactive Waste, G. S. Barney, J. D. Navratil, and W. W. Schulz (eds.), 25-43, ACS Symposium Series 246, American Chemical Society, Washington, D.C.

J.L. Waite. 1991. "Tank wastes discharged directly to the soil at the Hanford Site." WHC-MR-0227, Westinghouse Hanford Company, Richland, WA.

F.B. Walton, J. Paquette, J.P.M. Ross, and W.E. Lawrence. 1986. "Tc(IV) and Tc(VII) Interactions with Iron Oxyhydroxides." Nuclear and Chemical Waste Management, 6:121-126.

\section{Feedback}

\section{Appendix}

The manuscript accepted for publication in Journal of Solution Chemistry entitled, " $A$ Thermodynamic Model for the Solubility of $\mathrm{TcO}_{2} \cdot \mathrm{xH}_{2} \mathrm{O}(\mathrm{am})$ in the Aqueous $\mathrm{Tc}(\mathrm{IV})-\mathrm{Na}^{+}$ - $\mathrm{Cl}^{-}-\mathrm{H}^{+}-\mathrm{OH}^{-}-\mathrm{H}_{2} \mathrm{O}$ System." 
A Thermodynamic Model for the Solubility of $\mathrm{TcO}_{2} \cdot x \mathrm{H}_{2} \mathrm{O}(\mathrm{am})$ in the Aqueous $\mathrm{Tc}(\mathrm{IV})-\mathrm{Na}^{+}-\mathrm{Cl}^{-}-\mathrm{H}^{+}-\mathrm{OH}^{-}-\mathrm{H}_{2} \mathrm{O}$ System

Nancy J. Hess

Yuanxian Xia

Dhanpat Rai

Steven D. Conradson*

January 2004

Prepared for Journal of Solution Chemistry

Environmental Simulations and Dynamics

Pacific Northwest National Laboratory

Richland WA 99352

* Materials Science and Technology Division

Los Alamos National Laboratory

Los Alamos NM 87545 
A Thermodynamic Model for the Solubility of $\mathrm{TcO}_{2} \cdot x \mathrm{H}_{2} \mathrm{O}(\mathrm{am})$ in the Aqueous $\mathrm{Tc}(\mathrm{IV})-\mathrm{Na}^{+}-\mathrm{Cl}^{-}$ - $\mathrm{H}^{+}-\mathrm{OH}^{-}-\mathrm{H}_{2} \mathrm{O}$ System

Nancy J. Hess ${ }^{1}$, Yuanxian Xia ${ }^{1}$, Dhanpat Rai ${ }^{1}$, and Steven D. Conradson ${ }^{2}$

1. Environmental Dynamics and Simulations, Pacific Northwest National Laboratory, Richland WA 99352

2. Material Science and Technology Division, Los Alamos National Laboratory, Los Alamos NM 87545

\begin{abstract}
Solubility studies of $\mathrm{TcO}_{2} \cdot x \mathrm{H}_{2} \mathrm{O}(\mathrm{am})$ have been conducted as a function of $\mathrm{H}^{+}$concentration from $1 \times 10^{-5}$ to $6 \mathrm{M} \mathrm{HCl}$ and as function of chloride concentration from $1 \times 10^{-3}$ to $5 \mathrm{M} \mathrm{NaCl}$. These experiments were conducted under carefully controlled reducing conditions such that the preponderance of Tc is present in solution is in the reduced oxidation state and was determined to be Tc(IV) by XANES analysis. The aqueous species and solid phases were characterized using a combination of techniques including thermodynamic analyses of solubility data, XRD, and XANES, EXAFS, and UV-Vis spectroscopies. Chloride was found to significantly affect Tc(IV) concentrations through 1) the formation of $\mathrm{Tc}(\mathrm{IV})$ chloro complexes [i.e., $\mathrm{TcCl}_{4}(\mathrm{aq})$ and $\mathrm{TcCl}_{6}{ }^{2-}$ ] and a stable compound [data suggests this compound to be $\mathrm{TcCl}_{4}(\mathrm{am})$ ] in highly acidic and relatively concentrated chloride solutions, and 2) its interactions with the positively charged hydrolyzed Tc(IV) species in solutions of relatively low acidity and high chloride concentrations. A thermodynamic model was developed, which included hitherto unavailable chemical potentials of Tc(IV)-chloro species and Pitzer ion-interaction parameters for Tc(IV) hydrolyzed species with bulk electrolyte ions used in this study. The thermodynamic model presented in this paper is consistent with the extensive data reported in this study and with the reliable literature data, and is applicable to a wide range in $\mathrm{H}^{+}$and $\mathrm{Cl}^{-}$concentrations and ionic strengths.
\end{abstract}

Keywords: Solubility, $\mathrm{TcO}_{2} \cdot x \mathrm{H}_{2} \mathrm{O}(\mathrm{am})$, Thermodynamic model, Chloride, XAS, UV-Vis. 


\section{Introduction}

Technetium-99 is a manmade radionuclide produced by the fission of U-235 and Pu-239 and has been introduced to the environment as a byproduct of the nuclear fuel cycle (predominately from the processing of spent fuel), discharges of low-level radioactive waste, and nuclear weapons testing. ${ }^{(1)}$ Globally, approximately 100 to $140 \times 10^{12} \mathrm{~Bq}$ of ${ }^{99} \mathrm{Tc}$ has been released through nuclear weapons testing, ca. $1 \times 10^{15} \mathrm{~Bq}$ of ${ }^{99} \mathrm{Tc}$ has been released by reprocessing spent fuel, and ca. $15 \times 10^{15} \mathrm{~Bq}$ of ${ }^{99} \mathrm{Tc}$ is present in nuclear wastes waiting for disposal. ${ }^{(1)}$ Because of its long half-life, $2.1 \times 10^{5} \mathrm{y}$, and environmental mobility, Tc is one of the most important radionuclides in calculating long-term, high-value risks. Thus knowledge of the chemical behavior of Tc in the environment is critical to the design and licensing of nuclear waste repositories. The fate of Tc in the environment depends on its oxidation state. While technetium can exist in multiple oxidation states in nature (III, IV, V, and VII), the most stable oxidation states under environmental conditions are VII and IV. The chemical behavior of Tc in these two oxidation states differs drastically. In the VII oxidation state, Tc forms highly soluble solids. In aqueous solution, Tc exists as pertechnetate, $\mathrm{TcO}_{4}{ }^{-}$, which is not strongly sorbed, and thus, is highly mobile. Indeed, studies have shown that under oxidizing conditions Tc(VII) will migrate at nearly $90 \%$ of groundwater velocity. ${ }^{(2)}$ In contrast, in the IV oxidation state, Tc forms the sparingly soluble hydrous dioxide, $\mathrm{TcO}_{2} \cdot x \mathrm{H}_{2} \mathrm{O}(\mathrm{am})$, and is relatively immobile in the absence of strongly complexing ligands. Fundamental data for environmentally important reactions of $\mathrm{Tc}(\mathrm{IV})$ and $\mathrm{Tc}(\mathrm{VII})$ are required to reliably predict the environmental behavior of Tc. This study is focused on the development of thermodynamic data for Tc(IV) reactions under acidic conditions and at high chloride concentration.

Rard et al. ${ }^{(3)}$ reviewed the thermodynamic data available prior to 1998 and have shown that $\mathrm{Tc}(\mathrm{IV})$ readily forms sparingly soluble hydrous oxide and a number of solution complexes in the hydroxide system. According to this review the most reliable published solubility studies of Tc(IV) hydrous oxide under acidic conditions were those performed by Meyer et al. ${ }^{(4,5)}$ Earlier studies reported higher and inconsistent solubilities but likely suffered from oxidation of Tc(IV) to Tc(VII), ${ }^{(6)}$ lack of Tc oxidation state determination, ${ }^{(7)}$ or the lack of adequate characterization of the solid phase. ${ }^{(8)}$ In Meyer's et al. ${ }^{(5)}$ study, a strong increase in $\mathrm{TcO}_{2} \cdot x \mathrm{H}_{2} \mathrm{O}($ am) solubility, indicated by four experimental points at $\mathrm{pH}$ values less than 3 , was observed and can be explained by the hydrolysis reactions first proposed by Gorski and Koch. ${ }^{(8)}$ However, the interpretation of the solubility data at very low $\mathrm{pH}, \mathrm{pH}$ values less than 1 , is more complicated because the presence of high concentrations of chloride was not accounted for in these experiments and chloride is known to form strong complexes with Tc(IV). ${ }^{(3,9)}$ In addition, Meyer et al. ${ }^{(5)}$ observed Tc(VII) concentrations 10 to 100 times in excess of Tc(IV) in the equilibrated aqueous phase across the $\mathrm{pH}$ range. The presence of such large concentrations of $\mathrm{Tc}(\mathrm{VII})$ indicates unsuccessful control of reducing conditions to result in predominately reduced Tc species in solution. Recently, the speciation of Tc(IV) in 1 to $6 \mathrm{M} \mathrm{HCl}$ solutions has been investigated using UV-Vis, Raman, and XAS spectroscopic probes and electrochemistry. ${ }^{(9)}$ They conclude that Tc-aquochloro complexes are present in 1 to $6 \mathrm{M} \mathrm{HCl}$ solutions but they did not determine thermodynamic properties for these species. Clearly, a more complete understanding of the Tc(IV) behavior in acidic and chloride systems is needed.

The objectives of this study are to develop a reliable thermodynamic model of Tc(IV) solubility applicable to highly acidic to near neutral conditions and to geologic environments containing significant concentrations of chloride, such as salt repositories. To meet these objectives we have conducted extensive solubility studies of $\mathrm{TcO}_{2} \cdot x \mathrm{H}_{2} \mathrm{O}(\mathrm{am})$ over a large range of $\mathrm{H}^{+}\left(6 \mathrm{M}^{-1} 10^{-5} \mathrm{M}\right.$ $\mathrm{HCl})$ and chloride concentrations $\left(10^{-3} \mathrm{M}\right.$ to $\left.5 \mathrm{M} \mathrm{NaCl}\right)$ from both over- and under-saturation directions. All solubility experiments were conducted under carefully controlled redox conditions such that greater than $80 \%$ of the Tc in solution is in the reduced $\mathrm{Tc}(\mathrm{IV})$ oxidation 
state for the majority of measurements. A combination of techniques involving solubility, XAS, spectroscopic measurements and XRD were used to identify the aqueous and solid phases. The thermodynamic model we have developed provides close agreement with extensive data obtained in this study and is consistent with the most reliable literature data.

\section{Methods and Materials}

All experiments and sample preparations were conducted in an atmosphere-controlled chamber under an $\mathrm{Ar}$ atmosphere. Deionized distilled water, degassed by boiling and cooling in the Ar atmosphere, was used in all cases. Steady state Tc concentrations in most solubility experiments were approached from the undersaturation direction. To verify that equilibrium solubility conditions were attained, solubility in three limited sets of experiments were approached from the oversaturation direction.

A $0.29 \mathrm{M}$ stock solution of $\mathrm{NH}_{4} \mathrm{TcO}_{4}$ was prepared, following purification, from irradiated $\mathrm{MoO}_{3}$ obtained from Oak Ridge National Laboratory. The purity of ammonium pertechnetate was checked spectrophotometrically, and its content was established by comparative measurement of the $\beta$-activity of actual and standard ${ }^{99} \mathrm{Tc}$ solutions. For undersaturation experiments, $\mathrm{TcO}_{2} \cdot x \mathrm{H}_{2} \mathrm{O}(\mathrm{am})$ precipitate was prepared individually for each sample starting from the stock solution and under basic conditions. Specifically, a small amount $(0.18 \mathrm{~mL})$ of the Tc stock solution was added to a $25-\mathrm{mL}$ glass centrifuge tube that contains $4.12 \mathrm{~mL}$ water and $0.195 \mathrm{M}$ freshly prepared $\mathrm{Na}_{2} \mathrm{~S}_{2} \mathrm{O}_{4}$ solution and the $\mathrm{pH}$ of this solution was adjusted to about 12 using $\mathrm{NaOH}$. A black precipitate formed quickly and was allowed to mature in the mother liquid for $72 \mathrm{hrs}$. The precipitate was then washed three times using $20 \mathrm{~mL}$ of freshly prepared 0.01 $\mathrm{M} \mathrm{Na}_{2} \mathrm{~S}_{2} \mathrm{O}_{4}$ in near neutral aqueous solution. The precipitate was equilibrated with $20 \mathrm{~mL}$ of $\mathrm{pH}$ adjusted solution for at least 3-days prior to initial sampling.

Several sets of experiments were conducted using the washed precipitates. These sets included 1) the low $\mathrm{pH}$ region ( $\mathrm{pH}$ values from 0 to 5) in the absence of $\mathrm{NaCl}, 2$ ) low $\mathrm{pH}$ region containing $0.8,2.5$, or $5.0 \mathrm{~m}$ $\mathrm{NaCl}$, and at high $\mathrm{HCl}$ concentrations $(6 \mathrm{M}$ to $0.06 \mathrm{M} \mathrm{HCl})$. A $20 \mathrm{~mL}$ volume of the appropriate solution containing $0.02 \mathrm{M}$ hydrazine or, for one experimental set $0.015 \mathrm{M} \mathrm{EuCl}_{2}$, used to maintain reducing conditions, were added to the washed precipitates. The $\mathrm{pH}$ values of the samples were readjusted using $\mathrm{NaOH}$ or $\mathrm{HCl}$. The tubes were tightly capped and placed on a shaker in an Argon atmospheric chamber.

After 3 days, the $\mathrm{pH}$ was measured using a Orion-Ross combination glass electrode calibrated against $\mathrm{pH}$ buffers. The $\mathrm{pH}$ meter readings for high chloride samples were converted to hydrogen ion concentrations using a modified Gran titration procedure. In the Gran titration method, the observed/measured $\mathrm{pH}$ $[\mathrm{pH}(\mathrm{obs})]$ is related to the concentration of hydrogen ions by the equation $\left(\mathrm{p} C_{\mathrm{H}^{+}}=\mathrm{pH}(\mathrm{obs})+\mathrm{A}\right)$, where $\mathrm{p} C_{\mathrm{H}^{+}}$is the negative logarithm of hydrogen ion concentration in molarity units and $\mathrm{A}$ is a constant. The values of $\mathrm{A}$ for $0.8,2.5$, and $5.0 \mathrm{M} \mathrm{NaCl}$ solutions were determined to be $0.24,0.5$, and 1.0 , respectively, using the procedure described by Rai et al. ${ }^{(10)}$

The oversaturation experiments required the preparation of concentrated Tc(IV) stock solutions. Two stock solutions were generated by solubilizing $\mathrm{TcO}_{2} \cdot \mathrm{xH}_{2} \mathrm{O}(\mathrm{am})$ precipitate, prepared following the procedure outlined above, in $10 \mathrm{~mL}$ of deionized, distilled, and degassed water containing $0.02 \mathrm{M}$ hydrazine and adjusted to $\mathrm{pH}=0.44$ or 0.79 . After equilibration for ca. 11 days the concentration was measured to be 5.6 $\mathrm{x} 10^{-5}$ and $8.3 \times 10^{-6} \mathrm{M}$ Tc for the $\mathrm{pH} 0.44$ and 0.79 solutions, respectively. The oxidation state was determined to be greater than $95 \% \mathrm{Tc}(\mathrm{IV})$ by solvent extraction techniques. Each of the equilibrated stock solutions and associated precipitate was divided into four tubes. The $\mathrm{pH}$ of the tubes was then increased by adding $\mathrm{NaOH}$ to span the $\mathrm{pH}$ range from ca. 2.1 to 4.2.

For both under and oversaturation experiments, $1.5 \mathrm{~mL}$ of the solution was withdrawn for analyses after different equilibration periods ( 3 to 4 days, 10 to 15 days, 30 days, and 60 days). The sampling procedure 
involved centrifuging the aliquot at $2000 \mathrm{rpm}$ for 10 minutes followed by filtering through a Centricon-30 filter (Amicon, Inc.) with an approximate 0.0036 micron pore size. The total Tc concentration in solution was determined by beta-scintillation counting using $0.5 \mathrm{~mL}$ subsample of the filtrate and $10 \mathrm{~mL}$ of scintillation cocktail. The detection limit for this technique is approximately $10^{-8} \mathrm{M} \mathrm{Tc}$. The concentration of $\mathrm{Tc}(\mathrm{VII})$ and reduced $\mathrm{Tc}$ in the sample were determined using the solvent extraction technique where tetraphenylphosphoniumchloride (TPPC) in chloroform extracts pertechnetate, $\mathrm{Tc}(\mathrm{VII})$, into the organic phase leaving reduced $\mathrm{Tc}$ in the aqueous phase. For this oxidation state analysis, the $\mathrm{pH}$ of a second 0.5 $\mathrm{mL}$ subsample of the filtrate was adjusted to $1 \mathrm{M} \mathrm{HCl}$ using $6 \mathrm{M} \mathrm{HCl}$ or $5 \mathrm{M} \mathrm{NaOH}$ and diluted to $1.0 \mathrm{~mL}$ with water. The diluted and $\mathrm{pH}$ adjusted filtrate was shaken vigorously with $1 \mathrm{~mL}$ of the TPPC and chloroform solvent mixture for 5 minutes. After centrifugation, the Tc concentration in the organic and aqueous fractions was subsequently determined by beta-scintillation counting. The concentrations of chloride and sodium in the equilibrated samples were calculated from the input molalities.

A limited number of solid samples were selected for powder X-ray diffraction (XRD) measurements on a Scintag PAD V X-ray diffractometer using $\mathrm{Cu} \mathrm{K \alpha}$ radiation at $45 \mathrm{KV}$ and $40 \mathrm{ma}$. Approximately $0.5 \mathrm{mg}$ of the solid phase was suspended in a solution of collodian in amyl acetate which was then deposited onto a glass slide using a disposable pipet and the solvent evaporated. Diffraction data were collected from 5 to $65^{\circ} 2 \Theta$ at a rate of $0.04^{\circ} / \mathrm{min}$. The analysis program Jade (from Materials Data, MDI) was used to identify crystalline phases.

Spectrophotometric measurements (Cary 500) were made in the UV to visible region from 200 to $450 \mathrm{~nm}$ to observe the change in $\mathrm{Tc}(\mathrm{IV})$ solution speciation from predominately chloride complexation to a coordination complex dominated by water molecules or hydroxyl groups as a function of $\mathrm{pH}$ and to verify Tc oxidation state. Approximately twenty samples that had been equilibrated for more than 500 days were selected. The oxidation state and Tc concentration were determined using solvent extraction and betascintillation counting techniques on an aliquot of the centrifuged, filtered samples prior to UV-Vis measurement. For the spectrophotometric measurements approximately $3 \mathrm{~mL}$ of filtered solution was transferred into a one-centimeter pathlength quartz cuvette and sealed under argon atmosphere to prevent oxidation. The sealed cuvette was then transferred to the spectrophotometer where spectra were collected. Spectra were collected in double beam mode at a scan rate of $300 \mathrm{~nm} /$ minute and $0.5 \mathrm{~nm}$ increments. The molar extinction coefficients for the $\mathrm{TcCl}_{6}^{2-}, \mathrm{TcCl}_{5}^{-}$, and $\mathrm{TcCl}_{4}(\mathrm{aq})$ species are reported in the literature. ${ }^{(11,12)}$ However, the molar extinction coefficient for the $\mathrm{TcO}^{2+}$ and $\mathrm{TcO}(\mathrm{OH})^{+}$species are unknown. Therefore, absorption spectra of $\mathrm{TcO}^{2+}$ and $\mathrm{TcO}(\mathrm{OH})^{+}$were measured as a function of concentration at constant $\mathrm{pH}$ to determine the molar extinction coefficients.

Nine equilibrated solid samples and solution samples were analyzed using X-ray absorption spectroscopy (XAS) at the Stanford Synchrotron Radiation Laboratory (SSRL) (beamline 4-2) to verify the Tc oxidation state and to characterize the equilibrated solution and solid phases. In general the concentration of Tc in solution must exceed $1 \times 10^{-4} \mathrm{M}$ for acquisition of data with acceptable signal-to-noise ratio for EXAFS analysis. Tc K-edge transmission and fluorescence data were measured simultaneously. All spectra were measured to photoelectron wavevector value of $13.0 \AA^{-1}$. Energy calibration was based on the assignment of the first inflection point in the absorption edge of the SSRL Tc standard to $21035 \mathrm{eV}$.

The EXAFS oscillations were extracted by fitting a polynomial spline function through the post-edge region and normalizing the difference between this approximation of the solitary-atom EXAFS and the actual data with the absorption decrease calculated using the McMaster tables. ${ }^{(13)}$ The resulting EXAFS oscillations are defined $\chi(k)=\left[\mu(k)-\mu_{0, \text { spline }}(k)\right] /\left[\Delta \mu_{\mathrm{k}=0} \mu_{0, \mathrm{M}}(k)\right]$, where $\mu(k)$ is the observed absorption coefficient, $\mu_{0, \text { spline }}(k)$ is the fitted spline, $\Delta \mu_{\mathrm{k}=0}$ is the observed absorption difference between the fitted spline and the extrapolation of the pre-edge polynomial at $k=0$, and $\mu_{0, \mathrm{M}}(k)$ is the calculated atomic absorption using the McMaster tables. ${ }^{(13)}$ Fourier transforms were taken over photoelectron wavevector 
range from 1.6 to $13.1 \AA^{-1}$. EXAFS nodes were selected as endpoints to the Fourier transform range and a sine window function was used to dampen the EXAFS oscillations at the endpoints.

The phase and amplitude for the Tc-O, Tc-Cl, and Tc-Tc interatomic scattering paths were calculated using the $a b$ initio code FEFF7.02 ${ }^{(14,15)}$ and the crystallographic data for $\mathrm{ReO}_{2}{ }^{(16)}, \mathrm{Tc}_{2} \mathrm{O}_{7}{ }^{(17)}$ and $\mathrm{ReOCl}_{4} \cdot \mathrm{H}_{2} \mathrm{O}{ }^{(18)}$ Parameterized versions of the calculated paths were then used to fit the experimental EXAFS. The number of atoms and the bond distances were determined using the normalized backscattering amplitude and phase functions from FEFF to fit the experimental EXAFS data using Equation 1, which is summed over all backscatters, $i$ :

$$
\chi(k)=\sum_{i} \frac{N_{i} S_{i} F_{i}(k)}{k R_{i}^{2}} \exp \left(-2 k^{2} \sigma_{i}^{2}\right) \exp \left(\frac{-2 R_{i}}{\lambda}\right) \sin \left(2 k R_{i}+\phi_{i}(k)\right)
$$

$N_{i}$ is the number of backscattering atoms at a distance $R_{i}$ from the absorber. Values of the scale factor $S_{i}$ are determined empirically by fitting standards with calculated scattering amplitudes. Values of $S_{i}$ were determined to be $0.68,0.9$ and 0.8 for Tc-O, Tc-Cl and Tc-Tc scattering paths, respectively. The quantities $F_{i}(k) \exp \left(-2 R_{i} / \lambda\right)$ and $\varphi_{i}$ are the backscattering amplitude and phase functions, respectively, that are calculated by FEFF7.02 for each path. $\sigma_{i}^{2}$, is the Debye-Waller factor, and represents the root mean squared variation in the absorber-backscatterer interatomic distance.

\section{Thermodynamic Model}

The ion-interaction model of Pitzer and co-workers ${ }^{(19,20)}$ was used to interpret the solubility data. This aqueous thermodynamic model emphasizes a detailed description of the specific ion interactions in the solution. The effects of specific ion interactions on the excess solution free energy are contained in the expressions for the activity coefficients. The activity coefficients can be expressed in a virial-type expansion as

$$
\ln \gamma_{\mathrm{i}}=\ln \gamma_{\mathrm{i}}^{\mathrm{DH}}+\sum_{\mathrm{j}} \beta_{\mathrm{ij}}(\mathrm{I}) \mathrm{m}_{\mathrm{j}}+\sum_{\mathrm{j}} \sum_{\mathrm{k}} \mathrm{C}_{\mathrm{ijk}} \mathrm{m}_{\mathrm{j}} \mathrm{m}_{\mathrm{k}}+\ldots
$$

where $\mathrm{m}$ is the molality, $\gamma_{\mathrm{i}}^{\mathrm{DH}}$ is a modified Debye-Hückel activity coefficient that is a universal function of ionic strength, and $\beta_{\mathrm{ijj}}(\mathrm{I})$ and $\mathrm{C}_{\mathrm{ijk}}$ are specific for each ion interaction and are functions of ionic strength. The third virial coefficient, $\mathrm{C}$, is understood to be independent of ionic strength. A detailed description of the exact form of Eq. (2) is published in Felmy and Weare ${ }^{(21)}$ and Felmy et al., ${ }^{(22)}$ and is contained in the nonlinear least-squares program INSIGHT ${ }^{(23)}$ for estimating activity coefficients and calculating chemical equilibria involving multiple solid and aqueous species. To interpret the experimental data with INSIGHT, all concentrations were converted to molality units.

\section{Results and Discussion}

In general, the $\mathrm{TcO}_{2} \cdot x \mathrm{H}_{2} \mathrm{O}(\mathrm{am})$ solubility in the low $\mathrm{pH}$ region decreases by about an order of magnitude with each unit increase in $\mathrm{pH} / \mathrm{p} C_{\mathrm{H}^{+}}$. At relatively high $\mathrm{pH} / \mathrm{p} C_{\mathrm{H}^{+}}$values (e.g., at $\left.\mathrm{pH} 4\right)$, the solubility appears to be independent of $\mathrm{pH} / \mathrm{p} C_{\mathrm{H}+}$. In the absence of $\mathrm{NaCl}$, the solubility of $\mathrm{TcO}_{2} \cdot x \mathrm{H}_{2} \mathrm{O}(\mathrm{am})$ as a function of $\mathrm{pH} / \mathrm{p} C_{\mathrm{H}^{+}}$is in good agreement with the results of Meyer et al. ${ }^{(4,5)}$ as shown in Figure 1, particularly under very acidic conditions. Above $\mathrm{pH}=2$, the measured solubilities are approximately an order of magnitude greater than those measured by Meyer et al. ${ }^{(4,5)}$ In the presence of fixed $\mathrm{NaCl}$ concentrations the solubility of $\mathrm{TcO}_{2} \cdot x \mathrm{H}_{2} \mathrm{O}(\mathrm{am})$ shows a similar dependence on $\mathrm{pH} / \mathrm{p} C_{\mathrm{H}+}$. A comparison of the Tc concentrations from the $\mathrm{TcO}_{2} \cdot x \mathrm{H}_{2} \mathrm{O}(\mathrm{am})$ solubility after 11 days in $0.8 \mathrm{M}, 2.5 \mathrm{M}$, and $5.0 \mathrm{M} \mathrm{NaCl}$ solutions as a function of $\mathrm{pC}_{\mathrm{H}^{+}}$and their comparison to the Tc concentrations in the absence of $\mathrm{NaCl}$ shows a finite increase in concentrations with the increase in $\mathrm{NaCl}$ concentrations (Figure 2). This increase in 
concentration with the increase in $\mathrm{NaCl}$ concentrations indicates that the interaction of electrolyte media with the Tc species is significant and cannot be ignored in the interpretation of data.

The measured Tc concentrations for solubility experiments conducted from the oversaturation direction are compared to the $0.8 \mathrm{M} \mathrm{NaCl}$ data set, which has comparable chloride concentrations (Figure 3). Subtle differences are observed in the number of days required to reach steady state concentration depending on the $\mathrm{pH}$ of the initial solution. This may correspond to the differences in the initial Tc solution species present. As will be shown below, the Tc solution species in the $0.4 \mathrm{pH}$ initial solution is most likely to be $\mathrm{TcO}^{2+}$, whereas the Tc solution species in the $0.8 \mathrm{pH}$ initial solution is likely to be $\mathrm{TcO}(\mathrm{OH})^{+}$. It appears that the $\mathrm{TcO}(\mathrm{OH})^{+}$is able to reach steady state concentrations more rapidly. This may result from the fact that increasing the $\mathrm{pH}$ of the 0.8 $\mathrm{pH}$ initial solution requires no change in the solution species in equilibrium with the $\mathrm{TcO}_{2} \cdot x \mathrm{H}_{2} \mathrm{O}(\mathrm{am})$ precipitate. In summary, although there is some scatter in the data, the steady state Tc concentrations in both under- and oversaturation sets appeared to have been reached in about 12 days.

Oxidation state analyses using solvent extraction technique indicate that under most solution conditions the percentage of reduced Tc species in solution exceeded $80 \%$ of the total measured Tc even after 500 days of equilibration. Lower percentages occur where the measured Tc concentration approaches the detection limit of the ICP-MS technique, approximately $10^{-8} \mathrm{M} \mathrm{Tc}$, where it is difficult to reliably determine Tc concentrations in solution. The high percentage of reduced Tc in solution is supported by the XANES analysis, which further indicates Tc is present in the Tc(IV) oxidation state, and the spectrophotometric measurements. The higher percentage of reduced Tc species in solution represents a significant improvement over earlier studies ${ }^{(4,5)}$ where the reduced Tc:Tc(VII) concentration ratio was estimated to be ca. 1:10 to 1:100. The measured $\mathrm{pH}$, the measured $\mathrm{Tc}(\mathrm{IV})$ concentration based on solvent extraction analyses, and the percentage of $\mathrm{Tc}(\mathrm{IV})$ of the total measured Tc in solution for all data sets are reported in Tables A-F of the Appendix.

Representative x-ray diffractograms of the solids equilibrated for 350 or 390 days are shown in Figure 4. At $\mathrm{pH}$ values greater than 0.2 and at low chloride concentrations, the amorphous nature of the Tc-solids is evident from the broad diffuse band at $20^{\circ} 2 \Theta$ and the lack of peaks for crystalline Tc-compounds. The only observed sharp diffraction peaks are attributed to talc $(\mathrm{T})$, most likely contamination from the glove liners, and to halite $(\mathrm{H})$ in samples with high chloride content. The similarity of the diffractograms of solids equilibrated at $\mathrm{pH}$ value of 0.2 to the solid equilibrated at $\mathrm{pH} 3.2$ indicates that the Tc solids are expected to be amorphous in this $\mathrm{pH}$ range, a range that encompasses most of the experimental data. At $\mathrm{pH}$ values less than 0.2 or at $\mathrm{pH}=0.5$ and high $\mathrm{NaCl}$ concentrations, broad diffraction peaks below $20^{\circ} 2 \Theta$ are apparent indicating the presence of a second amorphous phase (Figure 4b). This result is significant because it indicates that there is a change in the solid phase controlling the solubility of $\mathrm{Tc}$ in high $\mathrm{HCl}$ concentration solutions. Although x-ray diffraction analyses of solids equilibrated for periods shorter than 350 days were not performed, since the solids are amorphous at 350-390 day equilibration periods one can expect that at shorter equilibration periods the solids must also be amorphous.

Spectrophotometric spectra of solution samples equilibrated for over 500 days and over a large range of $\mathrm{pH}$ and $\mathrm{Tc}$ concentrations display no evidence of $\mathrm{Tc}(\mathrm{VII})$ species indicating that reducing conditions have been maintained. In addition, four distinctive $\mathrm{Tc}(\mathrm{IV})$ solution species are observed as a function of $\mathrm{pH}$ and chloride concentration. In Figure 5, the spectra are displayed with absorption normalized at $300 \mathrm{~nm}$ so that the features can be compared independently of the Tc concentration. The spectrum of the $\mathrm{TcCl}_{6}{ }^{2-}$ species exhibits two characteristic peaks at 234 and $338 \mathrm{~nm}$ and agrees well with the spectra in the literature. ${ }^{(9)}$ The 
presence of the $\mathrm{TcCl}_{6}{ }^{2-}$ complex is expected due to its reported stability in solutions with under extremely acidic conditions and high chloride concentrations. ${ }^{(3)}$ At lower chloride concentrations and at $\mathrm{pH}$ values less than 0.2 , a species with an absorption maximum at 345 to $355 \mathrm{~nm}$ is observed and has been assigned to the neutral $\mathrm{TcCl}_{4}(\mathrm{aq})$ species based on the spectroscopic and electrophoretic study of Kanchiku. ${ }^{(12)}$ As described below, EXAFS analysis of selected solutions under similar chemical conditions confirms the chloride complexation. At $\mathrm{pH}$ values between 0.5 and 0.8 , spectra with absorbance maximums at $225 \mathrm{~nm}$ and 330 to $345 \mathrm{~nm}$ are observed. We have assigned the $\mathrm{TcO}^{2+}$ to this characteristic spectrum based on generally accepted hydrolysis model of Tc(IV). Due to the correspondence of absorption peaks in the 330 to $350 \mathrm{~nm}$ range, the absorption peak at $225 \mathrm{~nm}$ distinguishes the $\mathrm{TcO}^{2+}$ species from the $\mathrm{TcO}(\mathrm{OH})^{+}$species. At $\mathrm{pH}$ values greater than 1 spectra exhibiting absorbance maximums at 225 and $275 \mathrm{~nm}$ are observed which we have assigned the $\mathrm{TcO}(\mathrm{OH})^{+}$species. Table I lists the UVVis results for all the samples analyzed.

Measurement of the molar extinction coefficients for the $\mathrm{TcO}^{2+}$ and $\mathrm{TcO}(\mathrm{OH})^{+}$species were attempted by sequential dilution of two samples where the $\mathrm{TcO}^{2+}$ and $\mathrm{TcO}(\mathrm{OH})^{+}$were believed to be the only species present. Molar extinction coefficients of the $\mathrm{TcO}^{2+}$ species at 225 and $329 \mathrm{~nm}$ were determined to be 5920 and $4840 \mathrm{~mol}^{-1} \mathrm{~cm}^{-1}$, respectively and are similar in magnitude to the extinction coefficients of other Tc(IV) aqueous species (Table II). Measurement of the extinction coefficient for the $\mathrm{TcO}(\mathrm{OH})^{+}$species was problematical because the observed absorbance values are small, ca. 0.060 to 0.003 , and this species is stable only over a narrow $\mathrm{pH}$ range where the $\mathrm{Tc}$ concentrations are above the detection limit for scintillation counting. As a result, the linear plots of measured absorption as a function of measured Tc(IV) concentration had higher than desired scatter. Initial calculations indicated that the molar extinction coefficient for the $\mathrm{TcO}(\mathrm{OH})^{+}$was in excess of $100000 \mathrm{~mol}^{-1} \mathrm{~cm}^{-1}$, which is an unrealistically high value for a simple hydroxide species. We conclude that the combined uncertainty in the absorbance measurement, the total Tc concentration, and the oxidation state distribution made accurate determination of the $\mathrm{TcO}(\mathrm{OH})^{+}$ molar extinction coefficient impossible.

The XANES profiles of the solution and solid samples are compared to the pertechnetate stock solution in Figure 6. The shape and energy position of the inflection point of the XANES profile of the stock solution differs from the profiles of the equilibrated solid and solution samples. These differences clearly indicate that the equilibrated samples are in a reduced oxidation state and that we were successful in maintaining reducing conditions during our experiments. In addition, the difference in the energy position of the inflection point is consistent with $\mathrm{Tc}(\mathrm{IV})$ species. $^{(24,25)}$ The determination of the Tc(IV) oxidation state is a significant finding since the solvent extraction technique can only separate Tc(VII) species from the reduced Tc species and does not identify which reduced oxidation states are present.

Fourier transforms of the EXAFS of three equilibrated solutions in Figure 7a show a single distinct peak. Fits to the corresponding phase and amplitude of this peak in the EXAFS spectrum unambiguously identifies the contribution as backscattering from chlorine atoms. This result indicates that the dominant Tc(IV) solution species is complexed by chloride at the Tc concentrations high enough for EXAFS analysis, ca. 1 x $10^{-4} \mathrm{M} \mathrm{Tc}$. The ability to distinguish between $\mathrm{TcCl}_{6}{ }^{2-}, \mathrm{TcCl}_{5}^{-}$, and $\mathrm{TcCl}_{4}(\mathrm{aq})$ requires determination of the number of chlorine atoms coordinating Tc and, ideally, any $\mathrm{Tc}-\mathrm{OH}_{2}$ interactions. The fits to the EXAFS data (Table III) distinguish two Tc-chloride species, one with four chlorine atoms coordinating Tc and one with five. To further substantiate the distinction between these two species, efforts were made to identify $\mathrm{Tc}-\mathrm{OH}_{2}$ contributions which complete the coordination of Tc(IV). There are no crystal structures in which the Tc- $\mathrm{OH}_{2}$ bond distance has been determined by diffraction techniques; however this bond length may be estimated from recent EXAFS investigations ${ }^{(9,25)}$. Ben Said et 
al. ${ }^{(9)}$ included a Tc-OH $\mathrm{OH}_{2}$ interaction at $1.9 \AA$ in their analysis of Tc-chloride solutions. We do not believe that a the $1.9 \AA$ distance is a realistic because this distance is approximately $0.1 \AA$ shorter than the $2.0 \AA$ bond distance typical of an ionic Tc(IV)-O interatomic distance in octahedral coordination despite the observation that metal-water interatomic distances are typically longer due to the weaker bonding interactions. In addition, given the electronegativity of $\mathrm{Cl}^{-}$, it is unlikely that a water molecule could form a stable configuration at a shorter bond length than the $\mathrm{Cl}$ atoms because of the repulsive interactions between the hydrogen and chlorine ions. In addition, attempts to include a Tc-O interaction at $1.9 \AA$ in fits to our data resulted in physically meaningless results, such as a negative number of oxygen atoms. A more reasonable $\mathrm{Tc}-\mathrm{OH}_{2}$ interatomic distance of $2.47 \AA$ has been suggested for the $\mathrm{TcO}_{2} \cdot x \mathrm{H}_{2} \mathrm{O}(\mathrm{am})$ solid $^{(25)}$ and a Tc-O interaction at this distance was included in fits to the data. The addition of this interaction did not result in a significantly better fit for any of the solution samples. Therefore, we conclude that the EXAFS data alone cannot be used to unambiguously distinguish between the possible Tc-chloride solution species, or a mixture of species, in these samples. However, our UV-Vis data on either samples of similar solution composition (Table I, sample 3-332) or the same sample (Table I, sample 5-301) suggests that the two Tc species determined by EXAFS are $\mathrm{TcCl}_{4}(\mathrm{aq})$ and $\mathrm{TcCl}_{6}{ }^{2-}$, respectively. Fits to the EXAFS indicates that the number of $\mathrm{Cl}$ atoms coordinating $\mathrm{Tc}$ in the latter sample (Table III, sample 5-301) is $5 \pm 1.3$. The assignment of the $\mathrm{TcCl}_{6}{ }^{2-}$ species is consistent with the known stability of $\mathrm{TcCl}_{6}{ }^{2-}$ species at high chloride concentrations, the spectrophotometric measurements, and within the error of the EXAFS analyses.

Fourier transforms of four solid samples equilibrated at $\mathrm{pH}$ values greater than 0.5 and over chloride concentrations ranging from 0 to $5 \mathrm{M} \mathrm{NaCl}$ (Figure 7b) show two distinct peaks corresponding to the nearest neighbor oxygen atoms and the next nearest neighbor Tc atoms. In contrast, the Fourier transform of the solid sample equilibrated in $1 \mathrm{~N} \mathrm{HCl}$ solution displays a single prominent peak at a longer radial distance. For the solids equilibrated at higher $\mathrm{pH}$ values, preliminary fits to the EXAFS data result in 4 oxygen atoms at approximately $2.0 \AA$ and a Tc-Tc interatomic distance at approximately $2.55 \AA$. The short Tc-Tc interatomic distance indicates that the Tc-O octahedra are in an edge sharing geometry in the amorphous structure. The remaining two oxygen atoms coordinating $\mathrm{Tc}$, which are associated with water molecules, are not readily apparent in the Fourier transform. A Tc- $\mathrm{OH}_{2}$ interaction at approximately $2.65 \AA$ was determined from the fits. This distance is significantly longer than the $2.47 \AA$ distance determined by Lukens et al. ${ }^{(26)}$ Fits to EXAFS data for the solid equilibrated in $1 \mathrm{~N} \mathrm{HCl}$ indicate that a mixture of $\mathrm{O}$ and $\mathrm{Cl}$ nearest neighbor atoms coordinates Tc. The low intensity peak at approximately $2.9 \AA$ radial distance corresponds to Tc atoms at $3.1 \AA$. A ternary solid with Tc-O-Cl composition has not been identified in the literature and the EXAFS signal may be a mixture of $\mathrm{TcO}_{2} \cdot x \mathrm{H}_{2} \mathrm{O}(\mathrm{am})$ solid and a unidentified Tc-Cl amorphous solid. Regardless, the EXAFS fitting results indicate a significant change in the composition of the solid phase at higher chloride compositions. This conclusion is consistent with the powder diffraction results, which indicate a change in the amorphous solid phase at very low $\mathrm{pH}$. The metrics obtained from the analysis of the EXAFS of the solid and solution samples are reported in Table III.

Solid phase and solution species distribution

Powder X-ray diffraction and EXAFS analyses were used to characterize the solid phases. These studies indicate the presence of amorphous $\mathrm{TcO}_{2} \cdot x \mathrm{H}_{2} \mathrm{O}$ as the solubility-limiting phase under most of the $\mathrm{pH}$ conditions investigated and the presence of a second amorphous phase at $\mathrm{pH} 0.3$ to $6 \mathrm{M} \mathrm{HCl}$. We have assumed that the composition of the second amorphous phase is $\mathrm{TcCl}_{4}(\mathrm{am})$, which is consistent with the analyses of solubility data presented in the next section. At high chloride concentrations, UV-Vis and EXAFS analyses of the solution samples confirmed the stability of the $\mathrm{TcCl}_{6}{ }^{2-}$ and $\mathrm{TcCl}_{4}(\mathrm{aq})$ species. Four distinctive UV-Vis spectra that could be assigned to $\mathrm{TcCl}_{6}^{2-}, \mathrm{TcCl}_{4}(\mathrm{aq}), \mathrm{TcO}^{2+}$, and $\mathrm{TcO}(\mathrm{OH})^{+}$species were observed over the range of 
experimental conditions investigated. At higher chloride concentrations, the stability of the $\mathrm{TcCl}_{6}{ }^{2-}$ and $\mathrm{TcCl}_{4}$ (aq) extends to higher $\mathrm{pH}$. For example, in the presence of $2.5 \mathrm{M} \mathrm{NaCl}$ the $\mathrm{TcCl}_{4}$ (aq) species is observed at $\mathrm{p} C_{\mathrm{H}^{+}}=0.6$ and in the presence of $5.0 \mathrm{M} \mathrm{NaCl}$ the $\mathrm{TcCl}_{6}{ }_{6}^{2-}$ species is observed at $\mathrm{p} C_{\mathrm{H}^{+}}=0.5$. Based on our spectrophotometric measurements and the assignments in the literature ${ }^{(11,12)}$, our observation of the existence Tc(IV)-aquochloro complexes rather than hydroxy or oxo-chloro Tc(IV) complexes under these solution conditions is in agreement with the conclusions of Ben Said et al. ${ }^{(9)}$ However, we do not observe the $\mathrm{TcCl}_{5}{ }^{-}$complex.

Our solubility studies indicate that the measured Tc concentration and Tc solution speciation have a complex dependence on the solubility limiting phase, $\mathrm{pH}$, and chloride concentration. The XRD and EXAFS analyses of the solid phases show the presence of two discrete amorphous Tc compounds whose stability is a stronger function of $\mathrm{pH}$ than chloride concentration. Therefore, the increase in solubility with increase in $\mathrm{NaCl}$ concentrations (Fig. 2) cannot be due to the solid phase transformations alone but must result from either the formation of chloride complexes of Tc(IV) or from the interactions of aqueous species with the electrolyte ions. As discussed above, the UV-Vis spectrophotometric analyses of aqueous species in the absence of $\mathrm{NaCl}$ show that the aqueous chloride complexes at $\mathrm{pH} \sim>0.1$ are not important and that the dominant species are either $\mathrm{TcO}^{2+}$ or $\mathrm{TcO}(\mathrm{OH})^{+}$. In the presence of greater than $2.5 \mathrm{M} \mathrm{NaCl}$, the aqueous chloride complexes are only important at $\mathrm{pH} \sim<1.0$. This information, along with the knowledge that the solubility-controlling phase at $\mathrm{pH}$ values greater than 0.5 is $\mathrm{TcO}_{2} \cdot x \mathrm{H}_{2} \mathrm{O}(\mathrm{am})$ and the assumption that the composition of the solubility-controlling phase at $\mathrm{pH}$ values less than 0.5 is $\mathrm{TcCl}_{4}$, was used to develop a thermodynamic model for the Tc(IV) system extending from $10^{-7} \mathrm{M}$ to $6 \mathrm{M} \mathrm{H}^{+}$ concentrations and $\mathrm{NaCl}$ concentrations extending to $5.0 \mathrm{M}$.

\section{Thermodynamic Analyses of Solubility data}

Thermodynamic data of Tc has been critically reviewed recently by Rard et al. ${ }^{(3)}$ and no new thermodynamic data for this system has since become available. Rard et al.$^{(3)}$ report $\mathrm{TcO}^{2+}$, $\mathrm{TcO}(\mathrm{OH})^{+}, \mathrm{TcO}(\mathrm{OH})_{2}(\mathrm{aq})$, and $\mathrm{TcO}(\mathrm{OH})_{3}{ }^{-}$as the expected $\mathrm{Tc}(\mathrm{IV})$ aqueous species in the hydroxide system. Based on these data, the $\mathrm{pH}$ regions where the different species are dominant are: $\mathrm{TcO}^{2+}$ at $\mathrm{pH}<1.5, \mathrm{TcO}(\mathrm{OH})^{+}$at $\mathrm{pH} 1.5$ to $2.5, \mathrm{TcO}(\mathrm{OH})_{2}(\mathrm{aq})$ at $\mathrm{pH} 2.5$ to 10.9 , and $\mathrm{TcO}(\mathrm{OH})_{3}{ }^{-}$at $\mathrm{pH}>10.9$. There are several uncertainties in the data presented by Rard et al. ${ }^{(3)}$ These uncertainties include: 1) only limiting value for $\mathrm{TcO}^{2+}$ is available, 2) the chemical potential of the $\mathrm{TcO}(\mathrm{OH})_{2}(\mathrm{aq})$ species is based on solubility measurements where the measured total Tc concentrations are low, near the detection limit, and the presence of only $\mathrm{Tc}(\mathrm{IV})$ in the solutions cannot be guaranteed, 3) there are large standard deviations in the reported chemical potentials of the species which translates into over 1.5 orders of magnitude variability in equilibrium constants involving these species, and 4) the data are based for the most part on solubility measurements in solutions of variable but relatively high chloride for which values of thermodynamic parameters (i.e., $\mathrm{Tc}-\mathrm{Cl}$ ion-interaction parameters and/or complexation constants) are not available. Even with these difficulties, Rard et al. ${ }^{(3)}$ data are the best that is available in the literature. Therefore, it is of interest to determine how closely the model based on the data reviewed by Rard et al. ${ }^{(3)}$ explain the $\mathrm{TcO}_{2} \cdot x \mathrm{H}_{2} \mathrm{O}$ solubility, as a function of wide range in $\mathrm{H}^{+}$and $\mathrm{NaCl}$ concentrations, determined in this study. For these calculations it was assumed that chemical potentials of aqueous Tc(IV) species and of the Tc(IV) solid phase $\left[\mathrm{TcO}_{2} \cdot 1.6 \mathrm{H}_{2} \mathrm{O}(\mathrm{am})\right]$ reported by Rard et al. ${ }^{(3)}$ (Table IV) is applicable to our system. In addition, Pitzer ion-interaction parameters for the bulk electrolyte (Table V) were included in these calculations.

Several general conclusions that can be drawn based on the comparisons of the predicted concentrations to the experimental data (Figures 8-9) are that the predicted concentrations: 1) agree well with the observed concentrations in relatively high $\mathrm{pH} / \mathrm{p} C_{\mathrm{H}^{+}}$solutions, where the 
$\mathrm{TcO}(\mathrm{OH})_{2}(\mathrm{aq})$ are dominant, 2) are about an order of magnitude lower in most of the systems (all equilibration periods for sets containing $0.8 \mathrm{M}, 2.5 \mathrm{M}$, and $5.0 \mathrm{M} \mathrm{NaCl}$ and for the 4 to 11 day equilibration period for set without $\mathrm{NaCl}$ ) in the intermediate $\mathrm{pH} / \mathrm{p} C_{\mathrm{H}^{+}}$region, and 3) are up to about two orders of magnitude higher in the acidic region. The similarity of the observed concentrations to the predicted concentrations in the region where $\mathrm{TcO}(\mathrm{OH})_{2}(\mathrm{aq})$ are dominant suggests that the chemical potential of the solid phase in our study must be similar to the value reported by Rard et al. ${ }^{(3)}$ Therefore, for further analyses we adopted the designation $\left[\mathrm{TcO}_{2} \cdot 1.6 \mathrm{H}_{2} \mathrm{O}(\mathrm{am})\right]$ and the chemical potential of this solid phase reported by Rard et al. ${ }^{(3)}$ These comparisons also indicate that the chemical potential/ion-interaction parameters of the aqueous species must be revised/determined to accurately describe our experimental data in the absence of $\mathrm{NaCl}$ (Fig. 8) and in the presence of different concentrations of $\mathrm{NaCl}$ (Fig. 9).

To develop a reliable model, we took advantage of the extensive $\mathrm{TcO}_{2} \cdot 1.6 \mathrm{H}_{2} \mathrm{O}(\mathrm{am})$ solubility data in addition to the spectroscopic identifications (EXAFS and UV-Vis) of the aqueous and solid species. Several different combinations of chemical potentials of the species along with the Pitzer ion-interaction parameters were tried to fit the data. A cursory look at the comparisons of the predicted concentrations using Rard et al. ${ }^{(3)}$ model (Fig. 8a, 9) indicated that the $\mathrm{TcO}^{2+}$ species has a large region of dominance and the $\mathrm{TcO}(\mathrm{OH})^{+}$species contributes only over a limited region. However, our spectrophotometric analyses of the aqueous phase identified the presence of the $\mathrm{TcO}(\mathrm{OH})^{+}$species between $\mathrm{pH}$ values of 0.8 to values up to about 2.5 (the $\mathrm{pH}$ region where measured Tc concentrations exceeded the detection limits) and the presence of the $\mathrm{TcO}^{2+}$ species at $\mathrm{pH}$ values between 0.1 and 0.8 . These considerations were kept in mind while developing a model for $\mathrm{TcO}_{2} \cdot 1.6 \mathrm{H}_{2} \mathrm{O}(\mathrm{am})$ solubility in the region where $\mathrm{H}^{+}$concentration $<1 \mathrm{M}$. The simplest model that described the entire data (data sets without $\mathrm{NaCl}$ at $\mathrm{pH}$ greater than zero, and sets containing $0.8 \mathrm{M}, 2.5 \mathrm{M}$, and $5.0 \mathrm{M} \mathrm{NaCl}$ ) included $\Delta \mathrm{G}_{\mathrm{f}}^{0} / \mathrm{RT}$ value of $-142.306 \pm 0.72$ for $\mathrm{TcO}(\mathrm{OH})^{+}$and values for $\mathrm{TcO}^{2+}, \mathrm{TcO}(\mathrm{OH})_{2}(\mathrm{aq})$ and $\mathrm{TcO}_{2} \cdot 1.6 \mathrm{H}_{2} \mathrm{O}(\mathrm{am})$ as reported in Rard et al. ${ }^{(3)}$ along with ion-interaction parameters listed in Table V. A close agreement between the Tc(IV) concentrations and the identity of aqueous species predicted by this model and those observed indicates the reliability of this model in predicting Tc(IV) concentrations in equilibrium with $\mathrm{TcO}_{2} \cdot 1.6 \mathrm{H}_{2} \mathrm{O}(\mathrm{am})$ over a wide range in $\mathrm{H}^{+}$concentrations (from $1.0 \mathrm{M}$ to $1.0 \times 10^{-6} \mathrm{M}$ ) and $\mathrm{NaCl}$ concentrations ranging up to $5.0 \mathrm{M}$.

We also determined the solubility of $\mathrm{TcO}_{2} \cdot 1.6 \mathrm{H}_{2} \mathrm{O}(\mathrm{am})$ in $\mathrm{HCl}$ solutions ranging in concentrations up to $6 \mathrm{M}$. The predicted Tc(IV) concentrations in equilibrium with $\mathrm{TcO}_{2} \cdot 1.6 \mathrm{H}_{2} \mathrm{O}(\mathrm{am})$ using the model described above were found to be several orders of magnitude higher than those observed. These comparisons indicated that the model would have to be enhanced in order to provide reliable predictions in the concentrated $\mathrm{HCl}$ solutions. The interpretation of these data in concentrated $\mathrm{HCl}$ solutions $(>1.0 \mathrm{M})$ is problematic due to very high concentrations of $\mathrm{HCl}$, the possible presence of multiple aqueous species (e.g., $\mathrm{TcCl}_{6}^{2-}$, $\left.\mathrm{TcCl}_{5}^{-}, \mathrm{TcCl}_{4}(\mathrm{aq}), \ldots\right),{ }^{(11,12)}$ and unavailability of chemical potentials for $\mathrm{Tc}(\mathrm{IV})-\mathrm{Cl}$ complexes and/or ion-interaction parameters for the dominant species in these systems with the bulk electrolyte ions $\left(\mathrm{H}^{+}\right.$and $\left.\mathrm{Cl}^{-}\right)$. An additional complication may also result in these systems where $\mathrm{Tc}(\mathrm{IV})$-chloro compounds may form under these conditions. Our spectrophotometric analyses of the aqueous phase from concentrated $\mathrm{HCl}$ solutions $(1.0$ to $6.0 \mathrm{M})$ indicate the presence of $\mathrm{TcCl}_{6}{ }^{2-}$ at high $\mathrm{HCl}$ concentrations and $\mathrm{TcCl}_{4}(\mathrm{aq})$ in moderate $\mathrm{HCl}$ concentrations. The literature data also reports the presence of these species along with the presence of species such as $\mathrm{TcCl}_{5}{ }^{-}$. $^{(11)}$ The dominance of any of these species at $1.0 \mathrm{M} \mathrm{HCl}$ would dictate over about six orders of magnitude increase in solubility with the increase in $\mathrm{HCl}$ concentrations from $1.0 \mathrm{M}$ to $6.0 \mathrm{M}$ (Eqs. 3-5).

$\mathrm{TcO}_{2} \cdot 1.6 \mathrm{H}_{2} \mathrm{O}(\mathrm{am})+6 \mathrm{Cl}^{-}+4 \mathrm{H}^{+}=\mathrm{TcCl}_{6}{ }^{2-}+3.6 \mathrm{H}_{2} \mathrm{O}$ [Eq. 3] 
$\mathrm{TcO}_{2} \cdot 1.6 \mathrm{H}_{2} \mathrm{O}(\mathrm{am})+5 \mathrm{Cl}^{-}+4 \mathrm{H}^{+}=\mathrm{TcCl}_{5}{ }^{-}+3.6 \mathrm{H}_{2} \mathrm{O}$

$\mathrm{TcO}_{2} \cdot 1.6 \mathrm{H}_{2} \mathrm{O}(\mathrm{am})+4 \mathrm{Cl}^{-}+4 \mathrm{H}^{+}=\mathrm{TcCl}_{4}(\mathrm{aq})+3.6 \mathrm{H}_{2} \mathrm{O}$

[Eq. 4]

[Eq. 5]

However, the experimental data indicate an increase in Tc concentration of only about an order of magnitude with the increase in $\mathrm{HCl}$ concentrations from $1.0 \mathrm{M}$ to $6.0 \mathrm{M}$. Therefore, if $\mathrm{TcCl}_{6}{ }_{6}^{2-}$ or $\mathrm{TcCl}_{4}(\mathrm{aq})$ are dominant at $\geq 1.0 \mathrm{M} \mathrm{HCl}$ concentration as indicated by the spectroscopic data, $\mathrm{TcO}_{2} \cdot 1.6 \mathrm{H}_{2} \mathrm{O}(\mathrm{am})$ cannot possibly be the solubility-controlling solid phase in these concentrated $\mathrm{HCl}$ solutions. Similar arguments can be made to show that alternative compounds such as $\mathrm{H}_{2} \mathrm{TcCl}_{6}(\mathrm{~s})$ and $\mathrm{TcOCl}_{2}(\mathrm{~s})$, assumed based either on data mentioned in Rard et al. ${ }^{(3)}$ or in analogy to the $\mathrm{U}(\mathrm{IV})-\mathrm{Cl}$ system, cannot be the solubility-controlling solid phases. For example, the dissolution of $\mathrm{H}_{2} \mathrm{TcCl}_{6}$ (s) to $\mathrm{TcCl}_{6}{ }^{2-}$ solution species (Eq. 6) dictates a decrease in $\mathrm{TcCl}_{6}{ }^{2-}$ concentration with increasing $\mathrm{H}^{+}$concentration, whereas the dissolution of $\mathrm{H}_{2} \mathrm{TcCl}_{6}(\mathrm{~s})$ to $\mathrm{TcCl}_{4}(\mathrm{aq})$ solution species (Eq. 7) requires four orders of magnitude increase in $\mathrm{TcCl}_{4}(\mathrm{aq})$ concentration with an order magnitude increase in $\mathrm{HCl}$ concentration. However, neither reaction is supported by the measured Tc concentration dependence on $\mathrm{HCl}$ concentration or the UV-Vis and EXAFS spectrometric data.

$$
\begin{aligned}
& \mathrm{H}_{2} \mathrm{TcCl}_{6}(\mathrm{~s}) \square \mathrm{TcCl}_{6}{ }^{2-}+2 \mathrm{H}^{+} \\
& \mathrm{TcOCl}_{2}(\mathrm{~s})+2 \mathrm{H}^{+}+2 \mathrm{Cl}^{-} \square \mathrm{TcCl}_{4}(\mathrm{aq})+\mathrm{H}_{2} \mathrm{O}
\end{aligned}
$$

These considerations lead us to conclude that the equilibrium with $\mathrm{TcCl}_{4}(\mathrm{~s})$ can satisfy the observed distribution of $\mathrm{TcCl}_{4}(\mathrm{aq})$ and $\mathrm{TcCl}_{6}{ }^{2-}$ and the observed solubility behavior in the concentrated $\mathrm{HCl}$ solutions. This conclusion is supported by the EXAFS data, which indicates the presence of a Tc(IV) compound containing chloride and the XRD data, which indicates the presence of a second amorphous compound. This unidentified compound may very well be $\mathrm{TcCl}_{4}(\mathrm{am})$ compound. However, because of the large number of difficulties discussed above and the lack of definitive identification of $\mathrm{TcCl}_{4}(\mathrm{am})$, only a preliminary model can be presented for this system. To develop this model, we first estimated the $\Delta \mathrm{G}_{\mathrm{f}}{ }^{0} / \mathrm{RT}$ value for $\mathrm{TcCl}_{4}(\mathrm{aq})$ (166.867) based on equilibrium with $\mathrm{TcO}_{2} \cdot 1.6 \mathrm{H}_{2} \mathrm{O}(\mathrm{am})$ and the observation that this is the dominant aqueous species in $1.0 \mathrm{M} \mathrm{HCl}$. This also required an ion-interaction value of 0.11 for $\mathrm{TcO}^{2+}-\mathrm{H}^{+}$pair, which is reasonable and identical to the value reported for $\mathrm{Ca}^{2+}-\mathrm{H}^{+}$pair ${ }^{(21)}$. We then determined $\Delta \mathrm{G}_{\mathrm{f}}{ }^{0} / \mathrm{RT}$ values for $\mathrm{TcCl}_{4}(\mathrm{am})$ and $\mathrm{TcCl}_{6}{ }^{2-}, 175.639$ and -269.356 , respectively, and the binary interaction parameters for the $\mathrm{TcCl}_{6}{ }^{2-}-\mathrm{Na}^{+}$pair. These parameters were included in the overall model, and the model was used to predict concentrations for the concentrated $\mathrm{HCl}$ solutions in equilibrium with $\mathrm{TcCl}_{4}(\mathrm{~s})$ and for systems with and without $\mathrm{NaCl}$, at $\mathrm{HCl}$ concentrations $<\sim 1 \mathrm{M}$, and in equilibrium with $\mathrm{TcO}_{2} \cdot 1 \cdot 6 \mathrm{H}_{2} \mathrm{O}(\mathrm{am})$. As expected, the inclusion of $\mathrm{TcCl}_{4}(\mathrm{aq})$ and $\mathrm{TcCl}_{6}{ }^{2-}$ did not significantly affect the predicted concentrations, with the exception of a few of the lowest $\mathrm{pH}$ data points. The predicted aqueous species and the concentrations are in very good agreement with the spectrophotometric and solubility data (Fig. 8-9).

\section{Conclusions}

Rigorous reducing conditions were maintained over a long period, in this case greater than 500 days, which resulted in a preponderance of $\mathrm{Tc}(\mathrm{IV})$ in solution. The measured $\mathrm{TcO}_{2} \cdot 1.6 \mathrm{H}_{2} \mathrm{O}(\mathrm{am})$ solubility in relatively low chloride solutions is in good agreement with earlier experimental studies. ${ }^{(4,5)}$ However, the presence of chloride significantly affects $\mathrm{TcO}_{2} \cdot 1.6 \mathrm{H}_{2} \mathrm{O}($ am) solubility. A revised free energy value of the $\mathrm{TcO}(\mathrm{OH})^{+}$and the addition of binary interaction parameters for $\mathrm{TcO}^{2+}-\mathrm{Cl}^{-}$and $\mathrm{TcO}(\mathrm{OH})^{+}-\mathrm{Cl}^{-}$species to the existing thermodynamic database ${ }^{(3)}$ results in 
model predictions of $\mathrm{TcO}_{2} \cdot 1.6 \mathrm{H}_{2} \mathrm{O}(\mathrm{am})$ solubility in good agreement with the experimental data over a wide range of $\mathrm{pH}$ and chloride concentrations. The lack of definitive identification of solubility-controlling solid phase at high chloride concentrations necessitated the development of a phenomenological interim model, which is consistent with the solid and aqueous phases data. Spectrophotometric and EXAFS measurements indicate that the most likely Tc species at high chloride concentrations are aquo-chlorocomplexes, $\mathrm{TcCl}_{6}{ }^{2-}$ and $\mathrm{TcCl}_{4}(\mathrm{aq})$, in agreement with model predictions.

\section{Acknowledgements}

The authors thank Mr. Evan Jenson for his assistance with the powder diffraction measurements and data analysis and Mr. Dean Moore for assistance with the solubility experiments. This work was supported by the Environmental Management Science Program (EMSP) and by the Division of Materials Science and Engineering, Office of Basic Energy Sciences, U.S. Department of Energy. XAS data were collected at the Stanford Synchrotron Radiation Laboratory (SSRL), which is operated by the Department of Energy (DOE), Office of Basic Energy Sciences. The SSRL Biotechnology Program is supported by the National Institutes of Health, National Center for Research Resources, Biomedical Technology Program, and by the DOE, Office of Biological and Environmental Research. PNNL is operated by Battelle for the U.S. Department of Energy under Contract DE-AC06-76RLO 1830. 


\section{Literature Cited}

1. E.H. Schulte and P. Scoppa, Sci. Total Environ. 64,163-179 (1987).

2. M.J. Rudin, C. Stanton, R.G. Patterson, and R.S. Garcia, National Low-Level Waste Management Program Radionuclide Report Series, Vol. 2, Technetium-99, Idaho National Engineering Laboratory Technical Report DOE/LLW-118, Idaho Falls, ID (1992).

3. J.A. Rard, M.H. Rand, G. Anderegg, and H. Wanner. In Chemical Thermodynamics of Technetium; M.C.A. Sandino and E. Östhols, Eds.; Chemical Thermodynamics 3, Elsevier, New York, NY 544p. (1999).

4. R.E. Meyer, W.D. Arnold, and F.I. Case, Oak Ridge National Laboratories Technical Report ORNL-6503, Oak Ridge, TN (1986).

5. R.E. Meyer, W.D. Arnold, F.I. Case, and G.D. O'Kelley, Radiochim. Acta 55, 11-18 (1991).

6. M. Lefort, Bull. Soc. Chim. France, 882-884 (1963).

7. A.C. Vikis, F. Garisto, R.J. Lemire, J. Paquette, N. Sagert, P.P.S. Saluja, S. Sunder, and P. Taylor, Procedings of International Symposium on Uranium and Electricity, p. 2-18, Saskatoon, SK (1988).

8. B. Gorsky and H. Koch, J. Inorg. Nuc. Chem. 31, 3565-3571 (1969).

9. K. Ben Said, M. Fattahi, Cl. Musikas, R. Revel, and J. Ch. Abbé, Radiochim. Acta 88, 567-571 (2000).

10. D. Rai, A.R. Felmy, S.P. Juracich, and L. Rao, Sandia National Laboratories Technical Report SAND94-1949, Albuquerque, NM (1995).

11. E. Ianovici, M. Kosinski, P. Lerch, and A.G. Maddock, J. Radioanal. Chem. 64, 315-326 (1981).

12. Y. Kanchiku, Bull. Chem. Soc. Japan 42, 2831-2835 (1969).

13. W.H. McMaster, N. Kerr del Grande, J.H. Mallett, and J.H.Hubbell, Compilation of Xray cross sections, University of California, Livermore, CA (1969).

14. A.L.Ankudinov, Ph. D. Thesis, University of Washington, Seattle, WA (1996).

15. J.J. Rehr, J. Mustre de Leon, S.I. Zabinsky, R.C. Albers, J. Amer. Chem. Soc. 113, 5135$5140(1991)$.

16. A. Magneli, Acta Cryst. 9, 1038-1039 (1956).

17. K. Krebs, Z. Anorgan. Allegem.Chem. 380,146-159 (1971).

18. P.W. Frais and J.L. Locke, Can. J. Chem. 50, 1811-1818 (1972).

19. K.S. Pitzer and G. Mayorga, J. Phys. Chem. 77, 2300-2308 (1973).

20. K.S. Pitzer, In Ion Interaction Approach: Theory and Data Correlation Activity; K.S. Pitzer, Ed. Activity Coefficients in Electrolyte Solutions, $2^{\text {nd }}$ edn., CRC Press, Boca Raton FL (1991).

21. A.R. Felmy and J.H. Weare, Geochim. Cosmochim. Acta 50, 2771-2783 (1986).

22. A.R. Felmy, D. Rai, J.A. Schramke, and J. Ryan, Radiochim. Acta 48, 29-35 (1989).

23. S.M. Sterner, A.R. Felmy, J.R. Rustad, and K.S. Pitzer, Battelle Technical Report PNWD-SA-4436., Richland, WA (1997).

24. I. Almahamid, J.C. Bryan, J.J. Bucher, A.K. Burrell, N.M. Edelstein, E.A. Hudson, N. Kaltsoyannis, W.W. Lukens, D.K. Shuh, H. Nitsche, and T. Reich, Inorg. Chem. 34, $193-$ 198 (1995).

25. W.W. Lukens, Jr., J.J. Bucher, N.M. Edelstein, and D.K. Shuh, Environ. Sci. Tech. 36, 1124-1129 (2002)

26. C.E. Harvie, N. Moller, and J.H. Weare, Geochim. Cosmochim. Acta 48, 723-751 (1984). 
Table I. UV-Vis measurements.

\begin{tabular}{|c|c|c|}
\hline $\begin{array}{l}\text { Sample set-number, } \\
\text { Solution composition }\end{array}$ & Absorbance peak, absorbance & Tc species \\
\hline $\begin{array}{c}5-301,6 \mathrm{~N} \mathrm{HCl},[\mathrm{Cl}]=6 \mathrm{M} \\
4-372, \mathrm{p} C_{\mathrm{H}^{+}}=0.45,[\mathrm{Cl}]=5 \mathrm{M}\end{array}$ & $\begin{array}{l}235 \mathrm{~nm}, 3.909^{\mathrm{f}} \\
235 \mathrm{~nm}, 1.543^{\mathrm{b}}\end{array}$ & $\begin{array}{l}\mathrm{TcCl}_{6}{ }^{2-} \\
\mathrm{TcCl}_{6}{ }^{2-}\end{array}$ \\
\hline $1-201, \mathrm{pH}=0.1,[\mathrm{Cl}]=1 \mathrm{M}$ & $350 \mathrm{~nm}, 3.945^{\mathrm{a}}$ & $\mathrm{TcCl}_{4}(\mathrm{aq})$ \\
\hline $2-351, \mathrm{p} C_{\mathrm{H}^{+}}=0.4,[\mathrm{Cl}]=1 \mathrm{M}$ & $350 \mathrm{~nm}, 3.396$ & $\mathrm{TcCl}_{4}(\mathrm{aq})$ \\
\hline $3-332, \mathrm{p} C_{\mathrm{H}^{+}}=0.6,[\mathrm{Cl}]=2.5 \mathrm{M}$ & $350 \mathrm{~nm}, 3.464$ & $\mathrm{TcCl}_{4}(\mathrm{aq})$ \\
\hline $3-333, \mathrm{p} C_{\mathrm{H}^{+}}=1.1,[\mathrm{Cl}]=2.5 \mathrm{M}$ & $350 \mathrm{~nm}, 1.099$ & $\mathrm{TcCl}_{4}(\mathrm{aq})$ \\
\hline $1-202, \mathrm{pH}=0.6,[\mathrm{Cl}]=0.3 \mathrm{M}$ & $329 \mathrm{~nm}, 0.508$ & $\mathrm{TcO}^{2+}$ \\
\hline $5-306, \mathrm{pH}=0.5,[\mathrm{Cl}]=0.4 \mathrm{M}$ & $329 \mathrm{~nm}, 0.510$ & $\mathrm{TcO}^{2+}$ \\
\hline $5-307, \mathrm{pH}=0.7,[\mathrm{Cl}]=0.2 \mathrm{M}$ & $329 \mathrm{~nm}, 0.054$ & $\mathrm{TcO}^{2+}$ \\
\hline $2-352, \mathrm{p} C_{\mathrm{H}+}=0.7,[\mathrm{Cl}]=0.8 \mathrm{M}$ & $329 \mathrm{~nm}, 0.749$ & $\mathrm{TcO}^{2+}$ \\
\hline $2-353, \mathrm{p} C_{\mathrm{H}^{+}}=1.2,[\mathrm{Cl}]=0.8 \mathrm{M}$ & $329 \mathrm{~nm}, 0.041$ & $\mathrm{TcO}^{2+}$ \\
\hline $1-203, \mathrm{pH}=1.1,[\mathrm{Cl}]=0.1 \mathrm{M}$ & $275 \mathrm{~nm}, 0.038$ & $\mathrm{TcO}_{(\mathrm{OH})^{+}}$ \\
\hline $5-308, \mathrm{pH}=1.1,[\mathrm{Cl}]=0.1 \mathrm{M}$ & $275 \mathrm{~nm}, 0.016$ & $\mathrm{TcO}(\mathrm{OH})^{+}$ \\
\hline $2-354, \mathrm{pC}_{\mathrm{H}+}=1.7,[\mathrm{Cl}]=0.8 \mathrm{M}$ & $275 \mathrm{~nm}, 0.012$ & $\mathrm{TcO}(\mathrm{OH})^{+}$ \\
\hline $2-355, \mathrm{p} C_{\mathrm{H}^{+}}=2.7,[\mathrm{Cl}]=0.8 \mathrm{M}$ & $275 \mathrm{~nm}, 0.032$ & $\mathrm{TcO}(\mathrm{OH})^{+}$ \\
\hline $4-375, \mathrm{p} C_{\mathrm{H}^{+}}=3.2,[\mathrm{Cl}]=5 \mathrm{M}$ & $275 \mathrm{~nm}, 0.008$ & $\mathrm{TcO}(\mathrm{OH})^{+}$ \\
\hline $4-376, \mathrm{p} C_{\mathrm{H}^{+}}=4.4,[\mathrm{Cl}]=5 \mathrm{M}$ & $275 \mathrm{~nm}, 0.003$ & $\mathrm{TcO}(\mathrm{OH})^{+}$ \\
\hline $7-401, \mathrm{pH}=2.3,[\mathrm{Cl}]=0.6 \mathrm{M}$ & $275 \mathrm{~nm}, 0.059$ & $\mathrm{TcO}(\mathrm{OH})^{+}$ \\
\hline $7-801, \mathrm{pH}=2.1,[\mathrm{Cl}]=0.6 \mathrm{M}$ & $275 \mathrm{~nm}, 0.061$ & $\mathrm{TcO}(\mathrm{OH})^{+}$ \\
\hline
\end{tabular}

Table II. Molar extinction coefficients for expected Tc solution species.

\begin{tabular}{|l|l|l|c|}
\hline \multicolumn{1}{|c|}{ Species } & \multicolumn{1}{|c|}{$\lambda_{\max }(\mathrm{nm})$} & \multicolumn{1}{c|}{$\varepsilon_{\max }\left(\mathrm{mol}^{-1} \mathrm{~cm}^{-1}\right)$} & Reference \\
\hline $\mathrm{TcCl}_{6}{ }^{-2}$ & 235,338 & 19200,10676 & $(11)$ \\
\hline $\mathrm{TcCl}_{5}{ }^{-}$ & 235,320 & 11334,8780 & $(11)$ \\
\hline $\mathrm{TcCl}_{4}(\mathrm{aq})$ & 354 & 5500 & $(12)$ \\
\hline $\mathrm{TcO}_{4}{ }^{-}$ & 244,287 & 6220,2360 & $(19)$ \\
\hline $\mathrm{TcO}^{2+}$ & 225,329 & 5920,4840 & This work \\
\hline $\mathrm{TcO}(\mathrm{OH})^{+}$ & 224,275 & Not determined & This work \\
\hline
\end{tabular}

a. Sample diluted by ten fold prior to UV-Vis measurement.

b. Detector saturated. 
Table III. EXAFS analysis of selected solutions and solid phases.

\begin{tabular}{|c|c|c|c|c|c|c|}
\hline & & & & & & \\
\hline $\begin{array}{l}\text { Sample set-number, } \\
\frac{\text { Solution composition }}{4-371}\end{array}$ & $\underline{\text { Atom }}$ & $\underline{\mathrm{n}}$ & $\underline{\mathrm{d}(\AA)}$ & $\underline{\sigma(\AA)}$ & $\underline{\delta \mathrm{E}_{0}}$ & $\underline{\mathrm{R}^{2}}$ \\
\hline $\begin{array}{c}\mathrm{p} C_{\mathrm{H}^{+}}=0,[\mathrm{Cl}]=5.0 \mathrm{M} \\
3-331\end{array}$ & $\mathrm{Cl}$ & $3.9 \pm 1.1$ & $2.36 \pm .02$ & $0.07 \pm .01$ & $-1.0 \pm 3.7$ & 1.8812 \\
\hline $\begin{array}{c}\mathrm{p} C_{\mathrm{H}^{+}}=0,[\mathrm{Cl}]=2.5 \mathrm{M} \\
5-301\end{array}$ & $\mathrm{Cl}$ & $3.9 \pm 1.1$ & $2.35 \pm .02$ & $0.07 \pm .01$ & $-0.8 \pm 3.7$ & 2.0800 \\
\hline $6 \mathrm{~N} \mathrm{HCl},[\mathrm{Cl}]=6.0 \mathrm{M}$ & $\mathrm{Cl}$ & $5.0 \pm 1.3$ & $2.36 \pm .02$ & $0.07 \pm .01$ & $-0.1 \pm 3.5$ & 1.8928 \\
\hline Solid phases & & & & & & \\
\hline $\begin{array}{l}\text { Sample set-number, } \\
\text { Solution composition }\end{array}$ & $\underline{\text { Atom }}$ & $\underline{n^{\mathrm{g}}}$ & $\underline{\mathrm{d}(\AA)^{\mathrm{h}}}$ & $\underline{\sigma(\AA)^{\mathrm{i}}}$ & $\underline{\delta \mathrm{E}_{0}^{\mathrm{j}}}$ & $\underline{\mathrm{R}^{2 \mathrm{k}}}$ \\
\hline & $\mathrm{O}$ & $4.6 \pm 1.1$ & $2.07 \pm .02$ & $0.10 \pm .02$ & $5.3 \pm 2.7$ & \\
\hline $6-258$ & $\mathrm{O}$ & $1.8 \pm 0.5$ & $2.71 \pm .02$ & $0.00 \pm .00$ & $6.2 \pm 2.9$ & 0.6533 \\
\hline $\mathrm{pH}=2.6,[\mathrm{Cl}]=0.3 \mathrm{M}$ & Tc & $1.0 \pm 0.3$ & $2.59 \pm 0.2$ & $0.09 \pm .01$ & $-9.4 \pm 4.2$ & \\
\hline EXAFS-01 & $\mathrm{O}$ & $4.6 \pm 1.1$ & $2.07 \pm .02$ & $0.10 \pm .02$ & $5.3 \pm 2.7$ & \\
\hline $\mathrm{p} C_{\mathrm{H}^{+}}=1.6$ & $\mathrm{O}$ & $1.8 \pm 0.5$ & $2.71 \pm .02$ & $0.00 \pm .00$ & $6.2 \pm 2.9$ & \\
\hline$[\mathrm{Cl}]=5.0 \mathrm{M}$ & Tc & $1.0 \pm 0.3$ & $2.59 \pm 0.2$ & $0.09 \pm .01$ & $-9.4 \pm 4.2$ & 0.7804 \\
\hline & $\mathrm{O}$ & $4.0 \pm 1.1$ & $2.06 \pm .02$ & $0.10 \pm .02$ & $2.9 \pm 2.9$ & \\
\hline $6-255$ & $\mathrm{O}$ & $2.2 \pm 0.6$ & $2.69 \pm .01$ & $0.00 \pm .00$ & $2.5 \pm 3.0$ & \\
\hline $\mathrm{pH}=2.0,[\mathrm{Cl}]=0.3 \mathrm{M}$ & $\mathrm{Tc}$ & $0.8 \pm 0.2$ & $2.60 \pm 0.2$ & $0.07 \pm .01$ & $-12.4 \pm 4.6$ & 0.6495 \\
\hline & $\mathrm{O}$ & $3.4 \pm 0.7$ & $2.04 \pm .02$ & $0.09 \pm .02$ & $2.6 \pm 2.6$ & \\
\hline $1-205$ & $\mathrm{O}$ & $1.7 \pm 0.4$ & $2.69 \pm .02$ & $0.00 \pm .00$ & $7.0 \pm 2.5$ & \\
\hline $\mathrm{pH}=2.1,[\mathrm{Cl}]=.03 \mathrm{M}$ & Tc & $1.6 \pm 0.4$ & $2.54 \pm 0.1$ & $0.09 \pm .01$ & $-11.7 \pm 3.6$ & 0.4046 \\
\hline & $\mathrm{O}$ & $4.3 \pm 1.2$ & $2.19 \pm .04$ & $0.15 \pm .02$ & $6.7 \pm 2.4$ & \\
\hline & $\mathrm{Cl}$ & $2.0 \pm 0.5$ & $2.27 \pm .02$ & $0.09 \pm .01$ & $2.5 \pm 3.2$ & \\
\hline $1-201$ & $\mathrm{O}$ & $1.0 \pm 0.3$ & $2.66 \pm .02$ & $0.00 \pm .00$ & $2.0 \pm 3.7$ & \\
\hline $\mathrm{pH}=0.2,[\mathrm{Cl}]=1 \mathrm{M}$ & $\mathrm{Tc}$ & $3.6 \pm 1.1$ & $3.01 \pm 0.2$ & $0.13 \pm .01$ & $-6.1 \pm 2.6$ & 0.6808 \\
\hline
\end{tabular}

${ }^{\mathrm{g}} \mathrm{n}=$ number of atoms

${ }^{\mathrm{h}} \mathrm{d}=$ distance in angstroms

${ }^{\mathrm{i}} \sigma=$ sigma in angstroms

${ }^{\mathrm{j}} \delta \mathrm{E}_{0}=$ energy shift from $\mathrm{E}_{0}$ in $\mathrm{eV}$

${ }^{\mathrm{k}} \mathrm{R}^{2}=$ goodness of fit 
Table IV. Dimensionless standard molar Gibbs energy of formation of different species.

\begin{tabular}{|c|c|c|}
\hline Species & $\Delta \mathrm{G}_{\mathrm{f}}^{0} / \mathrm{RT}$ & Reference \\
\hline $\mathrm{TcCl}_{6}{ }^{2-}$ & $-269.356 \pm 0.39$ & This work ${ }^{1}$ \\
\hline $\mathrm{TcCl}_{4}(\mathrm{aq})$ & $-166.867 \pm 0.39$ & This work $^{\mathrm{m}}$ \\
\hline $\mathrm{TcO}^{2+}$ & $>-47.161$ & (3) \\
\hline $\mathrm{TcO}(\mathrm{OH})^{+}$ & $-142.306 \pm 0.72$ & This work $^{\mathrm{n}}$ \\
\hline & $-139.327 \pm 3.634$ & $(3)^{\mathrm{o}}$ \\
\hline $\mathrm{TcO}(\mathrm{OH})_{3}^{-}$ & $-299.798 \pm 3.685$ & (3) \\
\hline $\mathrm{TcO}(\mathrm{OH})_{2}(\mathrm{aq})$ & $-229.234 \pm 3.568$ & (3) \\
\hline $\mathrm{TcO}_{2} \cdot 1.6 \mathrm{H}_{2} \mathrm{O}(\mathrm{am})$ & $-305.974 \pm 3.377$ & (3) \\
\hline $\mathrm{TcCl}_{4}(\mathrm{am})$ & $-175.639 \pm 0.39$ & This work \\
\hline $\mathrm{Cl}^{-}$ & -52.955 & $(26)$ \\
\hline $\mathrm{OH}^{-}$ & -63.435 & (26) \\
\hline $\mathrm{H}_{2} \mathrm{O}(1)$ & -95.663 & (26) \\
\hline
\end{tabular}

Table V. Pitzer ion-interaction parameters used in this study.

\begin{tabular}{cccccc}
\hline Species & \multicolumn{5}{c}{ Binary Parameters } \\
& $\beta^{(0)}$ & $\beta^{(1)}$ & $\beta^{(2)}$ & $\mathrm{C}^{(\Phi)}$ & Reference \\
\hline $\mathrm{TcO}^{2+}-\mathrm{Cl}^{-}$ & 0.3053 & 1.7090 & 0 & 0.0022 & This work \\
$\mathrm{TcO}(\mathrm{OH})^{+}-\mathrm{Cl}^{-}$ & -0.2010 & 0 & 0 & 0 & This work \\
$\mathrm{H}^{+}-\mathrm{TcCl}_{6}^{2-}$ & 0.567 & 0 & 0 & 0 & This work \\
$\mathrm{H}^{+}-\mathrm{Cl}^{-}$ & 0.1775 & 0.2945 & 0 & 0.0008 & $(26)$ \\
$\mathrm{Na}^{+}-\mathrm{TcCl}_{6}^{2-}$ & 0.6470 & 0 & 0 & -0.1146 & This work \\
$\mathrm{Na}^{+}-\mathrm{OH}^{-}$ & 0.0864 & 0.2530 & 0 & 0.0044 & $(26)$ \\
$\mathrm{Na}^{+}-\mathrm{Cl}^{-}$ & 0.0765 & 0.2664 & 0 & 0.00127 & $(26)$ \\
\hline \multicolumn{7}{c}{ Common-ion ternary parameters } \\
\hline $\mathrm{OH}^{-}-\mathrm{Cl}^{-}-\mathrm{Na}^{+}$ & -0.006 & 0 & Reference \\
$\mathrm{H}^{+}-\mathrm{Na}^{+}$ & 0.036 & 0 & $(26)$ \\
$\mathrm{OH}^{-}-\mathrm{Cl}^{-}$ & -0.050 & 0 & & $(26)$ \\
$\mathrm{TcO}^{2+}-\mathrm{H}^{+}$ & 0.110 & 0 & & This work
\end{tabular}

${ }^{1}$ The reported $\Delta \mathrm{G}_{\mathrm{f}}^{0} / \mathrm{RT}$ values of these species are dependent on the value to $\mathrm{TcCl}_{4}(\mathrm{am})$, see footnote 2 for details, and should be considered only as interim values.

${ }^{m}$ Definitive identification of this compound is lacking, although XRD and EXAFS data suggest the presence of another amorphous compound other than $\mathrm{TcO}_{2} \cdot 1.6 \mathrm{H}_{2} \mathrm{O}(\mathrm{am})$ and which contains chloride. The solubility data are consistent with the formation of this compound.

${ }^{\mathrm{n}}$ The standard deviation is based on solubility data in the presence and absence of $\mathrm{NaCl}$, where clear outlier points were excluded from calculations.

${ }^{\circ}$ The data obtained in our study is consistent with average $\Delta \mathrm{G}_{\mathrm{f}}^{0} / \mathrm{RT}$ values reported by Rard et al. ${ }^{(3)}$ for these species however, our data shows much lower standard deviations, \pm 0.72 , in these numbers.

${ }^{\mathrm{p}}$ Assumed to be identical to the parameters for $\mathrm{Ca}^{2+}-\mathrm{Cl}^{-}$reported by Pitzer $^{(20)}$. 


\section{Figure Captions}

Figure 1. Measured Tc(IV) solubility as a function of $\mathrm{pH}$ and high chloride concentrations. Smaller sized symbols indicate data points where there is greater uncertainty in either the measured Tc concentrations or the oxidation state distribution. The data of Meyer et al. ${ }^{(4,5)}$ is shown with grey symbols for comparison. Note that the first four data points represent the solubility in $6.0 \mathrm{M}, 4.0 \mathrm{M}, 2.0 \mathrm{M}$, and $1.0 \mathrm{M} \mathrm{HCl}$ and are plotted as $\mathrm{pH}$ values $-0.78,-0.60,-0.30$, and 0.0 , respectively, for easy comparison to the other data.

Figure 2. Measured Tc(IV) solubility after 11-days equilibration for data sets with no $\mathrm{NaCl}$ added, $0.8 \mathrm{M}, 2.5 \mathrm{M}$, and $5.0 \mathrm{M} \mathrm{NaCl}$ as a function of $\mathrm{pH}$ or $\mathrm{p} C_{\mathrm{H}^{+}}$. The solubility of $\mathrm{TcO}_{2} \cdot x \mathrm{H}_{2} \mathrm{O}(\mathrm{am})$ increases with increasing chloride concentration. Note that the first four data points represent the solubility in $6.0 \mathrm{M}, 4.0 \mathrm{M}, 2.0 \mathrm{M}$, and $1.0 \mathrm{M} \mathrm{HCl}$ and are plotted as $\mathrm{pH}$ values $-0.78,-0.60,-0.30$, and 0.0 , respectively, for easy comparison to the other data.

Figure 3. Measured $\mathrm{Tc}(\mathrm{IV})$ concentration as a function of $\mathrm{p} C_{\mathrm{H}^{+}}$for solubility experiments approached from the oversaturation direction in the presence of $\mathrm{TcO}_{2} \cdot x \mathrm{H}_{2} \mathrm{O}(\mathrm{am})$ compared to the $0.8 \mathrm{M} \mathrm{NaCl}$ data set in grey tone. For $0.8 \mathrm{M} \mathrm{NaCl}$ data set, $\mathrm{x}=4$-day, $\diamond=14$-day, and $\bigcirc=29$ day. Vertical dotted lines trace the $\mathrm{pH}$ adjustment, horizontal dotted arrows trace the observed decrease in Tc solubility. Smaller sized symbols indicate data points where there is greater uncertainty in either the measured Tc concentrations or the oxidation state distribution.

Figure 4. Diffractogram of solid phase equilibrated with aqueous solution after 350 to 390 days. The amorphous nature of the solid phases is evident from the broad diffuse bands at $20^{\circ} 2 \Theta$ at low chloride concentrations and below $20^{\circ} 2 \Theta$ at high chloride concentrations.

Figure 5. Characteristic spectrophotometric data of the four Tc(IV) solution species observed as a function of $\mathrm{pH}$ and chloride concentration. The spectra correspond to the following set-sample number and solution conditions: $\mathrm{TcCl}_{6}{ }^{2-}(5-301,6 \mathrm{~N} \mathrm{HCl},[\mathrm{Cl}]=6 \mathrm{M}) ; \mathrm{TcCl}_{4}(\mathrm{aq})(3-332, \mathrm{pH}=$ $0.6,[\mathrm{Cl}]=2.5 \mathrm{M}) ; \mathrm{TcO}^{2+}(5-306, \mathrm{pH}=0.5,[\mathrm{Cl}]=0.4 \mathrm{M})$; and $\mathrm{TcO}(\mathrm{OH})^{+}(5-308, \mathrm{pH}=1.1$, $[\mathrm{Cl}]=0.1 \mathrm{M})$.

Figure 6. Tc K-edge XANES profiles of equilibrated solid and solution samples compared to Tc(VII) stock solution. The equilibrated samples have XANES profiles and edge energies that are consistent with the $\mathrm{Tc}(\mathrm{IV})$ oxidation state. (a) Pertechnetate stock solution, $\mathrm{TcO}^{4-}$; (b) 6-255, $\mathrm{pH}=2.0,[\mathrm{Cl}]=0.3 \mathrm{M}$; (c) 1-205, $\mathrm{pH} 2.2,[\mathrm{Cl}]=0.03 \mathrm{M}$; (d) 6-258, $\mathrm{pH}=2.6,[\mathrm{Cl}]=0.3 \mathrm{M}$; (e) 4$371, \mathrm{pH}=0,[\mathrm{Cl}]=5.0 \mathrm{M}$; (f) 3-331, $\mathrm{pH}=0,[\mathrm{Cl}]=2.5 \mathrm{M}$; (g) 5-301, $6 \mathrm{~N} \mathrm{HCl},[\mathrm{Cl}]=6.0 \mathrm{M}$.

Figure 7. Fourier transforms of the Tc K-edge EXAFS of the equilibrated solutions (a) and solids (b). Analysis of the EXAFS, in conjunction with UV-Vis data, indicate that the compositions of the solutions are $\mathrm{TcCl}_{4}(\mathrm{aq})(4-371,3-331)$ and $\mathrm{TcCl}_{6}{ }^{2-}(5-301)$ and the solid phases are $\mathrm{TcO}_{2} \cdot x \mathrm{H}_{2} \mathrm{O}(\mathrm{am})$, except for sample 1-201 which is likely to be a mixture of $\mathrm{TcO}_{2} \cdot x \mathrm{H}_{2} \mathrm{O}(\mathrm{am})$ and $\mathrm{TcCl}_{4}(\mathrm{am})$.

Figure 8. Comparison of the model predictions of $\mathrm{TcO}_{2} \cdot x \mathrm{H}_{2} \mathrm{O}(\mathrm{am})$ solubility as a function of $\mathrm{pH}$ and in the absence of $\mathrm{NaCl}$ based on the thermodynamic data presented by Rard et al. ${ }^{(3)}$ (a) and developed in this study based on the 11-day solubility measurements (b). The contributions of the individual Tc(IV) species to the observed solubility is indicated.

Figure 9. Comparison of the model predictions of $\mathrm{TcO}_{2} \cdot x \mathrm{H}_{2} \mathrm{O}(\mathrm{am})$ solubility as a function of $\mathrm{p} C_{\mathrm{H}^{+}}$based on the thermodynamic data developed presented by Rard et al., ${ }^{(3)}$ panel a, and 
developed in this study, panel $\mathrm{b}$, for different chloride concentrations. $0.8 \mathrm{M} \mathrm{NaCl}$ (top); $2.5 \mathrm{M}$ $\mathrm{NaCl}$ (middle); 5.0 M NaCl (bottom). 


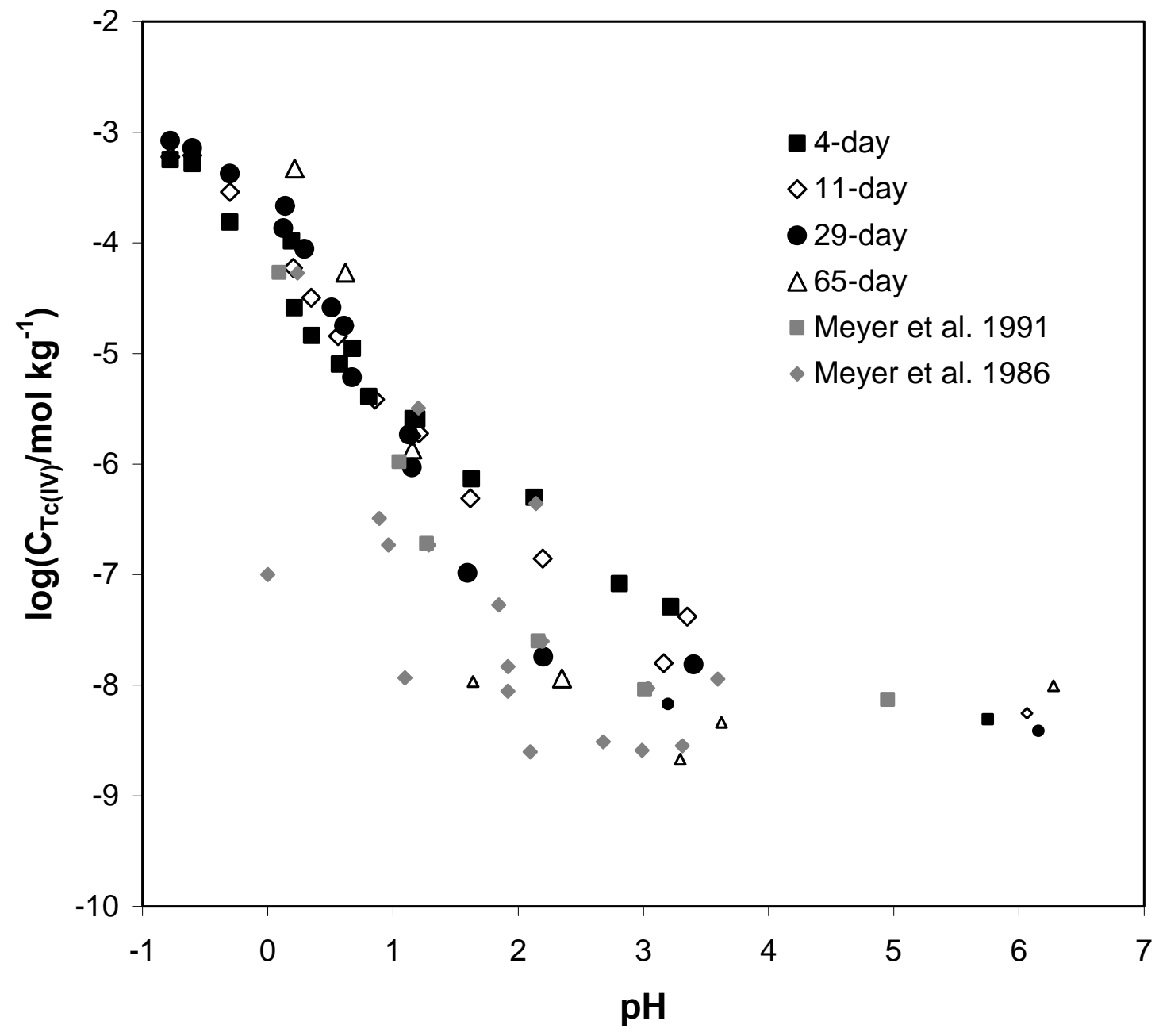

Figure 1. 


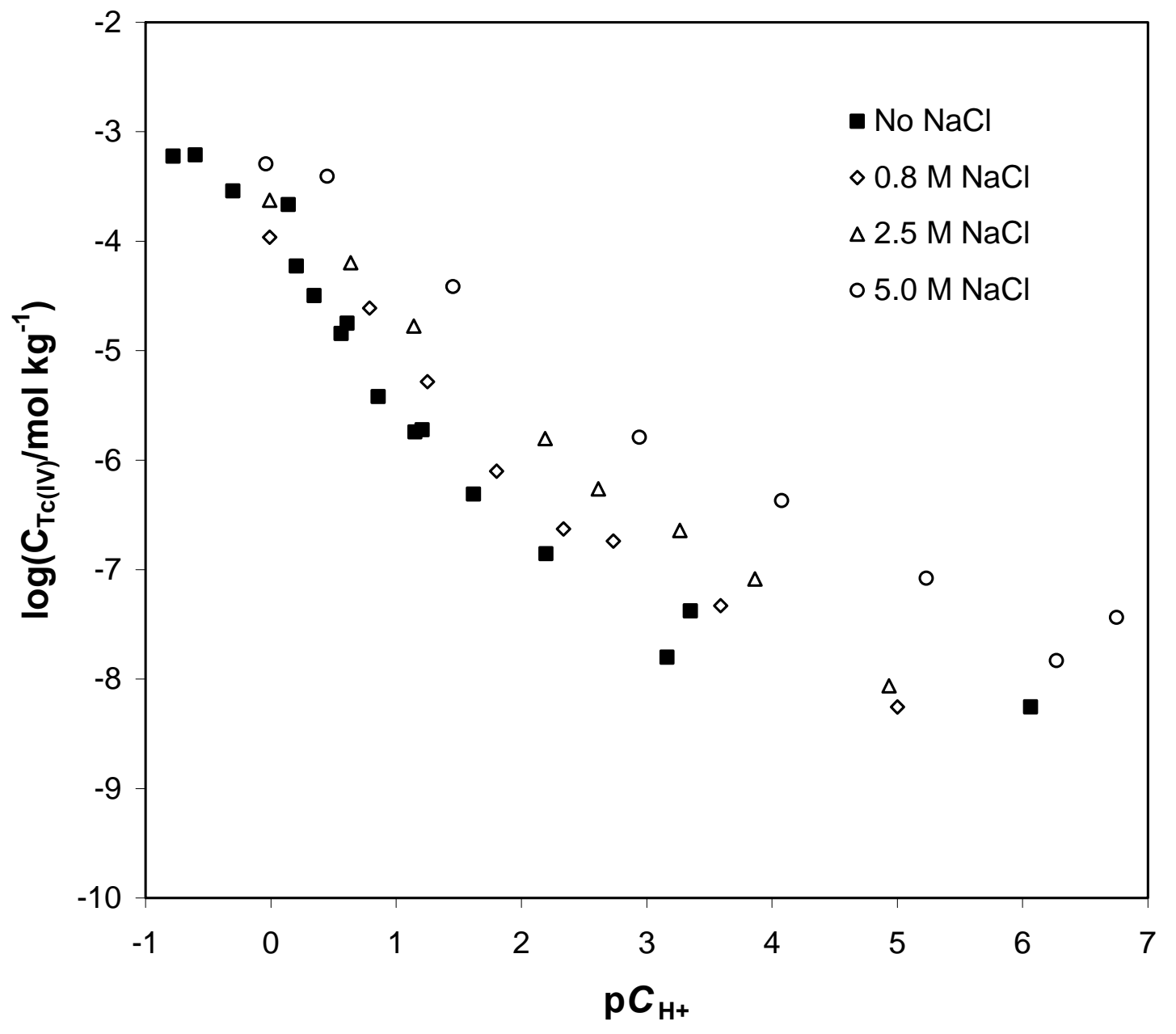

Figure 2. 


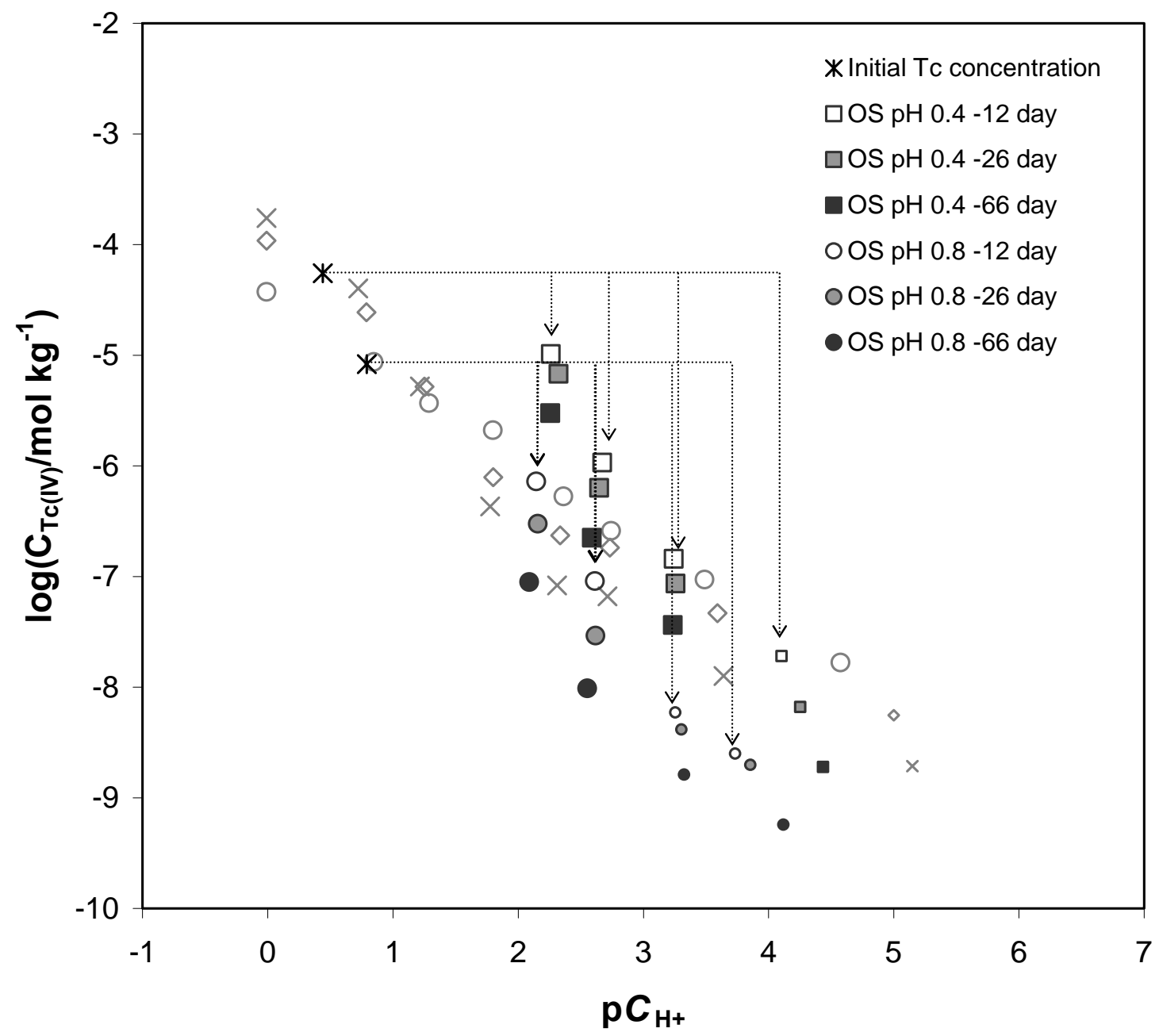

Figure 3. 

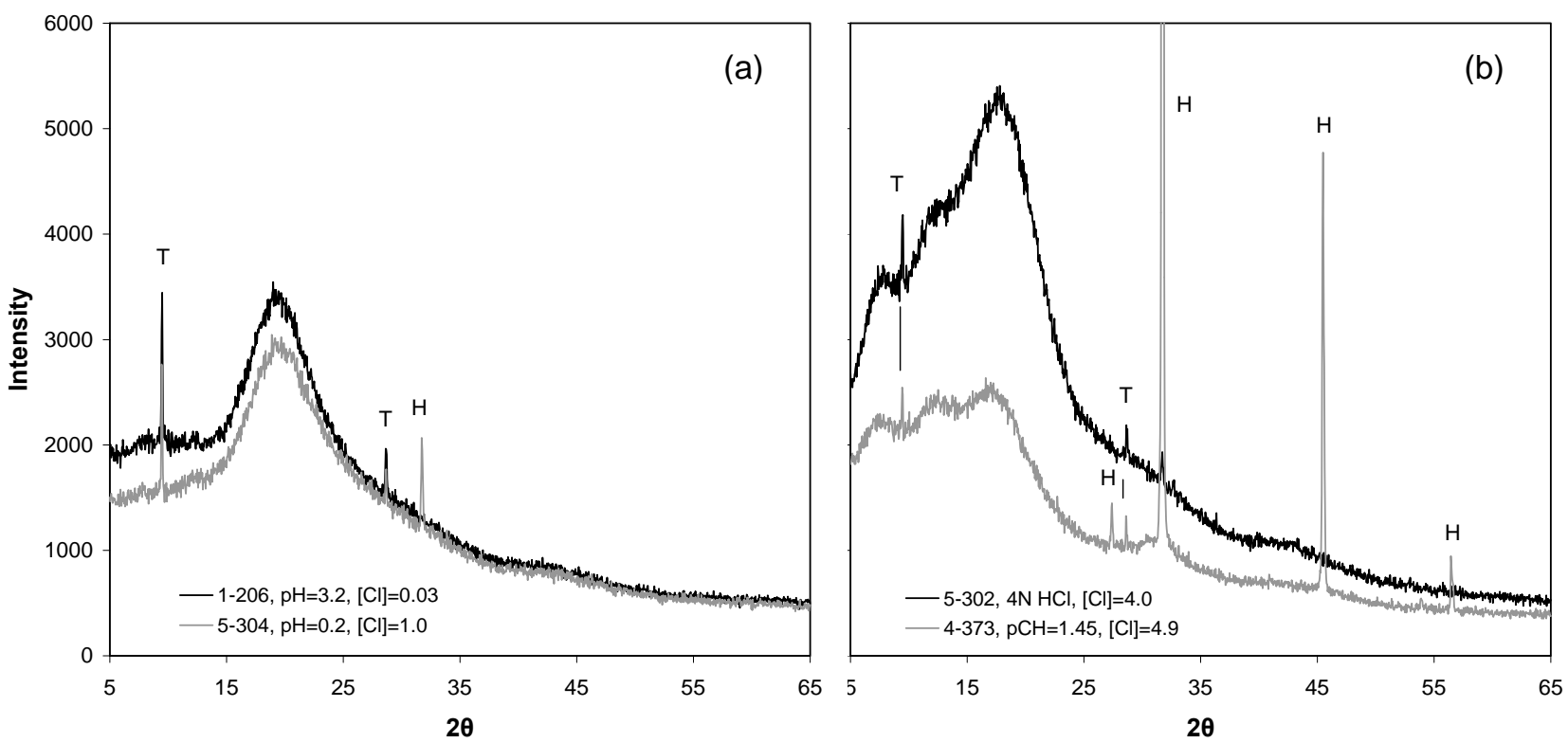

Figure 4. 


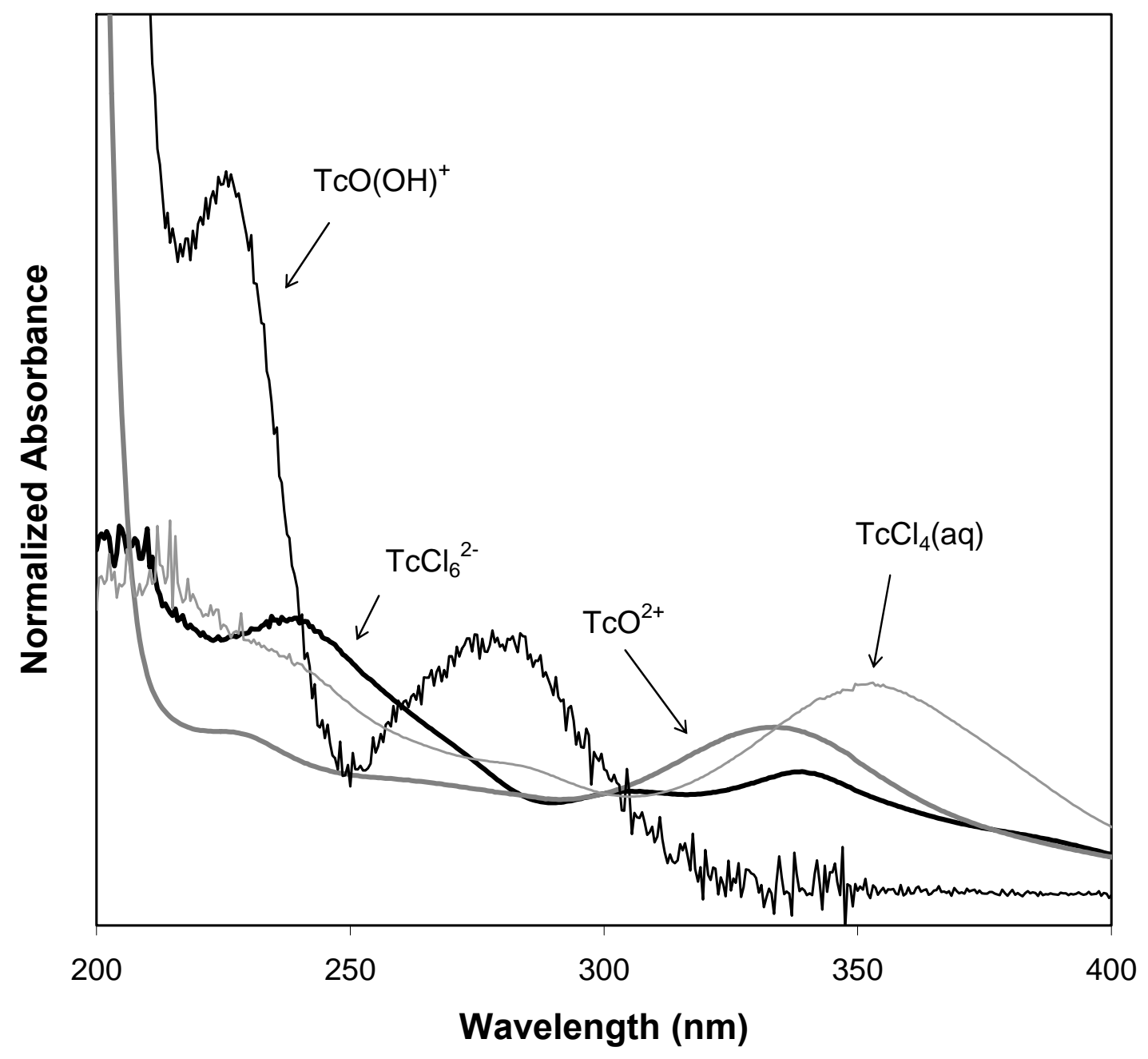

Figure 5. 


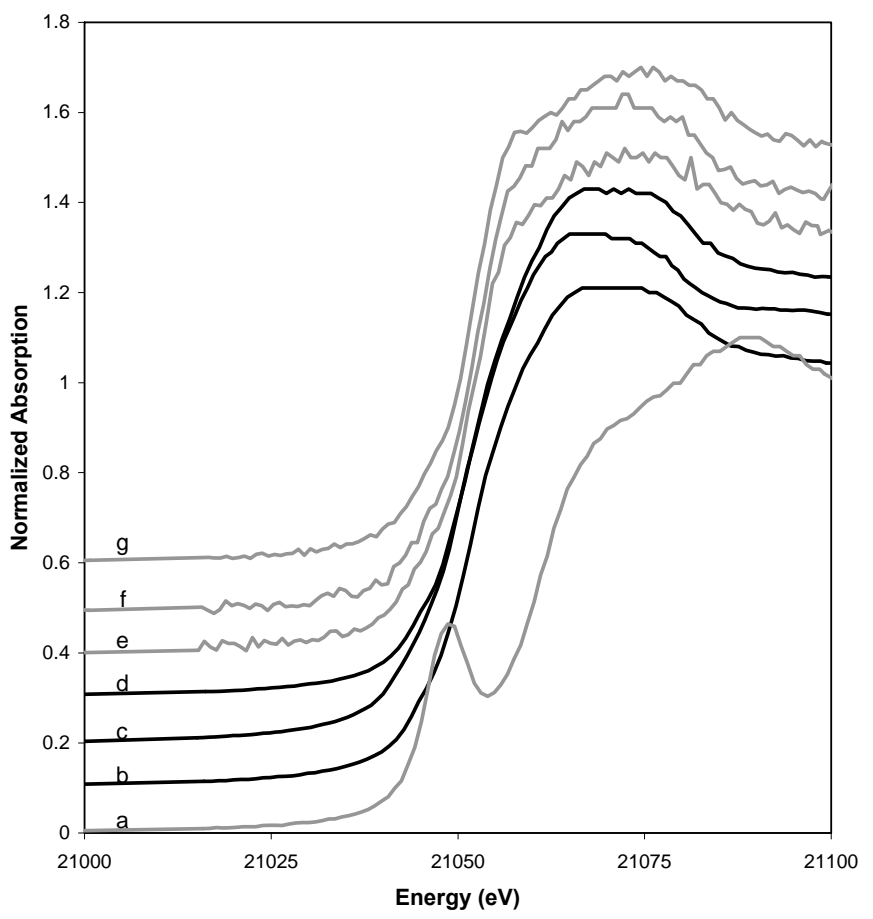

Figure 6. 

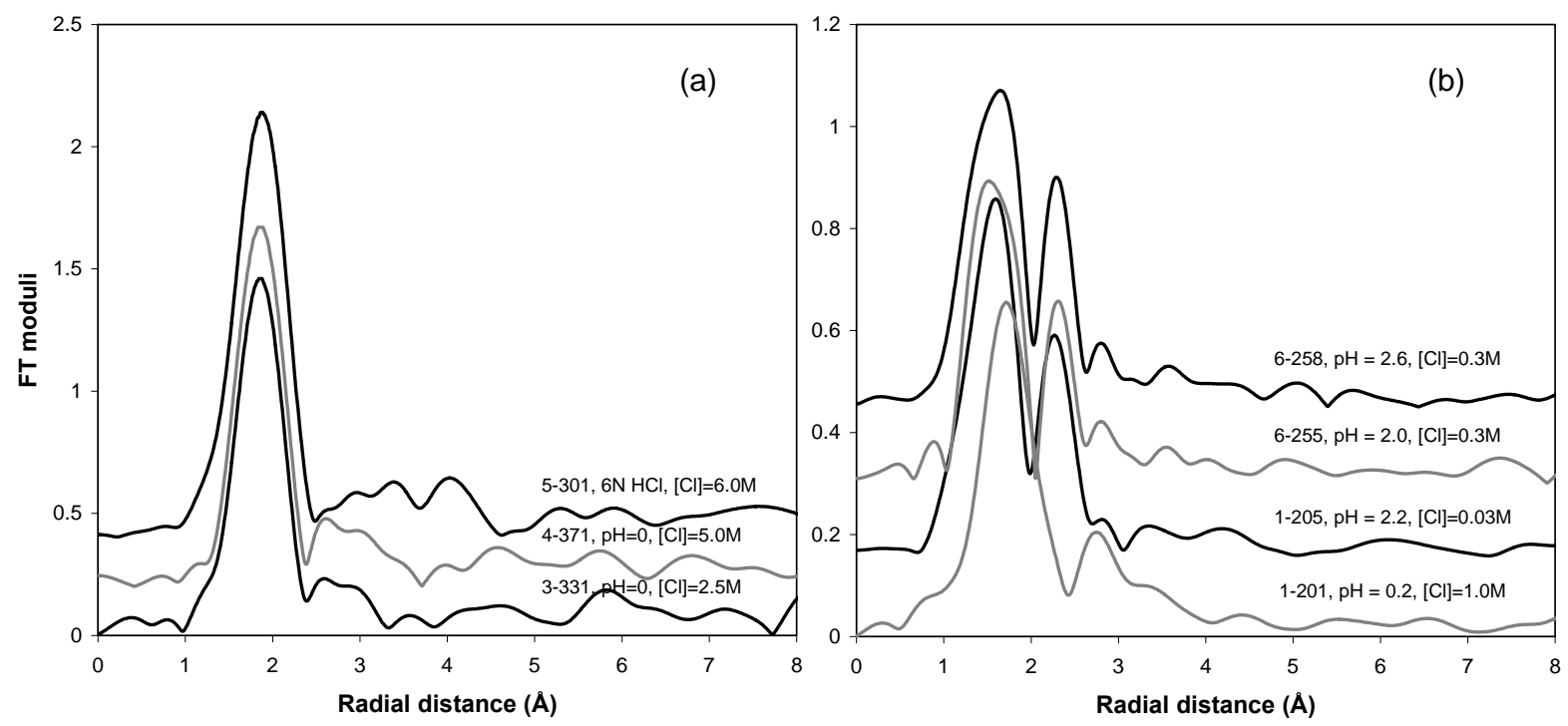

Figure 7. 

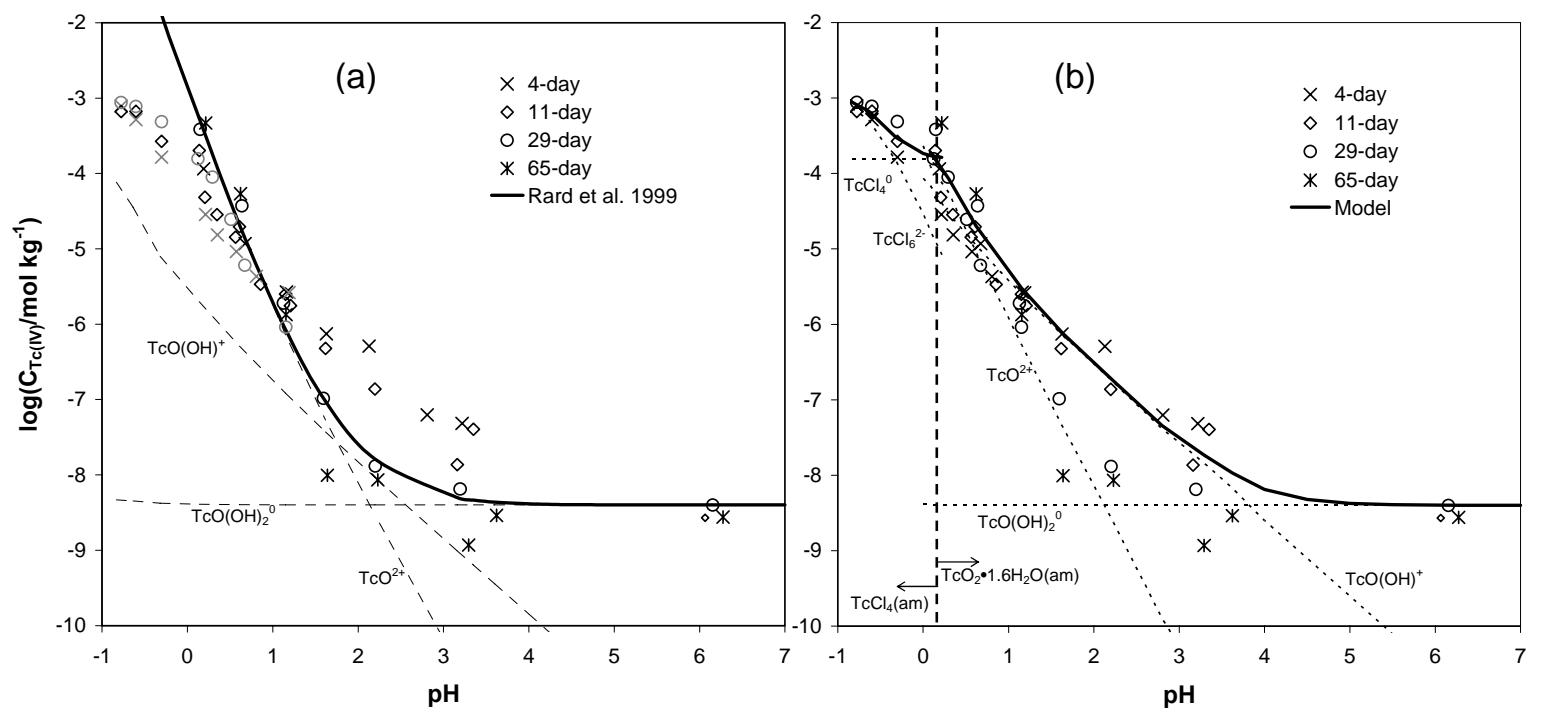

Figure 8. 

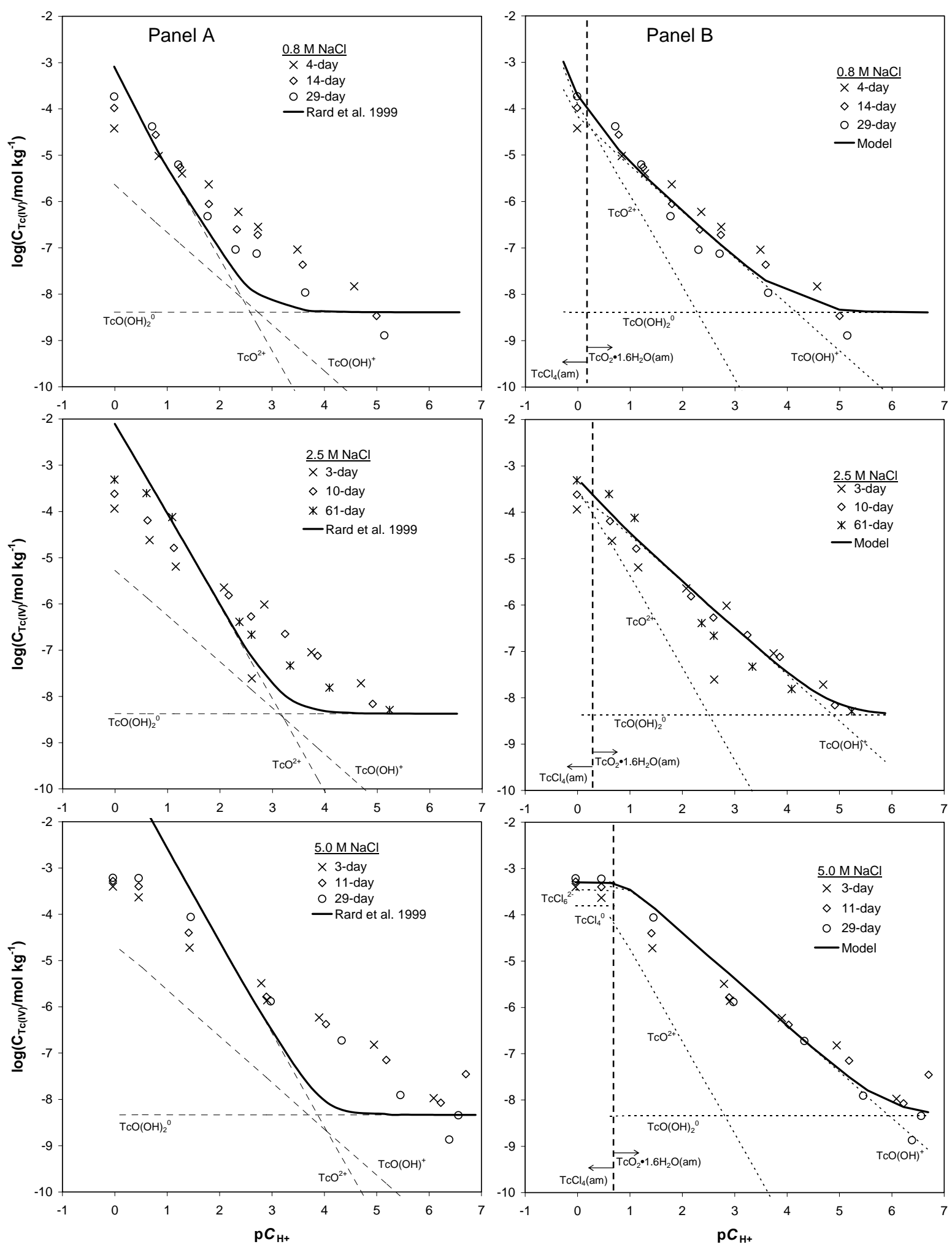

Figure 9. 
APPENDIX

Set 1. $\mathrm{TcO}_{2} \cdot \mathrm{xH}_{2} \mathrm{O}(\mathrm{am})$ solubility at different equilibration periods in aqueous solution containing $0.02 \mathrm{M}$ hydrazine.

\begin{tabular}{|c|c|c|c|c|c|c|c|c|c|c|c|c|}
\hline \multirow[b]{2}{*}{$\begin{array}{l}\text { Sample } \\
\text { number }\end{array}$} & \multicolumn{3}{|c|}{4 Day } & \multicolumn{3}{|c|}{11 Day } & \multicolumn{3}{|c|}{29 Day } & \multicolumn{3}{|c|}{ 65 Day } \\
\hline & $\mathrm{pH}$ & $\begin{array}{c}\text { Log } \\
\text { Tc(IV) }\end{array}$ & $\begin{array}{c}\% \\
\text { Tc(IV) }\end{array}$ & $\mathrm{pH}_{\mathrm{m}}$ & $\begin{array}{c}\log \\
\text { Tc(IV) }\end{array}$ & $\begin{array}{c}\% \\
\operatorname{Tc}(I V)\end{array}$ & $\mathrm{pH}_{\mathrm{m}}$ & $\begin{array}{c}\log \\
\text { Tc(IV) }\end{array}$ & $\begin{array}{c}\% \\
\operatorname{Tc}(I V)\end{array}$ & $\mathrm{pH}_{\mathrm{m}}$ & $\begin{array}{c}\log \\
\operatorname{Tc}(\mathrm{IV})\end{array}$ & $\begin{array}{c}\% \\
\operatorname{Tc}(I V)\end{array}$ \\
\hline 201 & 0.19 & -3.95 & 98 & 0.14 & -3.71 & 98 & 0.15 & -3.43 & 98 & 0.22 & -3.34 & 98 \\
\hline 202 & 0.68 & -4.94 & 98 & 0.61 & -4.71 & 98 & 0.64 & -4.44 & 99 & 0.62 & -4.28 & 98 \\
\hline 203 & 1.16 & -5.57 & 97 & 1.15 & -5.60 & 97 & 1.13 & -5.72 & 99 & 1.16 & -5.87 & 95 \\
\hline 204 & 1.63 & -6.13 & 96 & 1.62 & -6.32 & 96 & 1.60 & -6.99 & 91 & 1.64 & -8.01 & 22 \\
\hline 205 & 2.13 & -6.29 & 97 & 2.20 & -6.86 & 96 & 2.20 & -7.88 & 65 & 2.23 & -8.07 & 73 \\
\hline 206 & 2.81 & -7.20 & 51 & 3.16 & -7.86 & 66 & 3.20 & -9.19 & 39 & 3.29 & -8.93 & 38 \\
\hline 207 & 3.22 & -7.31 & 74 & 3.35 & -7.39 & 81 & 3.40 & -7.96 & 66 & 3.62 & -8.54 & 45 \\
\hline 208 & 5.75 & -8.69 & 35 & 6.06 & -8.57 & 47 & 6.16 & -8.40 & 99 & 6.28 & -8.56 & 55 \\
\hline
\end{tabular}

Set 2. $\mathrm{TcO}_{2} \cdot x \mathrm{H}_{2} \mathrm{O}(\mathrm{am})$ solubility at different equilibration periods in $0.8 \mathrm{M} \mathrm{NaCl}$ solution containing $0.02 \mathrm{M}$ hydrazine.

\begin{tabular}{|c|c|c|c|c|c|c|c|c|c|}
\hline \multirow[b]{2}{*}{$\begin{array}{l}\text { Sample } \\
\text { number }\end{array}$} & \multicolumn{3}{|c|}{$\underline{4 \text { Day }}$} & \multicolumn{3}{|c|}{14 to 18 Day } & \multicolumn{3}{|c|}{29 to 33 Day } \\
\hline & $\mathrm{p} C_{\mathrm{H}^{+}}$ & $\log \mathrm{Tc}(\mathrm{IV})$ & $\% \mathrm{Tc}(\mathrm{IV})$ & $\mathrm{p} C_{\mathrm{H}^{+}}$ & $\log \mathrm{Tc}(\mathrm{IV})$ & $\% \mathrm{Tc}(\mathrm{IV})$ & $\mathrm{p} C_{\mathrm{H}^{+}}$ & $\log \mathrm{Tc}(\mathrm{IV})$ & $\% \mathrm{Tc}(\mathrm{IV})$ \\
\hline 351 & -0.01 & -4.42 & 96 & -0.01 & -3.98 & 97 & -0.01 & -3.73 & 96 \\
\hline 352 & 0.84 & -5.02 & 97 & 0.78 & -4.56 & 99 & 0.71 & -4.38 & 98 \\
\hline 353 & 1.28 & -5.40 & 97 & 1.25 & -5.26 & 98 & 1.21 & -5.20 & 96 \\
\hline 354 & 1.79 & -5.63 & 97 & 1.80 & -6.05 & 90 & 1.77 & -6.32 & 90 \\
\hline 355 & 2.36 & -6.22 & 93 & 2.33 & -6.60 & 89 & 2.30 & -7.04 & 77 \\
\hline 356 & 2.74 & -6.55 & 82 & 2.73 & -6.72 & 84 & 2.71 & -7.13 & 73 \\
\hline 357 & 3.48 & -7.04 & 79 & 3.59 & -7.36 & 67 & 3.63 & -7.97 & 36 \\
\hline 358 & 4.57 & -7.83 & 59 & 4.99 & -8.47 & 35 & 5.14 & -8.89 & 20 \\
\hline
\end{tabular}

Set 3. $\mathrm{TcO}_{2} \cdot x \mathrm{H}_{2} \mathrm{O}(\mathrm{am})$ solubility at different equilibration periods in $2.5 \mathrm{M} \mathrm{NaCl}$ solution containing $0.02 \mathrm{M}$ hydrazine.

\begin{tabular}{|c|c|c|c|c|c|c|c|c|c|}
\hline \multirow[b]{2}{*}{$\begin{array}{l}\text { Sample } \\
\text { number }\end{array}$} & \multicolumn{3}{|c|}{3 Day } & \multicolumn{3}{|c|}{10 to 13 Day } & \multicolumn{3}{|c|}{ 61 Day } \\
\hline & $\mathrm{p} C_{\mathrm{H}^{+}}$ & $\log \mathrm{Tc}(\mathrm{IV})$ & $\% \mathrm{Tc}(\mathrm{IV})$ & $\mathrm{p} C_{\mathrm{H}^{+}}$ & $\log \mathrm{Tc}(\mathrm{IV})$ & $\% \operatorname{Tc}(\mathrm{IV})$ & $\mathrm{p} C_{\mathrm{H}^{+}}$ & $\log \mathrm{Tc}(\mathrm{IV})$ & $\% \mathrm{Tc}(\mathrm{IV})$ \\
\hline 331 & -0.01 & -3.94 & 88 & -0.01 & -3.62 & 90 & -0.01 & -3.31 & 88 \\
\hline 332 & 0.66 & -4.62 & 87 & 0.62 & -4.19 & 91 & 0.60 & -3.61 & 89 \\
\hline 333 & 1.16 & -5.19 & 90 & 1.12 & -4.79 & 91 & 1.09 & -4.12 & 91 \\
\hline 334 & 2.08 & -5.64 & 92 & 2.17 & -5.81 & 86 & 2.37 & -6.39 & 56 \\
\hline 335 & 2.84 & -6.02 & 88 & 3.24 & -6.65 & 62 & 3.34 & -7.33 & 33 \\
\hline 336 & 2.61 & -7.61 & 26 & 2.59 & -6.27 & 69 & 2.60 & -6.66 & 60 \\
\hline 337 & 3.74 & -7.04 & 61 & 3.86 & -7.12 & 52 & 4.09 & -7.81 & 22 \\
\hline 338 & 4.69 & -7.72 & 42 & 4.91 & -8.16 & 25 & 5.24 & -8.30 & 24 \\
\hline
\end{tabular}


Set 4. $\mathrm{TcO}_{2} \cdot x \mathrm{H}_{2} \mathrm{O}(\mathrm{am})$ solubility at different equilibration periods in $5.0 \mathrm{M} \mathrm{NaCl}$ solution containing $0.02 \mathrm{M}$ hydrazine.

\begin{tabular}{|c|c|c|c|c|c|c|c|c|c|}
\hline \multirow[b]{2}{*}{$\begin{array}{l}\text { Sample } \\
\text { Number }\end{array}$} & \multicolumn{3}{|c|}{4 Day } & \multicolumn{3}{|c|}{11 Day } & \multicolumn{3}{|c|}{29 Day } \\
\hline & $\mathrm{p} C_{\mathrm{H}^{+}}$ & $\log \mathrm{Tc}(\mathrm{IV})$ & $\% \mathrm{Tc}(\mathrm{IV})$ & $\mathrm{p} C_{\mathrm{H}^{+}}$ & $\log \mathrm{Tc}(\mathrm{IV})$ & $\% \mathrm{Tc}(\mathrm{IV})$ & $\mathrm{p} C_{\mathrm{H}^{+}}$ & $\log \mathrm{Tc}(\mathrm{IV})$ & $\% \mathrm{Tc}(\mathrm{IV})$ \\
\hline 371 & -0.04 & -3.40 & 86 & -0.04 & -3.28 & 86 & -0.04 & -3.21 & 84 \\
\hline 372 & 0.45 & -3.63 & 86 & 0.45 & -3.40 & 87 & 0.45 & -3.22 & 87 \\
\hline 373 & 1.45 & -4.72 & 88 & 1.41 & -4.40 & 89 & 1.45 & -4.06 & 90 \\
\hline 374 & 2.80 & -5.49 & 93 & 6.70 & -7.45 & 48 & 6.56 & -8.35 & 28 \\
\hline 375 & 2.91 & -5.86 & 90 & 2.89 & -5.78 & 92 & 2.98 & -5.88 & 84 \\
\hline 376 & 3.90 & -6.23 & 87 & 4.03 & -6.38 & 88 & 4.33 & -6.73 & 75 \\
\hline 377 & 4.95 & -6.82 & 83 & 5.18 & -7.15 & 80 & 5.45 & -7.91 & 48 \\
\hline 378 & 6.09 & -7.97 & 30 & 6.22 & -8.07 & 52 & 6.39 & -8.87 & 21 \\
\hline
\end{tabular}

Set 5. $\mathrm{TcO}_{2} \cdot x \mathrm{H}_{2} \mathrm{O}(\mathrm{am})$ solubility at different equilibration periods in very acidic solutions containing $0.02 \mathrm{M}$ hydrazine.

\begin{tabular}{|c|c|c|c|c|c|c|c|c|c|}
\hline \multirow[b]{2}{*}{$\begin{array}{l}\text { Sample } \\
\text { number }\end{array}$} & \multicolumn{3}{|c|}{3 Day } & \multicolumn{3}{|c|}{11 Day } & \multicolumn{3}{|c|}{ 36 Day } \\
\hline & $\mathrm{pH}$ & $\log \mathrm{Tc}(\mathrm{IV})$ & $\%$ Tc(IV) & $\mathrm{pH}_{\mathrm{m}}$ & $\log \mathrm{Tc}(\mathrm{IV})$ & $\%$ Tc(IV) & $\mathrm{pH}_{\mathrm{m}}$ & $\log \mathrm{Tc}(\mathrm{IV})$ & $\% \operatorname{Tc}(\mathrm{IV})$ \\
\hline 301 & $6.0 \mathrm{~N} \mathrm{HCl}$ & -3.10 & 67 & $6.0 \mathrm{~N} \mathrm{HCl}$ & -3.18 & 68 & $6.0 \mathrm{~N} \mathrm{HCl}$ & -3.06 & 86 \\
\hline 302 & $4.0 \mathrm{~N} \mathrm{HCl}$ & -3.28 & 92 & $4.0 \mathrm{~N} \mathrm{HCl}$ & -3.18 & 93 & $4.0 \mathrm{~N} \mathrm{HCl}$ & -3.11 & 92 \\
\hline 303 & $2.0 \mathrm{~N} \mathrm{HCl}$ & -3.78 & 93 & $2.0 \mathrm{~N} \mathrm{HCl}$ & -3.57 & 92 & $2.0 \mathrm{~N} \mathrm{HCl}$ & -3.31 & 90 \\
\hline 304 & 0.21 & -4.54 & 98 & 0.20 & -4.32 & 97 & 0.12 & -3.81 & 95 \\
\hline 305 & 0.35 & -4.81 & 97 & 0.35 & -4.55 & 98 & 0.29 & -4.05 & 98 \\
\hline 306 & 0.57 & -5.04 & 97 & 0.56 & -4.85 & 98 & 0.51 & -4.61 & 98 \\
\hline 307 & 0.81 & -5.37 & 98 & 0.86 & -5.47 & 98 & 0.67 & -5.22 & 96 \\
\hline 308 & 1.19 & -5.58 & 97 & 1.21 & -5.75 & 98 & 1.15 & -6.04 & 93 \\
\hline
\end{tabular}

Set 6. $\mathrm{TcO}_{2} \cdot x \mathrm{H}_{2} \mathrm{O}(\mathrm{am})$ solubility at different equilibration periods in aqueous solution containing $0.02 \mathrm{M} \mathrm{EuCl}_{2}$.

\begin{tabular}{ccccccc}
\hline $\begin{array}{c}\text { Sample } \\
\text { number }\end{array}$ & $\mathrm{pH}$ & $\log \mathrm{Tc}(\mathrm{IV})$ & $\% \mathrm{Tc}(\mathrm{IV})$ & $\mathrm{pH}$ & $\log \mathrm{Tc}(\mathrm{IV})$ & $\% \mathrm{Tc}(\mathrm{IV})$ \\
\hline 251 & 0.21 & -3.99 & 77 & 0.18 & -3.83 & 77 \\
252 & 0.70 & -4.62 & 94 & 0.67 & -4.68 & 98 \\
253 & 1.08 & -4.73 & 98 & 1.03 & -4.91 & 98 \\
254 & 1.58 & -5.11 & 98 & 1.53 & -5.68 & 97 \\
255 & 1.99 & -6.29 & 95 & 1.94 & -6.97 & 81 \\
256 & 2.53 & -5.77 & 97 & 2.48 & -7.49 & 68 \\
257 & 3.04 & -8.03 & 68 & 3.01 & -8.71 & 49 \\
258 & 4.04 & -9.21 & 35 & 4.05 & & 0
\end{tabular}


Set 7. Oversaturation experiments - $\mathrm{TcO}_{2} \cdot x \mathrm{H}_{2} \mathrm{O}(\mathrm{am})$ solubility at different equilibration periods in aqueous solution containing $0.02 \mathrm{M}$ hydrazine.

\begin{tabular}{|c|c|c|c|c|c|c|c|c|c|}
\hline \multirow[b]{2}{*}{$\begin{array}{l}\text { Sample } \\
\text { number }\end{array}$} & \multicolumn{3}{|c|}{12 Day } & \multicolumn{3}{|c|}{28 Day } & \multicolumn{3}{|c|}{$\underline{66 \text { Day }}$} \\
\hline & $\mathrm{pH}$ & $\log \mathrm{Tc}(\mathrm{IV})$ & $\% \mathrm{Tc}(\mathrm{IV})$ & $\mathrm{pH}$ & $\log \mathrm{Tc}(\mathrm{IV})$ & $\% \mathrm{Tc}(\mathrm{IV})$ & $\mathrm{pH}$ & $\log \mathrm{Tc}(\mathrm{IV})$ & $\% \mathrm{Tc}(\mathrm{IV})$ \\
\hline $401^{\mathrm{a}}$ & 2.26 & -4.99 & 96 & 2.32 & -5.17 & 97 & 2.26 & -5.52 & 96 \\
\hline $402^{\mathrm{a}}$ & 2.67 & -5.97 & 91 & 2.65 & -6.20 & 89 & 2.59 & -6.65 & 79 \\
\hline $403^{\mathrm{a}}$ & 3.24 & -6.84 & 72 & 3.26 & -7.06 & 64 & 3.24 & -7.44 & 57 \\
\hline $404^{\mathrm{a}}$ & 4.10 & -7.72 & 43 & 4.25 & -8.18 & 48 & 4.44 & -8.72 & 44 \\
\hline $801^{\mathrm{b}}$ & 2.14 & -6.14 & 96 & 2.16 & -6.52 & 92 & 2.09 & -7.05 & 89 \\
\hline $802^{\mathrm{b}}$ & 2.61 & -7.04 & 76 & 2.62 & -7.53 & 73 & 2.55 & -8.01 & 59 \\
\hline $803^{b}$ & 3.25 & -8.23 & 39 & 3.30 & -8.38 & 45 & 3.33 & -8.79 & 28 \\
\hline $804^{\mathrm{b}}$ & 3.73 & -8.60 & 31 & 3.85 & -8.70 & 42 & 4.12 & -9.24 & 24 \\
\hline
\end{tabular}

a. In the presence of $\mathrm{TcO}_{2} \cdot x \mathrm{H}_{2} \mathrm{O}(\mathrm{am})$; initial solution $\mathrm{pH}=0.44, \log \mathrm{Tc}(\mathrm{IV})=-4.26, \% \mathrm{Tc}(\mathrm{IV})=98$.

b. In the presence of $\mathrm{TcO}_{2} \cdot x \mathrm{H}_{2} \mathrm{O}(\mathrm{am})$; initial solution $\mathrm{pH}=0.79, \log \mathrm{Tc}(\mathrm{IV})=-5.08, \% \mathrm{Tc}(\mathrm{IV})=97$. 